Florida International University FIU Digital Commons

$10-10-2013$

\title{
Social Capital, HIV Risk Behavior and Substance Use among Recent Latino Immigrants in South Florida
}

Elena Cyrus

Florida International University, ecyru002@fiu.edu

DOI: $10.25148 /$ etd.FI13120414

Follow this and additional works at: https://digitalcommons.fiu.edu/etd

Part of the Epidemiology Commons

\section{Recommended Citation}

Cyrus, Elena, "Social Capital, HIV Risk Behavior and Substance Use among Recent Latino Immigrants in South Florida" (2013). FIU Electronic Theses and Dissertations. 977.

https://digitalcommons.fiu.edu/etd/977 


\section{FLORIDA INTERNATIONAL UNIVERSITY}

Miami, Florida

SOCIAL CAPITAL, HIV RISK BEHAVIOR AND SUBSTANCE USE AMONG RECENT

LATINO IMMIGRANTS IN SOUTH FLORIDA

A dissertation submitted in partial fulfillment of the

requirements for the degree of

DOCTOR OF PHILOSOPHY

in

PUBLIC HEALTH

by

Elena Cyrus

2013 
To: $\quad$ Dean Michele Ciccazzo

Robert Stempel College of Public Health and Social Work

This dissertation, written by Elena Cyrus, and entitled Social Capital, HIV Risk Behavior and Substance Use among Recent Latino Immigrants in South Florida, having been approved in respect to style and intellectual content, is referred to you for judgment.

We have read this dissertation and recommend that it be approved.

Ahmed Albatineh

Kristopher Fennie

Erica Gollub

Mario De La Rosa

Mary Jo Trepka, Major Professor

Date of Defense: October 10, 2013

The dissertation of Elena Cyrus is approved. 


\section{DEDICATION}

Earning my $\mathrm{PhD}$ has been both a personal and professional journey which would have never been possible without the support of my family and friends who gave me the spiritual and emotional fortitude I needed to finish. My daughter, Asha Reign has been the light and love in my life, and she inspired me to move forward when I thought there was nothing left. This dissertation is dedicated first and foremost to her, and I hope this work inspires her to always excel, persevere, and be brave. My eternal gratification to my mother - Gail, my brother - James and aunt -

Deborah who provided unconditional love and support. Also to Frances who made me laugh, restore balance and gave me perspective. Finally, to my best friend and confidant Adrian Clarke who showed up out of nowhere and remained a constant force, providing a base where I could recuperate. I love you all fiercely.

I would also like to acknowledge my father James Francis Cyrus III and my Grandmother Eva Herbert. My father gave me the confidence to attempt anything. I would give anything to be able to have one more talk with my grandmother on the bottom of her stairs. I miss them both. I wish they were here to share this with me. 


\section{ACKNOWLEDGMENTS}

I would like to thank the Department of Epidemiology and my committee members who always believed in me. Many thanks to Dr. Mary Jo Trepka who exercised the utmost patience and generosity with me, while exemplifying the highest standards of research and methodology. I'm indebted to Dr. Erica Gollub for collaborating with me in the early stages of my training and for the numerous hours in her office helping me to understand the simplest concepts. I would also like to thank Dr. Nasar Ahmed who helped me through my first two years in the program and who encouraged me whenever I was in doubt, Dr. Fennie and Dr. Li who struggled with me to the end on my analysis, and to the incomparable Dr. Mario de La Rosa, for taking me on at CRUSADA, giving me what I needed to finish. I believe any success I achieve from this point forward will be because of all your efforts. Thank you.

This study was supported by Award Number P20MD002288 from the National Institute on Minority Health \& Health Disparities (NIMHD). The content is solely the responsibility of the authors and does not necessarily represent the official views of NIMHD or the National Institutes of Health.

This study was also supported by the FIU Graduate School Dissertation Year Fellowship. 
ABSTRACT OF THE DISSERTATION

SOCIAL CAPITAL, HIV RISK BEHAVIOR AND SUBSTANCE USE AMONG RECENT

LATINO IMMIGRANTS IN SOUTH FLORIDA

\author{
by
}

Elena Cyrus

Florida International University, 2013

Miami, Florida

Associate Professor Mary Jo Trepka, Major Professor

Social capital, or social cohesion or group connectedness, can influence both HIV risk behavior and substance use. Because recent immigrants undergo a change in environment, one of the consequences can be a change in social capital. There may be an association among changes in social capital, and HIV risk behavior and substance use post immigration. The dissertation focused on the interface of these three variables among recent Latino immigrants (RLIs) in South Florida.

The first manuscript is a systematic review of social capital and HIV risk behavior, and served as a partial background for the second and third manuscripts. Twelve papers with a measure of social capital as an independent variable and HIV risk as the dependent variable were included in the analysis. Eleven studies measured social capital at the individual level, and one study measured social capital at the group level. HIV risk was influenced by social capital, but the type of influence was dependent on the type of social capital and on the study population.

Cognitive social capital, or levels of collective action, was protective against HIV in both men and women. The role of structural social capital, or levels of civic engagement/group participation, on HIV risk was dependent on the type of structural social capital and varied by gender. Microfinance programs and functional group participation were protective for women, 
while dysfunctional group participation and peer-level support may have increased HIV risk among men.

The second manuscript was an original study assessing changes in social capital and HIV risk behavior pre to post immigration among RLIs in South Florida $(\mathrm{n}=527)$. HIV risk behavior was assessed through the frequency of vaginal-penile condom use, and the number of sexual partners. It was a longitudinal study using secondary data analysis to assess changes in social capital and HIV risk behavior pre immigration to two years post immigration, and to determine if there was a relationship between the two variables. There was an $8 \%$ decrease in total social capital ( $\mathrm{p}<.05)$. Reporting of 'Never use' of condoms in the past 90 days increased in all subcategories $(p<.05)$. Single men had a decrease in number of sexual partners $(p<.05)$. Lower social capital measured on the dimension of 'friend and other' was marginally associated with fewer sexual partners.

The third manuscript was another original study looking at the association between social capital and substance use among RLIs in South Florida $(n=527)$. Substance use with measured by frequency of hazardous alcoholic drinking, and illicit drug use. It was a longitudinal study of social capital and substance-use from pre to two years post immigration. Post-immigration, social capital, hazardous drinking and illicit drug use decreased $(\mathrm{p}<.001)$. After adjusting for time, compared to males, females were less likely to engage in hazardous drinking $(\mathrm{OR}=.31, \mathrm{p}<.001)$, and less likely to engage in illicit drug use $(\mathrm{OR}=.67, \mathrm{p}=.01)$. Documentation status was a moderator between social capital and illicit drug use. 'Business' and 'Agency' social capital were associated with changes in illicit drug use for documented immigrants. After adjusting for gender and marital status, on average, documented immigrants with a one-unit increase in 'business' social capital were 1.2 times more likely to engage in illicit drug use $(\mathrm{p}<.01)$, and documented immigrants with one-unit increase in 'agency' social capital were $38 \%$ less likely to engage in illicit drug use $(\mathrm{p}<.01)$. 'Friend and other' social capital was associated with a decrease 
in illicit drug use among undocumented immigrants. After adjusting for gender and marital status, on average, undocumented immigrants with a one-unit increase in 'friend and other' social capital were $45 \%$ less likely to engage in hazardous drinking and $44 \%$ less likely to use illicit drugs $(\mathrm{p}<.01, \mathrm{p}<.05)$.

Studying these three domains is relevant because HIV continues to be a public health issue, particularly in Miami-Dade County, which is ranked among other U.S. regions with high rates of HIV/AIDS prevalence. Substance use is associated with HIV risk behavior; in most studies, increased substance use is associated with increased chances of HIV risk behavior. Immigration, which is the hypothesized catalyst for the change in social capital, has an impact on the dynamic of a society. Greater immigration can be burdensome on the host country's societal resources; however immigrants are also potentially a source of additional skilled labor for the workforce. Therefore, successful adaption of immigrants can have a positive influence on receiving communities. With Florida being a major receiver of immigrants to the U.S, this dissertation attempts to address an important public health issue for South Florida and the U.S. at large. 


\section{TABLE OF CONTENTS}

CHAPTER

PAGE

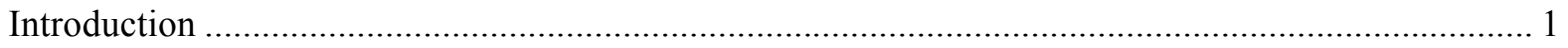

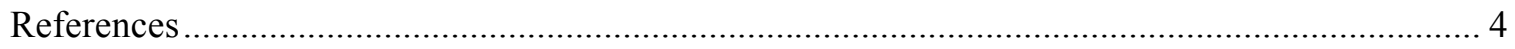

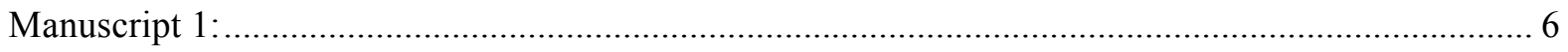

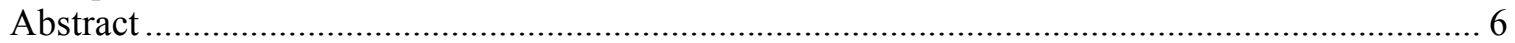

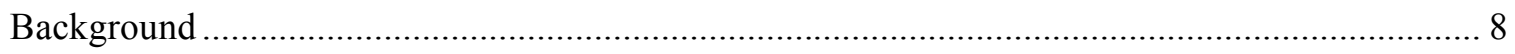

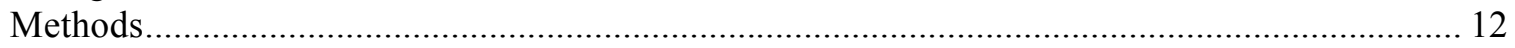

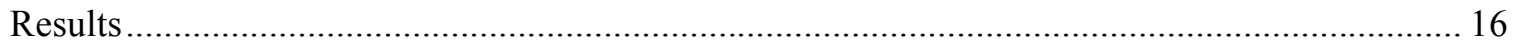

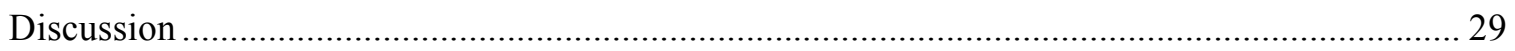

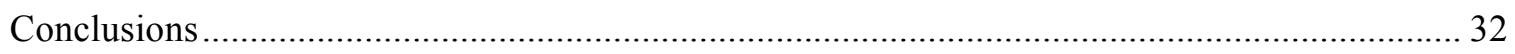

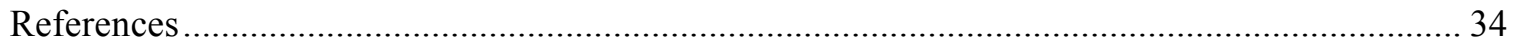

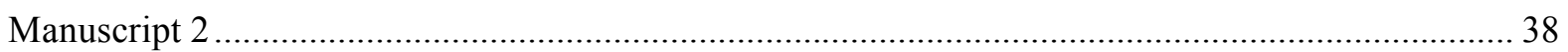

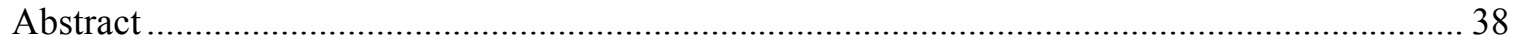

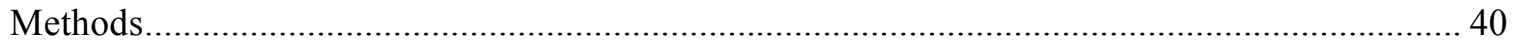

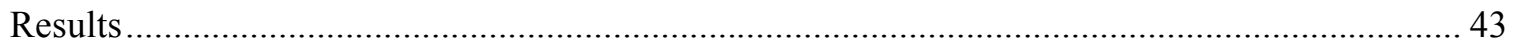

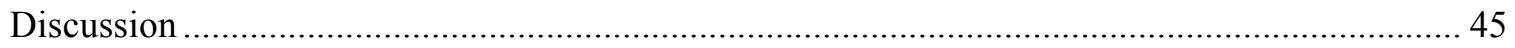

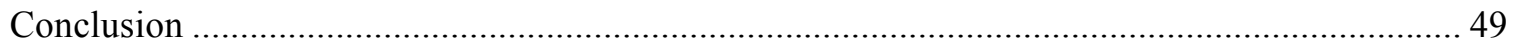

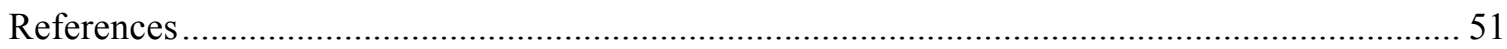

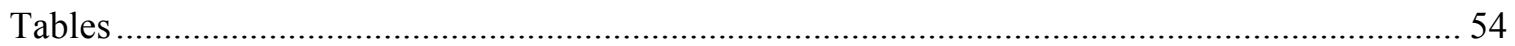

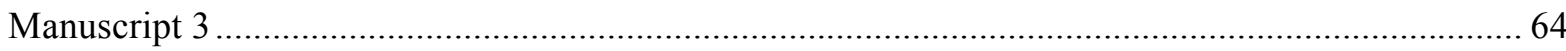

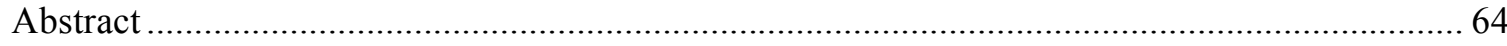

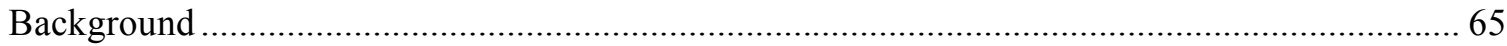

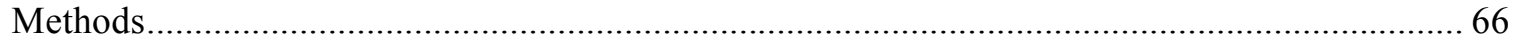

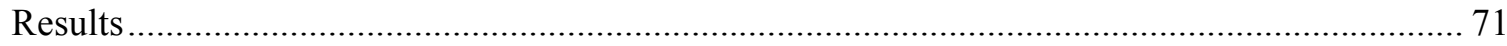

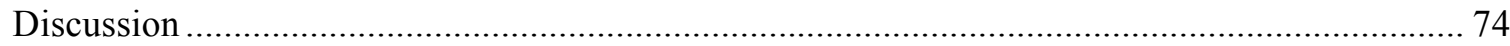

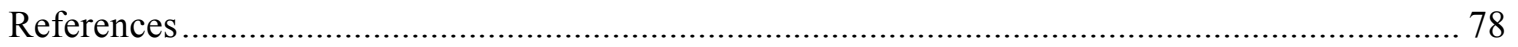

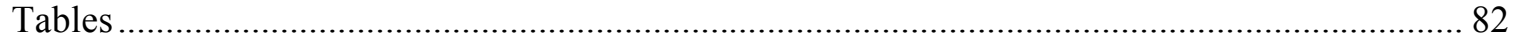

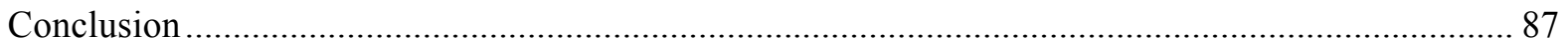

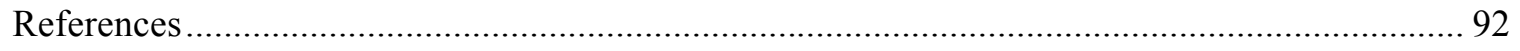

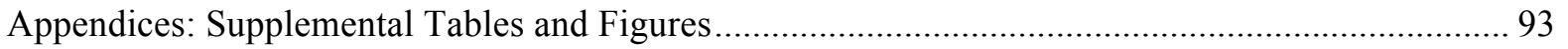

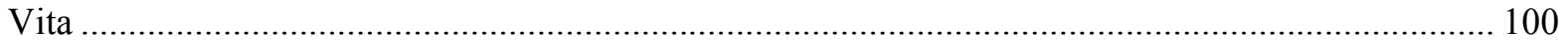




\section{ABBREVIATIONS AND ACRONYMS}

$\mathrm{ABC}$

ANOVA

AUDIT

CDC

CFA

CFI

CINAHL

DF

FIU

GEE

GLM

IRB

HIV

LR

MLR

MV

NIDA

NIMHD

OR

Qual

RLI

RMSEA

$\mathrm{SC}$

SAMSHA

Sass
Abstinence, being faithful, and using condoms

Analysis of variance

Alcohol use identification tests

Centers for Disease Control and Prevention

Confirmatory factor analysis

Comparative fit index

Cumulative index to nursing and allied health literature

Degrees of freedom

Florida International University

Generalized estimating equations

Generalized linear model

Institutional review board

Human immunodeficiency virus

Logistic regression

Multiple linear regression

Multivariate analysis

National Institute on Drug Abuse

National Institute on Minority Health \& Health Disparities

Odds ratio

Qualitative methods

Recent Latino immigrants

Root mean square error of approximation

Social capital

Substance Abuse \& Mental Health Services Administration

Significant association 
SEM

$\operatorname{Sinv}$

SIRB

SISC

SRRB

TLI

UNAIDS

U.S.
Structural equation modeling

Significant inverse relationship

Significant increase in HIV risk behavior

Significant increase in social capital

Significant reduction in HIV risk behavior

Tucker-Lewis index

Joint United Nations Programme on HIV/AIDS

United States 


\section{Introduction}

As a port of entry, South Florida receives one of the largest numbers of Latino and Caribbean immigrants (Patten, 2012), and Miami has the highest number of HIV reported cases in the United States (Centers for Disease Control and Prevention (CDC), 2007). During the process of immigration, some immigrants are prone to search for and engage in stress-relieving and coping mechanisms such as substance use (alcohol and illicit drugs) and high risk sexual behavior such as unprotected sex and multiple sexual partners (Deren et al, 2005, Sanchez et al, 2004).

Social capital is an umbrella term used by researchers which measures 'family support', 'emotional support', 'access to resources', and 'civic engagement.' Studies have established that lower levels of social capital may be associated with increased HIV risk behavior. Social capital can be defined as an intangible asset derived from the interaction of individuals within a community or society at large, and that intangible asset used for gain and advancement within society (Bordieu and Wacquant 1992, Coleman, 1988, Lin, 2001, Lin et al, 2001, Portes, 1998, Putnam, 1995). Previous research has documented that immigrants experience a change in social capital from pre immigration in their country of origin, to post immigration after arrival in the host country (Battacharya, 2005). Additionally, it has also been documented that post immigration, immigrants experience a change in sexual behavior, which is typically an increase in high risk sexual behavior (Shedlin et al, 2005). Lower levels of social capital have also been linked with higher rates of substance use (Lundborg, 2005). This existing evidence supports a need to explore the associations between the change in social capital and HIV risk behavior and substance use as it relates to immigration.

There is evidence that substance use (whether alcohol or illicit drug-use) increases HIV risk behavior (Leigh and Stall, 1993, Shurtleff and Lawrence, 2012). There is a direct link with illicit drug and alcohol use and HIV transmission through use of unclean needles, engaging in 
sexual acts while under the influence of a narcotic or alcohol, or exchanging sexual acts for illicit drugs (American Academy of Pediatrics, 2006, Staton et al. 1999).

Studies of the association between HIV risk behavior and social capital have had varying results, and the role of social capital for HIV risk remains ambiguous (Cene, 2009, Pronyk, et al, 2008). For example, in a study by Pronyk et al (2008) in South Africa, higher rates of social capital were found to be protective for risky sexual behavior, but they were also associated with higher HIV incidence.

The relationship among all three variables is even more complex, as both social capital and substance use can change sexual behavior. As with HIV, the relationship between social capital and substance use is also inconclusive. Social capital has been seen increasing substance use (Bhattacharya, 2005) as well as decreasing the likelihood of substance use (Hodge et al, 2011, Reynoso-Vallejo, 2011). Kalichman et al (2006) found HIV risk closely related to individual social capital proxy variables such as poor education, unemployment, and discrimination, and as well as a relationship between the social capital proxy variables and substance use. The Kalichman study asserts that there is a relationship between social capital and substance use, where social capital may lead to changes in substance use or vice versa.

Although it has been established that immigrant populations are a vulnerable population that may be predisposed to riskier sexual behavior, the existing body of research in this area among any immigrant population is limited. To address this gap, the first manuscript provided a background through a systematic review of social capital and HIV risk behavior. The systematic review will provide additional evidence for the association between social capital and HIV risk behavior that exists. It will give researchers additional information on the pertinence of considering social capital in HIV interventions/prevention programs. The second and third papers were original studies examining the changes in social capital, HIV risk behavior and substance use among RLIs from Cuba and other Central and South American countries. The purpose of the se- 
cond and third paper was to demonstrate how the change in social capital, possibly initiated through the act of immigration, influences HIV risk behavior and substance use post-immigration. If the time period immediately following immigration increases immigrants' vulnerability for risky sexual behavior and substance use, immigrants should be targeted during this phase for primary prevention. 


\section{References}

American Academy of Pediatrics. (2006). Reducing the risk of HIV associated illicit drug use. Pediatrics, 117(2), 566-571.

Bhattacharya, G. (2005). Social capital and HIV risks among acculturating Asian Indian men in New York City. AIDS Education and Prevention: Official Publication of the International Society for AIDS Education, 17(6), 555-567.

Bordieu, P. and L. Wacquant. (1992). Invitation to Reflexive Sociology. Chicago: University of Chicago Press

Cené, C. W., Akers, A. Y., Lloyd, S. W., Albritton, T., Powell Hammond, W., \& Corbie-Smith, G. (2011). Understanding social capital and HIV risk in rural African American communities. Journal of General Internal Medicine, 26(7), 737-744.

Centers for Disease Control and Prevention. (2007). Diagnosis of HIV infection and AIDS in the United States and Dependent areas, 2009. HIV/AIDS Surveillance Report, 21

Coleman, J. S. (1988). Social capital in the creation of human capital. The American Journal of Sociology, 94, S95-S120.

Deren, S., Shedlin, M., Decena, C.U., Mino, M. (2005). Research challenges to the study of HIV/AIDS among migrant and immigrant Hispanic populations in the United States. Journal of Urban Health: Bulletin of the New York Academy of Medicine, 82(2), iii13iii25, doi: 10.1093/jurban/jti060

Hodge, D.R., Marsiglia, F.F., Nieri,T. (2011). Religion and substance use among youths of Mexican heritage: A social capital perspective. Social Work Research, 35(3), 137-146

Kalichman, S.C., Simbayi, L.C., Kagee, A., Toefy, Y. Cain, D., Cherry, C. (2006). Association of poverty, substance use, and HIV transmission risk behaviors in three South African communities. Social Science and Medicine, 62, 1641-1649

Leigh, B.C., Stall, R. (1993). Substance use and risk sexual behavior for exposure to HIV. American Psychologist, 48(10), 1035-1045.

Lin, N. (2001). Social capital: A theory of social structure and action. New York: Cambridge University Press

Lin, N., Cook, K., Burt, R.S. (eds) (2001). Social Capital: Theory and Research. New York: Aldine De Gruyter

Lundborg, P. (2005). Social capital and substance use among Swedish adolescents -an explorative study. Social Science and Medicine, 61(6), 1151-1158

Patten, E. (2012). Statistical portrait of the foreign-born population in the United States, 2010. Washington, DC: Pew Hispanic Center 
Portes, A. (1998). Social Capital: Its origins and applications in modern sociology. Annual Review of Sociology, 22, 1-24.

Pronyk, P. M., Kim, J. C., Abramsky, T., Phetla, G., Hargreaves, J. R., Morison, L. A., \& Porter, J. D. (2008a). A combined microfinance and training intervention can reduce HIV risk behaviour in young female participants. AIDS (London, England), 22(13), 1659-1665. doi: 10.1097/QAD.0b013e328307a040

Putnam, R. (1995). Bowling Alone: America's declining social capital. Journal of Democracy, 6, 65-78.

Reynoso-Vallejo, H. (2011). Social capital influence in illicit drug use among racial/ethnic groups in the United States. Journal of Ethnicity in Substance Use, 10, 91-111

Sanchez, M.A., Lemp, G.F., Magis-Rodriguez, C., Bravo-Garcia, B.A., Carter, S., Ruiz, J.D. (2004). The epidemiology of HIV among Mexican immigrants and recent immigrants in California and Mexico. Journal of Acquired Immune Deficiency Syndrome, 37(4), S204S214.

Shedlin, M.G., Decenta, C.U., Oliver-Velez, D. (2005). Initial acculturation and HIV risk among new Hispanic immigrants. Journal of National Medical Association, 97(7 Suppl), 32-7S.

Shurtleff, D., Lawrence,D. (2012). HIV and Substance Abuse: A Commentary. Current HIV Research, May 10, 2012. [Epub]. PMID: 22591360 


\section{Manuscript 1: \\ Does social capital matter? A systematic review of social capital and HIV risk}

\section{Abstract}

The reduction of HIV-risk behaviors in populations has proven to be challenging and requires multifaceted interventions at the individual and community level. One potentially important avenue to consider is social capital. The term social capital is used to describe concepts related to social cohesion and group connectedness. The purpose of the systematic review was to assess the relationship between individual and aggregate level social capital and HIV risk using findings from quantitative and qualitative studies. A search was performed using prominent electronic databases, and through a review of references of published papers. Studies were included if there was a measure of either individual or aggregate level social capital as well as a measure of HIV risk behavior as the outcome. After the search, 124 articles were selected to be tested for inclusion. Out of the 124 selected, twelve papers met the study inclusion criteria.

Eleven studies measured social capital at the individual level, and only one study measured social capital at the group level, which limited inference into the application of community level social capital on HIV risk behavior. Eight of the studies were cross sectional or had one time point, and did not allow for causal inferences. Among the eleven studies measuring individual level social capital, one study had an all-male population, one study had a transgender population, five studies had at-risk female populations, and four studies had both male and female participants. Four studies were conducted in the United States, and the remaining eight studies were conducted in Haiti, India, South Africa, Tanzania, Uganda, and Zimbabwe. Overall, HIV risk was influenced by social capital, but the type of influence was dependent on the type of social capital and on the study population. Cognitive social capital, or levels of collective action, was protective against HIV in both men and women. The role of structural social capital, or levels of civic engagement/group participation, on HIV risk was dependent on the type of structural social capital and varied by gender. Microfinance programs and functional group participation were 
protective for women, while dysfunctional group participation and peer-level support may have increased HIV risk among men. Social capital can potentially be a useful HIV prevention tool, but its level of usefulness is context dependent.

KEY WORDS: SOCIAL CAPITAL, HIV RISK, REVIEW 


\section{Background}

\section{Social Capital}

Early $20^{\text {th }}$ century European philosophers used the term "social capital" to describe concepts of social cohesion and group connectedness (Kawachi \& Berkman, 2000; Macinko \& Starfield, 2001). There are many ways in which social capital is conceptualized and defined in the literature. One definition describes social capital as "those features of social structures—such as levels of interpersonal trust and norms of reciprocity and mutual aid - which act as resources for individuals and facilitate collective action" (Kawachi \& Berkman, 2000).

Lin defines social capital as "social relations with expected returns in the marketplace" (Lin, 2001). This definition is at the individual-level, but social capital is also perceived as a public common good at a community or society level or "a public good created by the byproduct of other activities" (Coleman, 1990). The World Bank offers a definition of social capital as "the institutions, relationships, and norms that shape the quality and quantity of society's social interactions... Social capital is not just the sum of the institutions which underpin a society—it is the glue that holds them together" (The World Bank, 1999). In more recent times, one of the more widely accepted definitions of social capital is Putnam's definition: “[Social capital is] networks, norms, and trust that enable participants to act together more effectively to pursue shared objectives." (Putnam, 1995). The evolution of social capital from the early $20^{\text {th }}$ century to today has yielded nomenclature, such as: community empowerment/movement, social resources, informal and formal social networks, good neighborliness, social cohesiveness, social connectedness, social embeddedness, and cultural capital (Portes \& Sensenbrenner, 1993).

When assessing the effect of social capital, the focus is not on the individual but rather on community (Arneil, 2006). Therefore, social capital is contextual; it is typically measured for individuals, but may be summed and applied at an aggregate level. There have been criticisms of this approach, primarily because summing individual measures of intangible social capital may 
not accurately determine the effect of social capital as a group measure. Specifically, social capital as measured for an individual, in terms of familial support, non-familial emotional support, civic engagement, and access to resources, does not necessarily accurately reflect the group benefit of social capital in terms of availability and provision of social services to a community. Coleman (1988) describes social capital as the movement created by actors, with the outcome as a public good that is created as a byproduct of other activities. There may be a disconnect in Coleman's interpretation in that individual level quantitative measures and scales are used to measure the benefit or effect at a community level. Researchers are aware of this limitation; However, for several reasons, there are still few prospective ecologic studies that examine the effects of social capital at an aggregate level.

The discourse on the role of social capital in social policy ranges from liberal perspectives which place importance on civic participation for individuals in a community and an individualist perspective that promotes a more individual path of success and prosperity (Shortt, 2004). According to social capital theory, investment in social capital will not only benefit the individual, but also other members of society (Arneil, 2006). During the 1960s in the United States, community mobilization and promotion of civic engagement among disadvantaged populations were operationalized to achieve more favorable outcomes for a community and were a cornerstone of Lyndon B. Johnson's social policy related to the War on Poverty (Alinsky, 1972; United States Congress House Committee on Education and Labor Subcommittee on War on Poverty Program, 1973). Despite this, Robert Putnam asserts that since the 1950s, the United States has experienced a decrease of social capital, specifically less civic engagement by individuals/families (Paxton, 1999; Putnam, 2000).

There have been numerous criticisms of the applicability of social capital outside of Western/European societies (McLean, Schultz, \& Steger, 2002). The relevance of the concept toward non-white men and women, immigrants, marginalized populations, and societies with a 
different historical perspective and social structure has been questioned. Additionally, participation in all civic groups does not necessarily promote civic bonding and inclusion, but may actually foster exclusivity (Arneil, 2006). For example, although fraternal orders increase social capital within that exclusive group, the order is also effectively marginalizing other members of society through disassociation with non-members (Arneil, 2006).

\section{Social Capital and Health Policy}

Social capital has been used as a conceptual framework in designing health policies in the United States, United Kingdom, Canada, and some European countries (Muntaner, Lynch, \& Davey Smith, 2001). The policies are not uniform or straightforward, and it is evident that social capital is often contextually based on economic and socio-political history (Campbell, 2000; Muntaner et al., 2001; Shortt, 2004). For example, applying social capital-based health policy may encourage delegating health policies to non-governmental organizations (NGO), or conversely it may be a rationale to increase the government's role in health policy development (Shortt, 2004).

Using the term "social capital" broadly may not be useful across all communities because the term itself is open to multiple interpretations and invokes preconceived ideas of its role in health behavior and outcomes. Norris and Davis (2003) compared social capital in the United States and Europe, considering only bridging social capital, which focuses on civic engagement and community participation. Bridging social capital may be more relevant to the United States and North-Western European countries where there is advanced economic and social development. However, in less developed countries where there may be fewer opportunities for civic engagement and political involvement, bonding social capital, which focuses on family and emotional support, may play a greater role. Therefore, when assessing the relevance of social capital and health, other factors such as the political and economic environment, societal history, 
and life experience of the individual should also be taken into consideration (Campbell, 2000; Shortt, 2004).

Research indicates that higher levels of individual social capital are possibly associated with better health outcomes (Muntaner et al, 2001; Putnam, 2000; Whitehead \& Diderischsen, 2001). At a macro level, the general well-being of citizens in a society is also positively affected by social capital. In a study examining state levels of social capital associated with individual self-rated health, Kawachi, Kennedy, and Glass (1999) found a correlation between individuals residing in states with low levels of social capital and poor self-rated health. Although a causal relationship was not established, the study was able to establish a link between societal social capital and individual health (Kawachi et al., 1999).

Diener and Chan (2011) found that a longer life span is associated with higher levels of happiness and that U.S. residents experience greater levels of happiness due to greater perceived fairness and general trust within their communities. These findings indicate the potential positive influence of perceived happiness, fairness, and trust—all components of social capital—on health outcomes.

\section{Social capital and HIV-risk behavior}

Lower levels of social capital are associated with increased HIV-risk behavior (Cené et al., 2011). Compared to the use of standard social determinants (e.g., gender, socioeconomic status, education, marital status, etc.), social capital has a broader context (access to formal and informal healthcare, civic engagement, role of religiosity, and trust and reciprocity norms within community/society), which allows for a more comprehensive framework on what can influence an individual's decision making and sexual behavior (Szreter \& Woolcock, 2004).

There are examples of HIV programs based on social capital. Microfinance empowerment programs, which empower women through financial independence, are linked with 
a reduction in HIV incidence in developing countries (Sherman, German, Cheng, Marks, \& Bailey-Kloche, 2006; Swendeman, Basu, Das, Jana, \& Rotheram-Borus, 2009). There are community empowerment programs where social capital is used as a protective variable in HIV behavioral research (Stratford, Mizuno, Williams, Courtenay-Quirk, \& O'leary, 2008). For example, the reduction in HIV prevalence in Uganda during the 1990s has been linked with the idea of "collective efficacy" from local community-based groups in Uganda (Epstein, 2007), and it is believed that the establishment of AIDS agencies in San Francisco promoted safer sexual practices and consequently influenced the decline of HIV rates (Wohlfeiler, 2002).

To our knowledge, this is the first systematic review of HIV risk and social capital. Although Poundstone, Strathdee, \& Celentano (2004) provide a comprehensive framework for social factors related to HIV/AIDS incidence, including cultural context, social networks, neighborhood effects, and social capital, our article adds to the literature by using a more specific definition of social capital and includes both ecologic (or community-level measurement of social capital) and individual measurement of social capital. In addition, this review focuses specifically on HIV risk behavior.

\section{Methods}

The purpose of this article is to systematically review the evidence for an association between social capital and HIV-risk behavior. The Preferred Reporting Items for Systematic reviews and meta-Analysis (PRISMA) was used as a guideline to complete the systematic review (Moher, Tetzlaff \& Altman, 2009). The system was modified for non-randomized studies. Therefore, items such as 'protocol registration' was omitted from the review. The search was conducted using prominent electronic databases, including PubMed, Medline, Cochrane Library, Cumulative Index to Nursing and Allied Health Literature (CINAHL), PsycInfo, Proquest, and Google Scholar. Additionally, hand searches through references were completed. 
Search terms for social capital were guided by a prior published systematic review for social capital and mental health (De Silva, McKenzie, Harpham, \& Huttly, 2005). The search terms used in this review included "social capital", "social embeddedness", "social*", "empowerment *", "collective efficacy", and "neighborhood organization/disorganization". Search terms for HIV risk were "HIV correlates", "HIV behavior", "HIV", "HIV risk", "HIV*”, and "sexual risk".

To capture all potential studies addressing the social epidemiology component of the potential relationship between social capital and HIV risk factors, both qualitative and quantitative studies were included. The initial electronic search of any document related to HIV (search term "HIV*") and social capital yielded over 5000 results. After a refined electronic search using the search terms listed above, 111 were identified. An additional 13 articles were identified through hand searches of references of existing publications. Of the 124 titles articles reviewed, 112 articles were excluded because: they were not original research papers; they were not related to HIV risk (e.g., they were related to HIV stigma, adherence, treatment, quality of life); or they were outside of the definition of social capital being used for this review (e.g., only addressed social networks). This left 12 papers for inclusion in the systematic review (see Figure $1)$. 
Figure 1: Selection of Studies

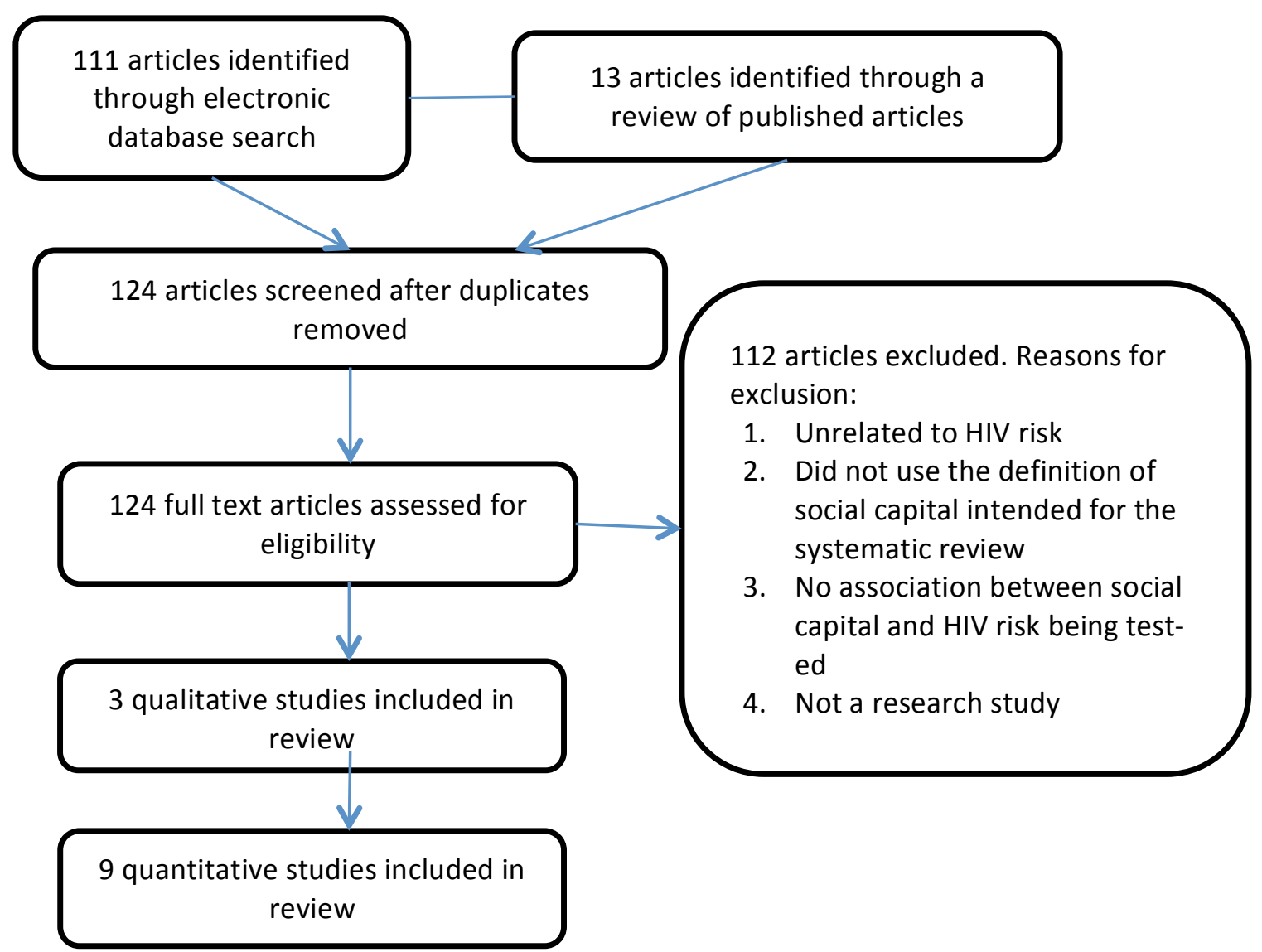

\section{Statistical Analysis}

The heterogeneity of definitions for social capital and HIV risk prevented a meta-analysis of the studies. Univariate descriptive analysis was performed in all 12 studies. Three qualitative studies did not report statistical analysis; nine studies featured complex statistical analysis. The results for the nine studies with more complex analyses were categorized into one of five groups: (a) indicated a significant inverse relationship between social capital and HIV-risk behavior (low social capital leads to more high risk sexual behavior (Sinv)), (b) indicated more social capital was associated with greater high risk sexual behavior (Sass), (c) indicated a significant increase in HIV-risk behavior (SIRB), (d) indicated a significant reduction in HIV-risk behavior (SRRB), or (e) indicated a significant increase in the level of social capital (SISC). 


\section{Measures}

HIV risk - The criteria used to identify HIV risk sexual behavior were based on existing scientific articles and are as follows: exchanging sex for drugs or money, being diagnosed with an STD, recent treatment for an STD, unprotected sexual acts (no condom use), multiple sexual partners of the opposite sex, having concurrent partners, having a non-monogamous partner, being a man who has sex with men, having a partner who is HIV positive, being a woman with male partners that have sex with men, increased substance use (alcohol or illicit drug use), having a partner who uses illicit drugs, and having sex under the influence (alcohol or illicit drug use)(Centers for Disease Control and Prevention, 2011; Chandra, Billioux, Copen, \& Sionean, 2012; Trepka \& Kim, 2010).

Social capital - Most of the concepts associated with social capital were included in the review. The social capital column of the results table (Table 1) differentiates social capital as either individual level (I) or aggregate level (G), and then further defines what type of social capital was measured (i.e., whether the social capital was measured as family support, emotional support, civic/religious engagement, or access to resources). Family and emotional support are considered cognitive social capital, and civic/religious engagement and access to resources are considered structural forms of social capital. Theoretically, social capital can be categorized as either cognitive social capital (an individual's perception of trust, sharing, or reciprocity) or structural social capital (bonding, bridging, or linking through social networks or civic engagement; Islam, Merlo, Kawachi, Lindstrom, \& Gerdtham, 2006). Both cognitive social capital and structural social capital are used in this systematic review.

Studies using microfinance programs as a mechanism of social capital are also included in this review, which may be a point of confusion because the eventual outcome of a microfinance program is financial gain or 'capital' in a traditional Marxist perspective. However, microfinance programs encourage participation in a community level endeavor. Microfinance 
programs are a result of collective action within a community and typically aim to reduce disparities for women in underserved settings (Rankin, 2002).

\section{Results}

Four studies (33.3\%) were conducted in the United States, and the remaining eight studies (66.7\%) were conducted in Haiti (1), India (1), South Africa (3), Tanzania (1), Uganda (1), and Zimbabwe (1). No studies were identified in Europe, Canada, or Australia. The four U.S. studies were among higher risk populations and recruited from vulnerable groups such as immigrants, individuals from lower socio-economic strata, women involved in prostitution, or individuals with a history of incarceration.

One study (8.3\%) measured social capital at the aggregate level using rural villages as sample units, the rest were samples of individuals, including one study (8.3\%) on an all-male population, one study $(8.3 \%)$ of a transgender population, five studies $(41.6 \%)$ of female populations (e.g. economically disadvantaged, sex-workers, or drug using women), and four studies $(33.3 \%)$ which included men and women.

Table 1 outlines the main characteristics of the 12 studies selected for the review.

\section{Description of Studies}

Undergraduate university students in Uganda were used for the Agardh, Emmelin, Muriisa, and Ostergren (2010) cross sectional study. The initial study sample of 1,220 was recruited from medical, science, and development studies faculties in 2005, and there was an $80 \%$ response rate for a final sample of 980 students. The authors found that social capital measured as trust in others or bridging trust was associated with $\mathrm{ABC}$ (abstinence, being faithful, and condom use) HIV prevention behavior. Gender and religion were effect modifiers in the relationship. Participants reporting that 'religion played a minor role' (one of the social capital variables of the study) in their family life exhibited high risk behavior. There was no significant association between 'religion playing a major role' and any of the HIV risk outcomes. 
The Battacharya (2005) study was an exploratory, qualitative study of 17 Indian immigrants in New York City. Recruitment was based on two phases. The first phase identified a subset of high-risk Indian immigrants through community-based, key informant interviews. These results allowed the principal investigator to develop eligibility criteria for the second phase: audio-taped participant interviews. Indian men were included if they were between 18-45 years of age and resided in New York City for at least one year. The final sample included Indian men who resided in New York for 2 to 21 years. Twelve earned U.S. graduate degrees or were currently enrolled in a graduate program. Peer support was found to be the most valuable resource, and study participants found casual sexual relationships to be a form of stress relief. Although there was technically an increase in social capital in terms of emotional support, in this instance, HIV-risk behavior increased when social capital in the form of peer support, increased. 
Table 1: Characteristics of studies assessing the relationship between social capital (individual and group level) and HIV risk factor

\begin{tabular}{|c|c|c|c|c|c|c|c|c|c|}
\hline $\begin{array}{l}\text { AUTHOR, } \\
\text { YEAR OF } \\
\text { PUB }\end{array}$ & LOCATION & $\begin{array}{l}\text { POP. AND } \\
\text { SAMPLE } \\
\text { SIZE (n) }\end{array}$ & $\begin{array}{l}\text { TYPE OF } \\
\text { STUDY }\end{array}$ & $\begin{array}{l}\text { TYPE OF } \\
\text { ANALYSIS }\end{array}$ & $\begin{array}{l}\text { INSTRUMENT/ } \\
\text { INTERVENTION }\end{array}$ & $\begin{array}{c}\text { SOCIAL } \\
\text { CAPITAL } \\
\text { MEASURE }\end{array}$ & HIV FACTOR & RESULTS & LIMITATIONS \\
\hline $\begin{array}{l}\text { Agardh, } \\
\text { Emmelin, } \\
\text { Muriisa, \& } \\
\text { Ostergren, } \\
2010\end{array}$ & Uganda & $\begin{array}{l}\text { University } \\
\text { students } \\
(\mathrm{n}=980)\end{array}$ & Cross sect. & MV LR & $\begin{array}{l}\text { Instrument was } \\
\text { self-administered } \\
\text { questionnaire }\end{array}$ & $\begin{array}{l}\text { I-bridging } \\
\text { trust, social } \\
\text { participation }\end{array}$ & 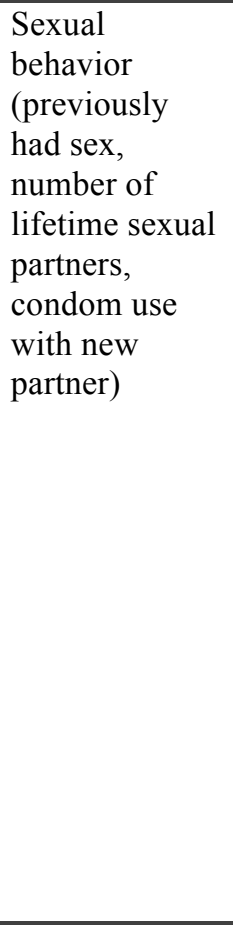 & $\begin{array}{l}\text { Sass: female } \\
\text { students with } \\
\text { low trust and } \\
\text { low probability } \\
\text { of having a } \\
\text { previous } \\
\text { sexual } \\
\text { experience } \\
\text { Sinv: male } \\
\text { students with } \\
\text { low trust had } \\
\text { high number of } \\
\text { sexual partners } \\
\text { Sass: male and } \\
\text { female } \\
\text { students with } \\
\text { high non- } \\
\text { dominant } \\
\text { bridging trust } \\
\text { had more } \\
\text { sexual partners }\end{array}$ & $\begin{array}{l}\text { Cross sectional } \\
\text { analysis - no } \\
\text { causal } \\
\text { inference } \\
\text { Possible } \\
\text { selection bias }\end{array}$ \\
\hline $\begin{array}{l}\text { Bhattacharya, } \\
2005\end{array}$ & $\begin{array}{l}\text { New York, } \\
\text { NY, USA }\end{array}$ & $\begin{array}{l}\text { Heterosexual } \\
\text { Asian Indian } \\
\text { immigrant } \\
\text { men aged } \\
18-45 \\
(\mathrm{n}=17)\end{array}$ & $\begin{array}{l}\text { Community } \\
\text { based } \\
\text { qualitative } \\
\text { study }\end{array}$ & Qual & $\begin{array}{l}\text { Instrument was } \\
\text { individual } \\
\text { interviews }\end{array}$ & $\begin{array}{l}\text { I-cognitive } \\
\text { and social } \\
\text { structural } \\
\text { capital }\end{array}$ & $\begin{array}{l}\text { HIV risk } \\
\text { (alcohol and } \\
\text { drug use, anal } \\
\text { sex, condom } \\
\text { use, STI status, } \\
\text { perceived risk } \\
\text { of HIV, } \\
\text { number of } \\
\text { times had sex }\end{array}$ & $\begin{array}{l}\text { Group } \\
\text { relationship } \\
\text { norms } \\
\text { influence HIV } \\
\text { risk and } \\
\text { protective } \\
\text { factors }\end{array}$ & $\begin{array}{l}\text { Small } \\
\text { population size, } \\
\text { no married men } \\
\text { with wives in } \\
\text { India were } \\
\text { included in } \\
\text { sample, self- } \\
\text { identification of } \\
\text { heterosexual }\end{array}$ \\
\hline
\end{tabular}




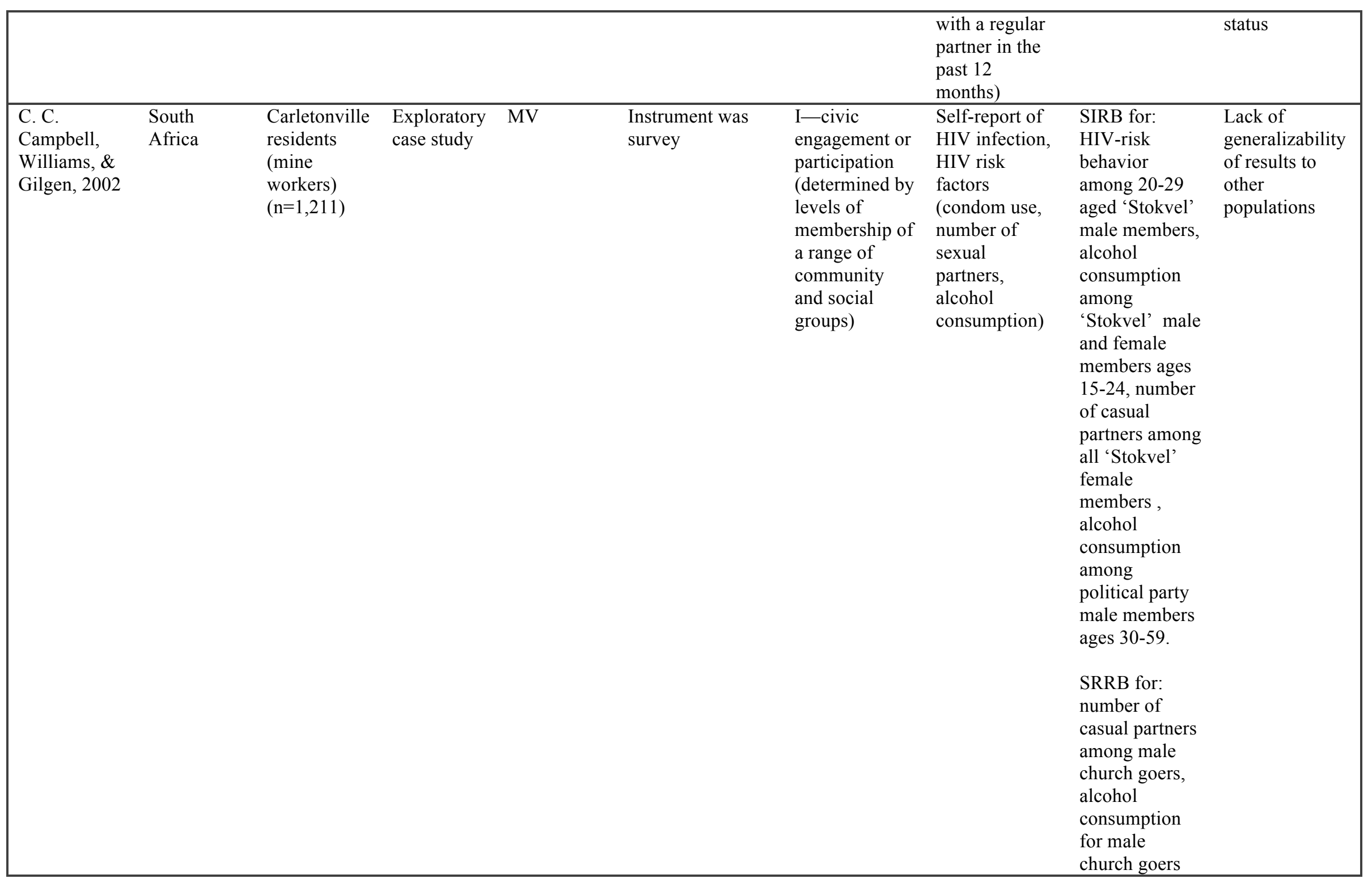




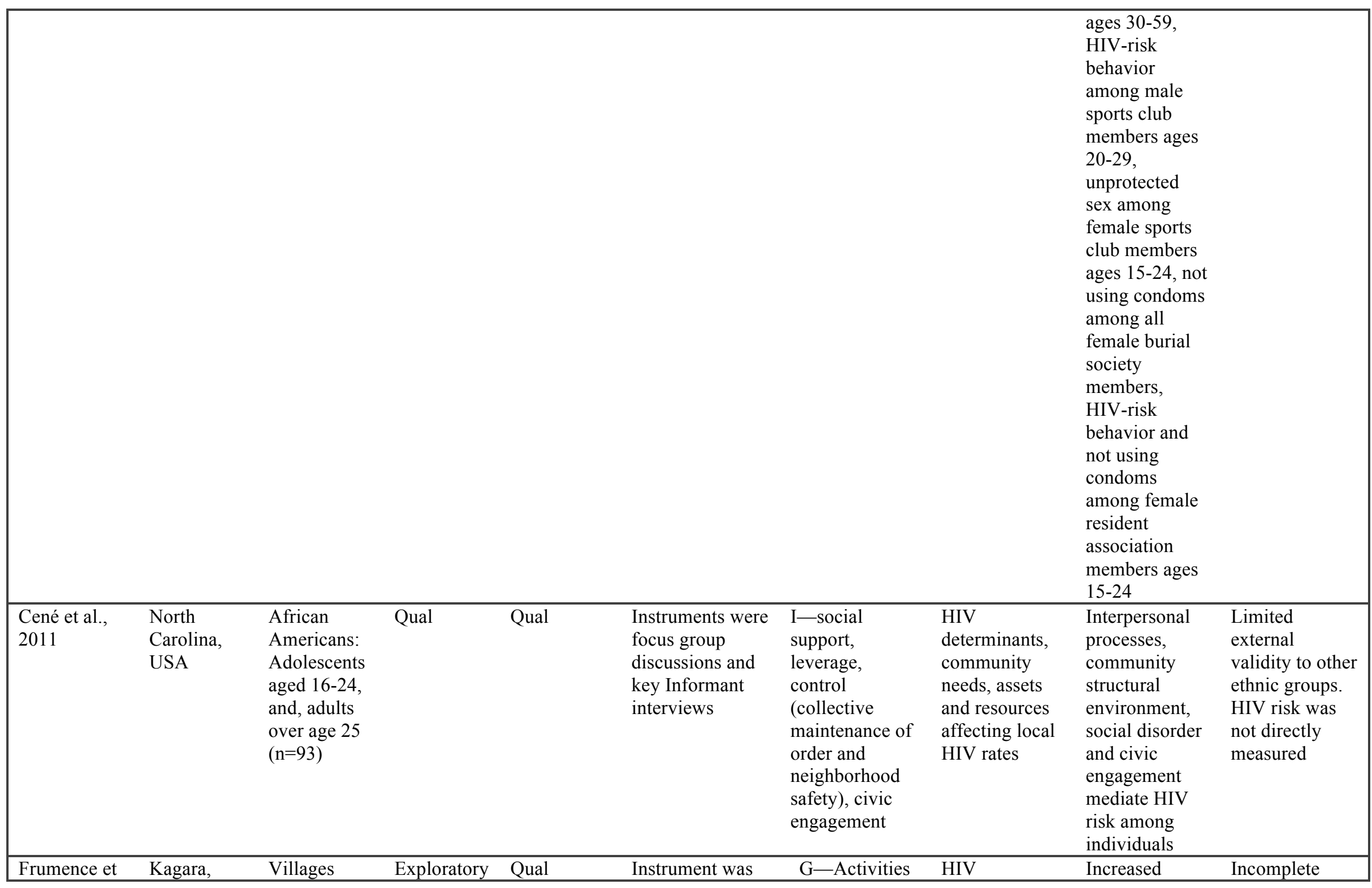




\begin{tabular}{|c|c|c|c|c|c|c|c|c|c|}
\hline al., 2010 & Tanzania & $(\mathrm{n}=3)$ & case study & & $\begin{array}{l}\text { focus group } \\
\text { discussions }\end{array}$ & $\begin{array}{l}\text { performed by } \\
\text { non- } \\
\text { governmental } \\
\text { and faith- } \\
\text { based } \\
\text { organizations } \\
\text { and social } \\
\text { groups in case } \\
\text { villages } \\
\text { (structural } \\
\text { (bonding, } \\
\text { bridging, and } \\
\text { linking) and } \\
\text { cognitive } \\
\text { social capital) }\end{array}$ & prevalence & $\begin{array}{l}\text { social capital } \\
\text { linked with a } \\
\text { decrease in } \\
\text { HIV } \\
\text { transmission } \\
\text { More social } \\
\text { capital in } \\
\text { activity in } \\
\text { areas with } \\
\text { higher HIV } \\
\text { prevalence } \\
\text { Social capital } \\
\text { groups } \\
\text { potentially } \\
\text { exclusionary, } \\
\text { thereby } \\
\text { increasing HIV } \\
\text { risk among } \\
\text { those excluded }\end{array}$ & $\begin{array}{l}\text { information on } \\
\text { some } \\
\text { organizations } \\
\text { and groups }\end{array}$ \\
\hline $\begin{array}{l}\text { Gregson, } \\
\text { Terceira, } \\
\text { Mushati, } \\
\text { Nyamukapa, } \\
\text { \& Campbell, } \\
2004\end{array}$ & Zimbabwe & $\begin{array}{l}\text { Female } \\
\text { Manicaland } \\
\text { residents } \\
\text { aged 15-24 } \\
(\mathrm{n}=2268)\end{array}$ & Cross sect. & MV LR & $\begin{array}{l}\text { Instrument was a } \\
\text { population-based } \\
\text { survey }\end{array}$ & $\begin{array}{l}\text { I-social } \\
\text { group } \\
\text { membership } \\
\text { Functionality } \\
\text { of group } \\
\text { membership }\end{array}$ & $\begin{array}{l}\text { Psychosocial } \\
\text { attributes } \\
\text { (including } \\
\text { knowledge } \\
\text { about } \\
\text { HIV/AIDS) }\end{array}$ & $\begin{array}{l}\text { Sinv: } \\
\text { compared to } \\
\text { participating in } \\
\text { a dysfunctional } \\
\text { group, } \\
\text { participation in } \\
\text { a well- } \\
\text { functioning } \\
\text { group } \\
\text { increased the } \\
\text { likelihood of } \\
\text { avoiding HIV } \\
\text { infection } \\
\text { Sinv: } \\
\text { compared to } \\
\text { not } \\
\text { participating in }\end{array}$ & $\begin{array}{l}\text { Cross sectional } \\
\text { analysis-no } \\
\text { causal } \\
\text { inference } \\
\text { Results may } \\
\text { reflect selective } \\
\text { participation in } \\
\text { groups by those } \\
\text { who already } \\
\text { practice a safer } \\
\text { lifestyle }\end{array}$ \\
\hline
\end{tabular}




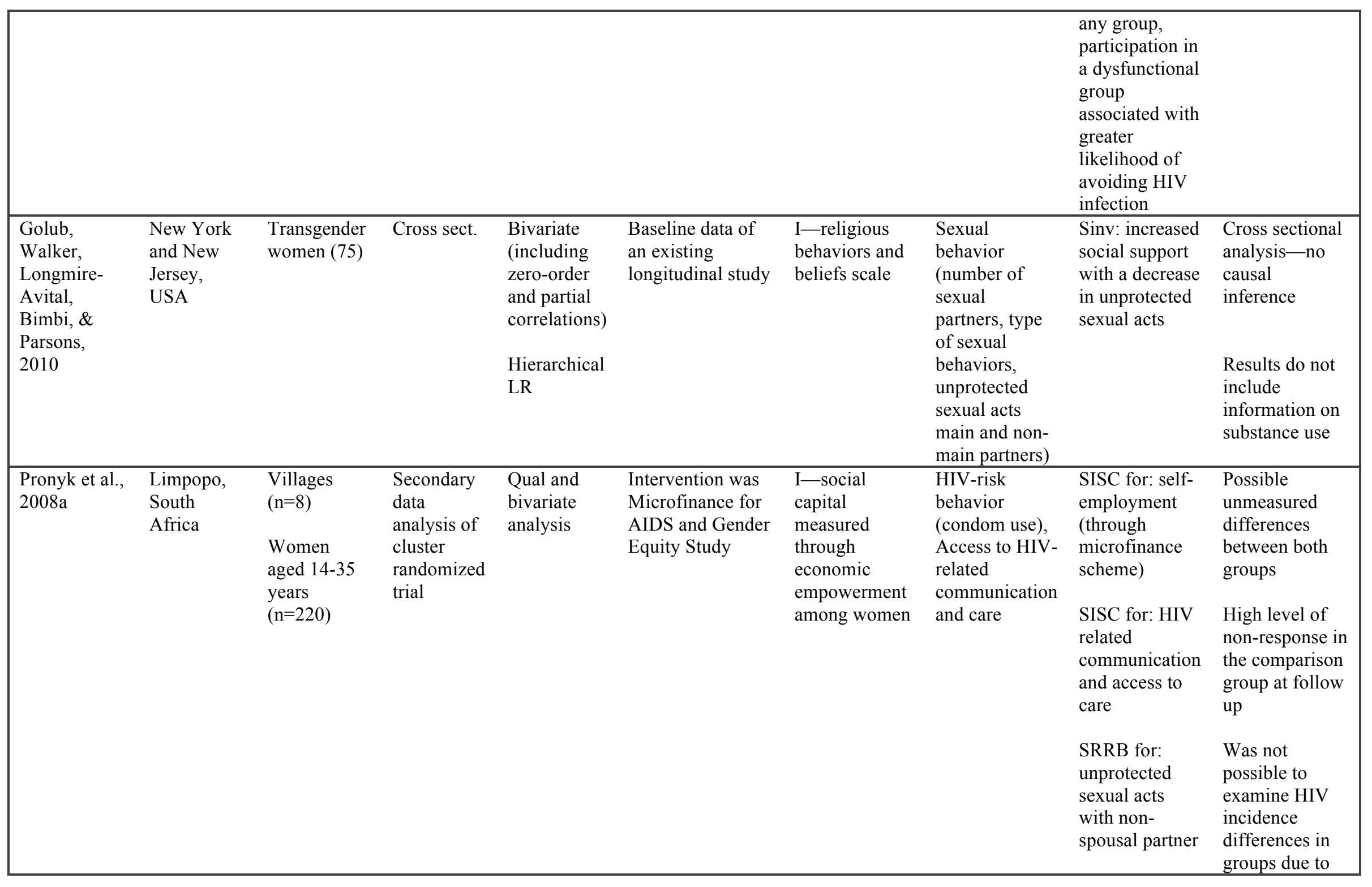




\begin{tabular}{|c|c|c|c|c|c|c|c|c|c|}
\hline & & & & & & & & & $\begin{array}{l}\text { low numbers of } \\
\text { infections }\end{array}$ \\
\hline $\begin{array}{l}\text { Pronyk et al., } \\
2008 \text { b }\end{array}$ & $\begin{array}{l}\text { Limpopo } \\
\text { province, } \\
\text { South } \\
\text { Africa }\end{array}$ & $\begin{array}{l}14-35 \text { aged } \\
\text { male and } \\
\text { female } \\
(n=1063)\end{array}$ & Long. & LR, MV LR & $\begin{array}{l}\text { Instruments were } \\
\text { surveys assessing } \\
\text { social capital and } \\
\text { HIV psychosocial } \\
\text { attributes, risk, } \\
\text { prevalence and } \\
\text { incidence }\end{array}$ & $\begin{array}{l}\text { G (household } \\
\text { levels)- } \\
\text { cognitive and } \\
\text { structural } \\
\text { social capital }\end{array}$ & $\begin{array}{l}\text { Psycho-social } \\
\text { attributes } \\
\text { (knowledge, } \\
\text { openness, } \\
\text { communication } \\
\text { risk perception, } \\
\text { collective } \\
\text { action), HIV- } \\
\text { risk behavior } \\
\text { (condom use, } \\
\text { number of } \\
\text { partners), } \\
\text { biological } \\
\text { outcomes HIV } \\
\text { prevalence and } \\
\text { incidence }\end{array}$ & $\begin{array}{l}\text { Sinv: males } \\
\text { and females } \\
\text { with higher } \\
\text { cognitive } \\
\text { social capital } \\
\text { with lower } \\
\text { HIV } \\
\text { prevalence }\end{array}$ & $\begin{array}{l}\text { Convenience } \\
\text { sample from } \\
\text { pre-existing } \\
\text { study, social } \\
\text { capital derived } \\
\text { from female } \\
\text { household } \\
\text { members only } \\
\text { and HIV risk } \\
\text { assessed among } \\
\text { a younger "at } \\
\text { risk" group }\end{array}$ \\
\hline $\begin{array}{l}\text { Rosenberg, } \\
\text { Seavey, } \\
\text { Jules, \& } \\
\text { Kershaw, } \\
2011\end{array}$ & Haiti & $\begin{array}{l}\text { Haitian } \\
\text { women aged } \\
18-49 \\
(\mathrm{n}=192)\end{array}$ & Cross Sect. & LR MLR & $\begin{array}{l}\text { Face to face } \\
\text { interviews with } \\
\text { microfinance } \\
\text { institution } \\
\text { "Fonkoze" clients }\end{array}$ & $\begin{array}{l}\text { I-Length of } \\
\text { participation } \\
\text { in } \\
\text { microfinance } \\
\text { program } \\
\text { (long } \\
\text { term=12 or } \\
\text { more } \\
\text { months, } \\
\text { short term= } \\
\text { less than } 12 \\
\text { months) }\end{array}$ & $\begin{array}{l}\text { HIV-risk } \\
\text { behavior and } \\
\text { relationship } \\
\text { power (partner } \\
\text { fidelity, } \\
\text { frequency of } \\
\text { condom use, } \\
\text { ever having } \\
\text { received an } \\
\text { HIV test) }\end{array}$ & $\begin{array}{l}\text { Sinv for: long } \\
\text { term Fonkoze } \\
\text { clients (high } \\
\text { social capital) } \\
\text { less likely to } \\
\text { have partners } \\
\text { who are } \\
\text { unfaithful, and } \\
\text { more likely to } \\
\text { use condoms }\end{array}$ & $\begin{array}{l}\text { Cross sectional } \\
\text { analysis - no } \\
\text { causal } \\
\text { inference } \\
\text { Fonkoze has a } \\
\text { high client } \\
\text { retention rate } \\
\text { which might } \\
\text { minimize the } \\
\text { differences that } \\
\text { would exist due } \\
\text { to clients who } \\
\text { drop out } \\
\text { Self-report of } \\
\text { HIV risk and } \\
\text { behavior }\end{array}$ \\
\hline & & & & & & & & & $\begin{array}{l}\text { Unblinded } \\
\text { principal }\end{array}$ \\
\hline
\end{tabular}




\begin{tabular}{|c|c|c|c|c|c|c|c|c|c|}
\hline & & & & & & & & & $\begin{array}{l}\text { investigator } \\
\text { administered } \\
\text { the interview } \\
\text { and recorded } \\
\text { data }\end{array}$ \\
\hline $\begin{array}{l}\text { Sherman, } \\
\text { German, } \\
\text { Cheng, } \\
\text { Marks, \& } \\
\text { Bailey- } \\
\text { Kloche, } 2006\end{array}$ & $\begin{array}{l}\text { Baltimore, } \\
\text { MD, USA }\end{array}$ & $\begin{array}{l}\text { HIV drug- } \\
\text { using } \\
\text { women } \\
\text { involved in } \\
\text { prostitution } \\
(\mathrm{n}=50)\end{array}$ & Pilot & MLR & $\begin{array}{l}\text { Intervention for } \\
\text { all participants } \\
\text { was a 2-hour } \\
\text { session for HIV } \\
\text { risk reduction and } \\
\text { prevention and, } \\
\text { making, } \\
\text { marketing and } \\
\text { selling of jewelry }\end{array}$ & $\begin{array}{l}\text { I-Job self- } \\
\text { efficacy } \\
\text { (above and } \\
\text { below median } \\
\text { jewelry sale } \\
\text { for those who } \\
\text { sold jewelry) }\end{array}$ & $\begin{array}{l}\text { Risk behavior } \\
\text { (Daily drug } \\
\text { use, needle } \\
\text { sharing, } \\
\text { median amount } \\
\text { of money spent } \\
\text { on drugs daily, } \\
\text { median } \\
\text { number of } \\
\text { sexual contacts } \\
\text { per month, } \\
\text { condom use } \\
\text { with male } \\
\text { casual partner } \\
\text { during vaginal } \\
\text { sex, condom } \\
\text { use with sex } \\
\text { trade partners } \\
\text { during vaginal } \\
\text { sex, median } \\
\text { number of sex } \\
\text { trade partners } \\
\text { per month) }\end{array}$ & $\begin{array}{l}\text { SISC for: job } \\
\text { self-efficacy } \\
\text { SRRB for: } \\
\text { receiving sex } \\
\text { for } \\
\text { drugs/money, } \\
\text { daily drug use, } \\
\text { daily crack } \\
\text { use, median } \\
\text { amount of } \\
\text { money spent } \\
\text { on drugs daily, } \\
\text { median } \\
\text { number of } \\
\text { sexual contacts } \\
\text { per month }\end{array}$ & $\begin{array}{l}\text { No control } \\
\text { group, internal } \\
\text { validity may be } \\
\text { compromised } \\
\text { due to social } \\
\text { desirability for } \\
\text { survey } \\
\text { questions, short } \\
\text { follow up time } \\
\text { ( } 3 \text { months) }\end{array}$ \\
\hline $\begin{array}{l}\text { Swendeman, } \\
\text { Basu, Das, } \\
\text { Jana, \& } \\
\text { Rotheram- } \\
\text { Borus, 2009 }\end{array}$ & $\begin{array}{l}\text { Kolkata, } \\
\text { India }\end{array}$ & $\begin{array}{l}\text { Female sex } \\
\text { workers } \\
(\mathrm{n}=216)\end{array}$ & $\begin{array}{l}\text { Quasi exp. } \\
\text { Long. }\end{array}$ & $\begin{array}{l}\text { Random- } \\
\text { effects } \\
\text { repeated } \\
\text { measures } \\
\text { regression } \\
\text { random- } \\
\text { effects } \\
\text { repeated } \\
\text { measures }\end{array}$ & $\begin{array}{l}\text { Intervention was } \\
\text { 'Sonagachi's } \\
\text { empowerment' } \\
\text { intervention } \\
\text { which focused on } \\
\text { HIV/STD } \\
\text { infection, condom } \\
\text { use, SC capital } \\
\text { measures (see } \\
\text { next column) }\end{array}$ & $\begin{array}{l}\text { I—skills for } \\
\text { sexual } \\
\text { negotiation } \\
\text { and workplace } \\
\text { autonomy, sex } \\
\text { "worker" } \\
\text { framework to } \\
\text { motivate } \\
\text { change, social } \\
\text { support via }\end{array}$ & $\begin{array}{l}\text { STI/HIV } \\
\text { knowledge }\end{array}$ & $\begin{array}{l}\text { SISC for: } \\
\text { Social Capital } \\
\text { measures }\end{array}$ & $\begin{array}{l}\text { None identified } \\
\text { by authors }\end{array}$ \\
\hline
\end{tabular}




\begin{tabular}{|c|c|c|}
\hline LR & $\begin{array}{l}\text { Standard of care } \\
\text { for control group } \\
\text { was peer } \\
\text { education and } \\
\text { condom } \\
\text { promotion }\end{array}$ & $\begin{array}{l}\text { organizing and } \\
\text { solidarity, } \\
\text { financial } \\
\text { security, } \\
\text { political } \\
\text { participation }\end{array}$ \\
\hline \multicolumn{3}{|c|}{$\begin{array}{l}\text { Key to analytical method: MLR=multiple linear regression, } \mathrm{LR}=\text { logistic regression, } \mathrm{MV}=\text { multivariate analysis, Qual=Qualitative methods, } \mathrm{SEM}=\text { structural equation } \\
\text { modeling, TM=ANOVA, } \mathrm{t} \text {-test or chi square. Key to social capital measure: } \mathrm{G}=\text { group, I=individual. Key to results: Sinv=more social capital associated with less } \\
\text { high risk sexual behavior or vice versa at least at } \mathrm{p}<.05 \text {, Sass=more social capital associated with greater high risk sexual behavior or vice versa at least at } \mathrm{p}<.05 \text {, } \\
\text { SIRB }=\text { significant increase in HIV-risk behavior at least at } \mathrm{p}<.05, \mathrm{SRRB}=\text { significant reduction in HIV-risk behavior at least at } \mathrm{p}<.05 \text {, SISC }=\text { significant increase in } \\
\text { social capital measure at least at } \mathrm{p}<.05 \text {,. [Note: For qualitative studies, statistical significance was not assessed.] }\end{array}$} \\
\hline
\end{tabular}


For the Campbell, Williams, and Gilgen (2002) exploratory study, a survey was administered to a random sample of 1,211 individuals between the ages of 30-60 in a gold-mining town in west South Africa. Social capital was defined as voluntary membership in community organizations or civic engagement. Because male partners were typically away at mining sites, and the sample was recruited within the community, the sample was overrepresented by women between the ages of 20-44 years. This study concluded that the relationship between social capital and HIV risk existed, but the direction of the association was influenced by age and gender. HIV prevalence increased for young men who were part of a Stokvel (social club), and casual partners increased for all women who were part of Stokvels. HIV prevalence decreased among both young men and women if they were part of a sports club. HIV prevalence and the number of casual partners decreased for young women who were part of a youth group.

The data for the Cené et al. (2011) qualitative study were from 38 African Americans aged 16-24 years. The study participants were recruited from North Carolina populations deemed by investigators as at 'greatest risk for HIV infection' and included individuals under the age of 18 years and individuals who were previously incarcerated. In this study, social capital was defined as a form of community engagement measured through social cohesion, group resources, and influence of the broader neighborhood environment on an individual. This study found community disorganization or disorder fueled HIV-risk behaviors, and the lack of civic engagement was partly due to churches' unwillingness to address HIV-related issues.

Key informants from high HIV prevalence rural villages in Tanzania participated in interviews and focus group discussions for the Frumence et al. (2010) qualitative study. Key informants provided information on community level social capital for their villages. Social capital was operationalized in this study through measures of 'education', 'care and treatment', 'counseling', 'preventive support', 'economic support', 'legal support' and 'social support'. Twenty-nine key informants from three villages were used, including five ward/village leaders, 
six faith-based organization leaders, and 18 leaders of informal organizations. Among the 12 studies in this review, only Frumence et al. (2010) measured social capital at the community level. Even at this aggregate level, through qualitative methods, it was concluded that social capital was associated with lower HIV rates in the geographical zone.

Gregson, Terceira, Mushati, Nyamukapa, and Campbell (2004) used an exploratory study to examine social capital and level of school education among young Zimbabwean women and their relationship to HIV avoidance. Young women aged 15-24 years $(n=2268)$ were recruited for a stratified population-based survey. The sampling frame was stratified into roadside trading centers, plantations, or farming areas. The authors found that higher levels of social capital, as measured by community group participation, were often associated with HIV avoidance, but this relationship was influenced by the group functionality and women's education level.

The Golub, Walker, Longmire-Avital, Bimbi, and Parsons (2010) study examined a unique transgender population in New York City and New Jersey. Transgender women were recruited from bars, programs, and nightclubs for a longitudinal study assessing issues related to transgender women. Baseline data from this study was used to examine the possible relationship between religiosity, social support, and HIV risk. In this study, religiosity was the social capital measure. Although the sample size was small in this study, it was the only one that provided information on a transgender population, a group at increased risk for HIV infection (ClementsNolle, Marx, Guzman, \& Katz, 2001; Edwards, Fisher, \& Reynolds, 2007). High risk sex was less likely for individuals who had higher levels of social support and low levels of religious behaviors.

Pronyk and colleagues conducted two studies involving different types of social capital and HIV risk among women in rural South Africa. The first study was a secondary data analysis of both quantitative and qualitative data from a randomized trial where microfinance was the intervention (Pronyk et al., 2008a). In this study, microfinance was the social capital measure. 
Pronyk's team found that the microfinance arrangement helped reduce HIV-risk behavior among women.

The second study conducted by Pronyk et al. (2008b) obtained cross sectional data on structural social capital (group membership), cognitive social capital (levels of reciprocity and community support, level of solidarity in response to a crisis, and levels of collective action), and HIV risk among both men and women in rural South Africa. The cross sectional study found cognitive social capital was linked to lower HIV prevalence and higher condom use. However, structural social capital, which was measured by degree of civic engagement and group participation, increased protective psychosocial attributes and risk behavior among women, but was also associated with higher HIV infection.

Women were recruited from Fonkoze loan centers in Haiti for the Rosenberg, Seavey, Jules, and Kershaw (2011) study. The Fonkoze microfinance institution fostered economic capital (primarily) among Haitian women, but also created solidarity among women by placing them into "solidarity groups" as a requirement to secure loans. In addition to small loans, the institution provided information and education on hygiene, reproductive health, and sexually transmitted diseases. Fonkoze encompasses social capital concepts because it encourages community engagement and networking, and facilitates access to both economic and social resources. Study participants were categorized as either short or long term members of Fonkoze. The main study finding was that long-term membership was associated with reduced HIV-risk behavior.

The Sherman et al. (2006) study assessed economic empowerment as an HIV prevention mechanism among drug-using women. The social capital intervention in this study was economic empowerment through educational sessions providing information on HIV prevention and on the making, marketing, and selling of jewelry. The study targeted drug-using commercial sex workers in Baltimore, MD. The empowerment program was considered successful because the study participants (commercial sex workers) had a reduction in sex-trade partners. 
In the final study, Swendeman et al. (2009) implemented another empowerment program among sex workers in Kolkata, India. This study had a broad frame of empowerment and included multiple HIV prevention strategies: community mobilization, rights-based framing, advocacy, and microfinance. The authors found all of the strategies were effective in reducing HIV-risk behavior among study participants and increasing HIV knowledge.

\section{Discussion}

In this review, a common method for studies conducted in both more and less developed countries was measuring the relationship between social capital and HIV risk in populations at higher risk or with a higher prevalence of HIV. The overall evidence provides some support for an underlying association between the two variables.

Four of the studies were longitudinal and allowed for causal inferences (Pronyk et al., 2008a, 2008b; Sherman et al., 2006; Swendeman et al., 2009). The remaining studies either used a cross sectional study design or used a survey instrument with one time point. Of the four longitudinal studies, the Pronyk et al. (2008b) study providing evidence of an inverse relationship between cognitive social capital and HIV prevalence had the strongest statistical power with a sample size of 1,063 . The sample sizes for the other studies ranged from 50 to 220 , and may not have had enough power to identify any association between social capital and HIV risk.

Varying measurements of social capital were used across all 12 studies. The most common applied definitions were social capital as a measure of trust, reciprocity of norms, peer and family support, neighborhood support, access to resources (microfinance projects), and community engagement. Social capital in this review can be categorized as: (a) social support/group participation/community engagement, (b) religiosity, and (c) microfinance programs. In some cases these categories have some overlap between them. 
The relationship between a specific application of social capital and HIV risk was also influenced by interaction with other variables such as gender or religion. For example, although most studies found social capital to be protective against high risk, males who had higher social capital through group membership in sports or social clubs exhibited greater HIV-risk behavior such as alcohol consumption and increased number of sexual partners.

For women, social capital in the form of a microfinance program was as a conduit to greater female empowerment and improved sexual negotiations for condom use and access to care. The Pronyk et al. (2008b) study on associations between (a) cognitive social capital and (b) structural social capital, and (c) HIV risk, HIV incidence, and HIV prevalence found structural social capital to be a protective factor for HIV risk among women; but unexpectedly, there was also higher HIV incidence and prevalence among women with higher levels of structural social capital. Although structural social capital encouraged low-risk HIV behavior, the authors hypothesized that by increasing structural social capital through community engagement, women were expanding their social networks and possibly sexual partners, and therefore, there was a greater likelihood of HIV exposure.

The Pronyk et al. (2008b) study was consistent with other studies concluding that components of social capital, such as peer and within-group norms, could either be protective or increase risk depending on the context and other influential factors. For example, Battacharya (2005) found that immigrants migrating into a region with existing networks of individuals from their country of origin were able to depend on within-group norms to successfully transition into the host country. This type of social capital aided in the process of acculturation, but also may have spawned casual sexual relationships among immigrants, who used these relationships as coping mechanisms for acculturative stress. 


\section{Study Limitations}

The three qualitative studies had smaller sample sizes, which may have affected the statistical power of the studies. Because specified sub-populations were used, results may not be generalizable to other populations. For example, some issues related to transgender women are not applicable to heterosexual men and women. Additionally, varying definitions of social capital, and separate research teams asking different research questions, limited the synthesis of the results. For example, in some studies, bonding or structural social capital increased HIV risk; in other studies, cognitive social capital (or norms of reciprocity and trust at the community level) was protective.

Measures for the studies using secondary data analysis were developed a priori, and therefore may not have captured all evidence supporting an association between social capital and HIV risk. Cross sectional designs provide limited information on directionality of the association between HIV risk and social capital. Finally, there was only one study measuring aggregate social capital, which limited any inference into the application of community level social capital on HIV risk.

Given these limitations, it is difficult to make a definitive statement on the causal relationship between social capital and HIV risk. However, taking the evidence together, this review does provide a justification for researchers to consider incorporating social capital-based interventions in HIV prevention programs.

\section{Limitations of this Review}

It is possible that manuscripts currently in press or not widely available may have been overlooked and not included in this review. Although an exhaustive search was performed, because social capital has many synonyms, it is also possible that an article with an unknown synonym measuring social capital may have also been overlooked. 


\section{Conclusion and Recommendations}

The studies in this review demonstrate a complex association between social capital and HIV risk. Whether social capital increases or decreases HIV risk depends on the definition of social capital that is being used and the population being targeted. Civic engagement and group participation in well-functioning groups was found to decrease HIV risk, but peer-level support potentially increased HIV risk through encouragement of high risk sexual behavior such as increased number of sexual partners or sex under the influence. Microfinance programs for women reduced HIV risk and further helped to increase women's leverage in sexual relationships. Non-membership or membership in a dysfunctional group increased HIV risk among individuals that were already marginalized or at increased risk.

Non-secular group engagement or religiosity was found to be protective. This is supported by evidence from Trinitapoli and Weinreb (2012), who found religiosity in Uganda increased age of sexual debut for adolescent girls, encouraged fidelity, and reduced high-risk sexual behavior, such as drunkenness and high number of partners, and encouraged more careful selection of partners.

Social capital is encompassed in the discipline of social epidemiology and is an extension of traditional socio-demographic factors used in epidemiologic health research (Poundstone, Strathdee \& Celentano, 2004). In intervention research, it can be used independently or as reinforcement of other behavioral and biomedical prevention methods. When using social capital as a risk reduction method, it should be applied within the context of the population it is intended to serve, and with careful consideration of the needs of that population.

The traditional research environment focuses on individual behavior change for HIV prevention, but this review demonstrates some value in also investigating community level assets such as social capital toward change in sexual risk behavior. As evidenced by microfinance empowerment programs for at-risk women, social capital can be fostered through public health 
and social welfare programs for individuals and communities (Pronyk et al., 2008b). Although there is no conclusive direction of the association between social capital and HIV risk behavior, the review is able to prove that a relationship exists. There is a need for more support and funding of research that examines social capital and other community level variables with regard to HIV risk behavior.

The same model can be applied to other high risk populations such as recent immigrants and other vulnerable populations in and outside of the United States. Further research is needed in other geographical areas where this type of research has not been conducted. Eastern Europe has the fastest growing HIV epidemic in the world (UNAIDS, 2012), and Canada has a substantial number of immigrants (Reitz, 2004) who may be at increased risk for HIV transmission, but no studies in these regions examining the association between social capital and HIV risk were identified. 


\section{References}

Agardh, A., Emmelin, M. M., Muriisa, R., \& Ostergren, P. O. (2010). Social capital and sexual behavior among Ugandan university students. Global Health Action, 3. doi: 10.3402/gha.v3i0.5432

Alinsky, S. D. (1972). Rules for radicals; a practical primer for realistic radicals ([1st ed.] ed.). New York: Vintage Books.

Arneil, B. (2006). Diverse communities : The problem with social capital. Cambridge, UK; New York: Cambridge University Press.

Bhattacharya, G. (2005). Social capital and HIV risks among acculturating Asian Indian men in New York City. AIDS Education and Prevention: Official Publication of the International Society for AIDS Education, 17(6), 555-567.

Campbell, C. (2000). Social capital and health: contextualising health promotion within local community networks. In S. Baron, J. Field, \& T. Schuller (Eds.) Social capital: critical perspectives (pp. 182-196). Oxford: Oxford University Press. .

Campbell, C., Williams, B., \& Gilgen, D. (2002). Is social capital a useful conceptual tool for exploring community level influences on HIV infection? An exploratory case study from South Africa. AIDS Care, 14(1), 41-54.

Cené, C. W., Akers, A. Y., Lloyd, S. W., Albritton, T., Powell Hammond, W., \& Corbie-Smith, G. (2011). Understanding social capital and HIV risk in rural African American communities. Journal of General Internal Medicine, 26(7), 737-744.

Centers for Disease Control and Prevention. (2011). Characteristics associated with HIV infection among heterosexuals in urban areas with high AIDS prevalence --- 24 cities, United States, 2006-2007. MMWR. Morbidity and Mortality Weekly Report, 60(31), 1045-1049.

Chandra, A., Billioux, V. G., Copen, C. E., \& Sionean, C. (2012). HIV risk-related behaviors in the United States household population aged 15-44 years: Data from the national survey of family growth, 2002 and 2006-2010. National Health Statistics Reports, 46, 1-19.

Clements-Nolle, K., Marx, R., Guzman, R., \& Katz, M. (2001). HIV prevalence, risk behaviors, health care use, and mental health status of transgender persons: Implications for public health intervention. American Journal of Public Health, 91(6), 915-921.

Coleman, J. S. (1988). Social capital in the creation of human capital. The American Journal of Sociology, 94, S95-S120.

Coleman, J. S. (1990). Foundations of Social Theory. Boston: Harvard University Press.

De Silva, M., McKenzie, K., Harpham, T., \& Huttly, S.R.A. (2005). Social capital and mental illness: A systematic review. Journal of Epidemiology and Community Health (1979), 59(8), 619-627. 
Diener, E., \& Chan, M. Y. (2011). Happy People Live Longer: Subjective Well-Being Contributes to Health and Longevity. Applied Psychology: Health and Well-Being, 3(1), $1-43$.

Edwards, J. W., Fisher, D. G., \& Reynolds, G. L. (2007). Male-to-female transgender and transsexual clients of HIV service programs in Los Angeles County, California. American Journal of Public Health, 97(6), 1030-1033.

Epstein, H. (2007). The invisible cure : Africa, the west, and the fight against AIDS (1st ed. ed.). New York: Farrar, Straus, and Giroux.

Frumence, G., Killewo, J., Kwesigabo, G., Nyström, L., Eriksson, M., \& Emmelin, M. (2010). Social capital and the decline in HIV transmission - A case study in three villages in the Kagera region of Tanzania. SAHARA J: Journal of Social Aspects of HIV/AIDS Research Alliance / SAHARA , Human Sciences Research Council, 7(3), 9-20.

Golub, S. A., Walker, J. J., Longmire-Avital, B., Bimbi, D. S., \& Parsons, J. T. (2010). The role of religiosity, social support, and stress-related growth in protecting against HIV risk among transgender women. Journal of Health Psychology, 15(8), 1135-1144.

Gregson, S., Terceira, N., Mushati, P., Nyamukapa, C., \& Campbell, C. (2004). Community group participation: Can it help young women to avoid HIV? an exploratory study of social capital and school education in rural Zimbabwe. Social Science \& Medicine (1982), 58(11), 2119-2132.

Islam, M. K., Merlo, J., Kawachi, I., Lindstrom, M., \& Gerdtham, U. (2006). Social capital and health: Does egalitarianism matter? A literature review. International Journal for Equity in Health, 5(1), 3.

Kawachi, I., \& Berkman, L. (2000). Social cohesion, social capital and health. Social Epidemiology. New York: Oxford University Press.

Kawachi, I., Kennedy, B., \& Glass, R. (1999). Social capital and self-rated health: A contextual analysis. American Journal of Public Health, 89(8), 1187-1193.

Lin, N. (2001). Social capital: A theory of social structure and action. New York: Cambridge University Press.

Macinko, J., \& Starfield, B. (2001). The utility of social capital in research on health determinants. The Milbank Quarterly, 79, 387-427.

McLean, S. L., Schultz, D. A., \& Steger, M. B. (2002). Social capital: Critical perspectives on community and "bowling alone". New York: New York University Press.

Moher, D., Liberati, A., Tetzlaff, D.G. (2009). Preferred reporting items for Sytematic Reviews and Meta-Analysis: The PRISMA statement. PLoS Med 6(7): e1000097. doi:10.1371/journal.pmed.1000097 
Muntaner, C., Lynch, J., \& Davey Smith, G. (2001). Social capital, disorganized communities, and the third way: Understanding the retreat from structural inequalities in epidemiology and public health. International Journal of Health Services, 31, 213-237.

Norris, P., \& Davis, J. A. (November 25-26, 2003). A transatlantic divide? social capital in the United States and Europe. European Social Survey Launch Conference, Brussels.

Patient Protection and Affordable Care Act, Pub. L. No. 111-148, §2702, 124 Stat. 119, 318-319 (2010).

Paxton, P. (1999). Is social capital declining in the United States? A multiple indicator assessment. American Journal of Sociology, 105(1), 88.

Portes, A., \& Sensenbrenner, J. (1993). Embeddedness and immigration: Notes on the social determinants of economic action. The American Journal of Sociology, 98(6), 1320-1350.

Poundstone, K. E., Strathdee, S. A., \& Celentano, D. D. (2004). The social epidemiology of human immunodeficiency virus/acquired immunodeficiency syndrome. Epidemiologic Reviews, 26(1), 22-35.

Pronyk, P. M., Kim, J. C., Abramsky, T., Phetla, G., Hargreaves, J. R., Morison, L. A., \& Porter, J. D. (2008a). A combined microfinance and training intervention can reduce HIV risk behaviour in young female participants. AIDS (London, England), 22(13), 1659-1665. doi: 10.1097/QAD.0b013e328307a040

Pronyk, P. M., Harpham, T., Busza, J., Phetla, G., Morison, L. A., Hargreaves, J. R.,Porter, J. D. (2008b). Can social capital be intentionally generated? A randomized trial from rural South Africa. Social Science \& Medicine, 67(10), 1559-1570.

Putnam, R.D. (1995). Tuning in, Tuning out: The strange disappearance of social capital in America. Political Science and Politics, 28(4), 664-683.

Putnam, R. D. (2000). Bowling alone: The collapse and revival of American community. New York: Simon \& Schuster.

Rankin, K. N. (2002). Social Capital, Microfinance, and the Politics of Development. Feminist Economics, 8(1), 1-24.

Reitz, J. G. (2004). Canada: Immigration and nation-building in the transition to a knowledge economy. In W. A. Cornelius (Ed.), Controlling immigration: A global perspective (pp. 97). Stanford, California: Stanford University Press.

Rosenberg, M. S., Seavey, B. K., Jules, R., \& Kershaw, T. S. (2011). The role of a microfinance program on HIV-risk behavior among Haitian women. AIDS and Behavior, 15(5), 911918.

Sherman, S. G., German, D., Cheng, Y., Marks, M., \& Bailey-Kloche, M. (2006). The evaluation of the JEWEL project: An innovative economic enhancement and HIV prevention 
intervention study targeting drug using women involved in prostitution. AIDS Care, 18(1), 1-11.

Shortt, S.E.D. (2004). Making sense of social capital, health and policy. Health Policy (Amsterdam, Netherlands), 70(1), 11.

Stratford, D., Mizuno, Y., Williams, K., Courtenay-Quirk, C., \& O'leary, A. (2008). Addressing poverty as risk for disease: Recommendations from CDC's consultation on microenterprise as HIV prevention. Public Health Reports (Washington, D.C.: 1974), 123(1), 9-20.

Swendeman, D., Basu, I., Das, S., Jana, S., \& Rotheram-Borus, M. J. (2009). Empowering sex workers in India to reduce vulnerability to HIV and sexually transmitted diseases. Social Science \& Medicine (1982), 69(8), 1157-1166.

Szreter, S., \& Woolcock, M. (2004). Health by association? social capital, social theory, and the political economy of public health. International Journal of Epidemiology, 33, 650-667.

The World Bank (1999). What is Social Capital? Retrieved from http://www.worldbank.org/poverty/scapital/whatsc.htm

Trepka, M. J., \& Kim, S. (2010). Prevalence of human immunodeficiency virus testing and highrisk human immunodeficiency virus behavior among 18 to 22 year-old students and nonstudents: Results of the national survey of family growth. Sexually Transmitted Diseases, 37(10), 653-659.

Trinitapoli, J. A., \& Weinreb, A. (2012). Religion and AIDS in Africa. New York: Oxford University Press.

UNAIDS. (2012). Eastern Europe's growing HIV epidemic under scrutiny. Retrieved from http://www.unaids.org/en/resources/presscentre/featurestories/2012/december/20121205 warsaw/

United States Congress House Committee on Education and Labor Subcommittee on War on Poverty Program. (1973). Economic opportunity act of 1964. hearings before the united states house committee on education and labor, subcommittee on war on poverty program, eighty-eighth congress, second session, on mar. 17-20, Apr. 7-10, 13, 14, 1964. Washington: U.S. G.P.O.

Whitehead, M., \& Diderischsen, F. (2001). Social capital and health: tip-toeing through the minefield of evidence. Lancet, 358, 165-6.

Wohlfeiler, D. (2002). From community to clients: The professionalization of HIV prevention among gay men and its implications for intervention selection. Sexually Transmitted Infections, 78(supplement 1), i176-i182. 


\title{
Manuscript 2 \\ Social capital and HIV sexual risk changes among recent Latino immigrants in South Florida
}

\begin{abstract}
A longitudinal study was conducted among recent Latino immigrants (RLIs) in South Florida ( $\mathrm{n}=527)$. The purpose of the study was to assess changes in social capital and HIV risk behavior pre immigration to 2 years post immigration, and to determine if there was a relationship between the two variables. A social assets inventory was used to measure social capital through five constructs: 'family', ‘friend and others', 'groups and associations', 'agencies' and 'businesses.' HIV risk behavior was measured through frequency of condom use in the last 90 days and number of sexual partners. There was an $8 \%$ decrease in total social capital $(\mathrm{p}<.05)$. Reporting of 'Never use' of condoms in the past 90 days increased in all subcategories $(p<.05)$. Single men had a decrease in number of sexual partners $(\mathrm{p}<.05)$. Lower social capital measured on the dimension of 'friend and others' was marginally associated with fewer sexual partners. These results provide further evidence that RLIs experience changes in social capital and HIV risk behavior that should be considered in the development of primary prevention programs among RLIs.
\end{abstract}

KEY WORDS: HIV RISK BEHAVIOR, SOCIAL CAPITAL, RECENT IMMIGRANTS 


\section{Background}

Social capital has been measured in health research by assessing community-level variables that may influence health behavior and health outcomes. A common definition of social capital is Putnam's definition (1993) which discusses "norms of reciprocity and trust" between an individual and his/her community (Szreter \& Woolcock, 2004). Community engagement, the social capital measure of this study, measures how much an individual interacts with his or her community or how much an individual depends or relies on community-level social support (Office of National Statistics, United Kingdom, 2001; Portes \& Sensenbrenner, 1993).

There is some evidence supporting an inverse relationship between social capital and HIV risk behavior, with higher levels of social capital being associated with lower HIV risk behavior (Cyrus et al, 2013; Cené et al., 2011; Holtgrave \& Crosby, 2003; Salaam, Sternberg, Zaidi, \& Aral, 2007). Another perspective is that social capital functioning within peer/group norms, can increase HIV risk behavior. In a study of recent Indian immigrants to New York, study participants found casual sexual relationships with multiple partners among peers from their country of origin, to be a form of stress relief (Battacharya, 2005). While there was an increase in social capital, in this instance social capital increased HIV risk behavior.

In terms of immigration, acculturation and HIV risk behavior, Nunn et al (1995) found migration to increase the possibility of risky sexual behavior (life time sexual partners and condom use) among young Ugandans; and higher rates of unprotected sex and multiple partners occurred for immigrant populations in Holland (Gras, van Benthem, Coutinho, \& van den Hoek, 2001). Among Latinos in the U.S., higher acculturation has been associated with higher rates of smoking and alcohol consumption (Abraido-Lanza, Chao, \& Florez, 2005), multiple sexual partners, and decreased condom use (Kasirye et al., 2005; Sabogal, Faigeles, \& Catania, 1993) .

There is limited research examining the association between social capital and HIV risk behavior (Cyrus et al, 2013), and even less research examining this association among recent La- 
tino immigrants. The purpose of the study was to examine changes in HIV risk behavior, social capital and its covariates, and to determine if changes in social capital and HIV risk behavior are associated.

\section{Methods}

This was a prospective longitudinal study observing two time points (baseline and two year follow up) of the original study sample. The aim of the original study was to investigate the influence of pre immigration factors on the health behavior trajectories of recent Latinos in Miami-Dade County. At baseline there were 527 participants, and at year 2 follow up, data were collected for 476 study participants. Reasons for loss to follow up included deportation or returning to the country of origin, withdrawing consent, and other reasons (incarceration, military enlistment and unknown reasons for loss to follow up).

Research indicates that undocumented Latino immigrants are often a hidden population due to the sensitivity of their legal status in the U.S. In the study, $30 \%$ of the participants were undocumented immigrants. A respondent-driven sampling approach primarily was used to recruit participants because this technique has been shown to be an effective strategy in recruiting participants from hidden or difficult-to-reach populations (Salganik \& Heckathorn, 2003).

According to the study's inclusion criteria, participants were 18-34 year old Latinos who had immigrated to the United States within one year of study enrollment from a Latin American country. Informed consent was obtained from all study participants prior to enrollment. Both the parent and present study were reviewed and approved by Florida International University (FIU) Institutional Review Board (IRB).

\section{Social Capital}

The Social Assets inventory measured access to 44 individual social capital items (see Appendix 1). The instrument categorized the individual items into five subscales: "family", "friends and other people", "groups and associations", "agencies", and "businesses" (Lengyel, 
Thompson, \& Niesl, 1997). The questionnaire determines the amount of social capital resources available to an individual in each of the five subscales. A total social capital score was calculated as a sum of the five sub-category scores.

\section{HIV Risk behavior}

The National Institute on Drug Abuse (NIDA) Risk Behavior Assessment was used to capture information on sexual risk (NIDA, 1993). HIV risk behavior was measured by two variables (1) condom use during penile-vaginal intercourse within the last 90 days and (2) number of sexual partners in the last 90 days.

By definition, a person who is married should be practicing monogamy, which can affect a person's risk of HIV transmission. Therefore an HIV sexual risk score that took marital status into account was calculated by combining the condom use score with the number of partners score. This HIV risk classification system used is outlined in Appendix 2.

\section{Covariates}

Demographic information was collected and included marital status, gender and documentation status. These were included as covariates in analyses. Marital status and gender were included in assessing HIV risk behavior. Documentation status was an additional covariate for social capital.

Analysis

In analysis to determine changes from pre to post immigration, cases were included if they were matched pairs from baseline and follow up. Consequently the sample size for the first variable (condom use) decreased to 326, and the sample size for second variable (number of sexual partners) decreased to 436. Data were assessed for non-normality and outliers in SPSS 18.0. To ensure relatively normally distributed variables, a cutoff of absolute values of 3.0 and 8.0 for skewness and kurtosis were used (Kline, 2005). Non-normal data were transformed using a 
square root transformation. Additionally, outliers were assessed by using leverage values and standardized DFbeta values. Any leverage values more than four times the mean leverage score, or any standardized DFbeta more than one absolute value from the mean score were considered outliers. Based on these assessments, no outliers were detected.

To assess the appropriateness of the social capital scale in this population, and to determine if the subcategories sufficiently represented the latent construct of social capital, a confirmatory factor analysis on the social capital scale for both baseline and follow up was undertaken. In addition to other fit indices for the CFA, a chi-square value was ascertained. A chi square value close to zero with a p-value greater than 0.05 indicate that there is little difference between the expected and observed covariance matrices, and this is at least one indicator of good fit (Kenny, 2013). With the exception of a significant chi square, which is typical for sample sizes close to or over 500, overall the measurement model pointed toward good general fit at baseline and follow up. At baseline the $\chi^{2}(\mathrm{DF}=5)$ was $17.5, \mathrm{p}=.0036$. The root mean square of approximation (RMSEA) was .069. The comparative fit index (CFI) was .98, and the Tucker-Lewis index (TLI) was .95. The factor loadings for the subcategories of social capital were family (.5), friend and other (.76), group (.6), agency (.75) and businesses (.56). At follow up the $\chi^{2}(\mathrm{DF}=5)$ was 17.93, $\mathrm{p}=.003$. The root mean square of approximation (RMSEA) was .074. The CFI was .95 , and the TLI was .91. The factor loadings for the subcategories of social capital were family (.46), friend and other (.73), group (.73), agency (.71) and businesses (.56). Based on these fit statistics at baseline and follow up, the individual social capital score loaded appropriately for the latent social capital score.

Differences between baseline and follow up were compared using a paired t-test for continuous variables and a Pearson Chi Square and McNemar test for binary and categorical variables in SPSS 18.0. Multivariate analysis tested for the effects of total social capital, and the subcategories of social capital on the HIV risk behavior variables. Associations between unprotected 
penile-vaginal sex and social capital variables were measured using a generalized linear model (PROC GENMOD SAS 9.3). Associations for the number of sexual partners within the past 90 days with the social capital variable were analyzed using the mixed linear model (PROC MIXED SAS 9.3).

At follow up, $17 \%$ of data were missing on the HIV outcome variables, number of partners and mean frequency of condom use. Because of the percentage of missing HIV risk behavior variables, a sensitivity analysis was performed on the HIV risk behavior variables to test for consistency. With and without the sensitivity analysis, the McNemar's paired t-test consistently illustrated a decline in condom use and a decline in the number of partners from pre-immigration to post immigration.

\section{Results}

Sample

Comparisons of baseline (pre immigration) and follow up (post immigration) demographic characteristics are provided in Table 1. Cubans, Colombians and Hondurans together represented the majority of the sample at $42.1 \%, 17.6 \%$, and $12.5 \%$ respectively. The sample had a statistically significant increase in percentage of people employed from $46.9 \%$ to $48.7 \%$ and median annual income from $\$ 1,200$ to $\$ 19,000$. There was a greater loss to follow up among the less educated and older participants. There was no significant change in documentation status.

There were more married participants at follow up (23.8\%) than at baseline $(21.9 \%)$. Of the participants who were lost to follow up, $15.3 \%$ and $24 \%$ reported being married and in a common law union at baseline, and $47.5 \%$ reported being single at baseline i.e. participants who reported being single at baseline had greater loss to follow up than those who reported being married or in a common law union.

[TABLE 1 HERE] 


\section{Changes in Social Capital}

For men and women combined, the total social capital score had a $38 \%$ decrease from pre to post immigration, with the greatest decrease among agency, group and businesses (Table 2). When stratified by gender, males experienced a greater decline in total social capital $(40.3 \%)$ than females (35.6\%) (Table 3). The amount of decrease for males and females was similar for 'family' and 'friends and other' social capital. For 'agency' and 'business' social capital, men had a greater decline. Women had a greater decrease for 'group' social capital.

[TABLES 2 AND 3 HERE]

\section{HIV Risk Behavior}

\section{Condom Use}

Among males, from pre to post immigration, there was an $86.3 \%$ increase in reporting 'never use' for condom use in the past 90 days versus a $31.1 \%$ increase among females (Table 4). However, there was also a decrease among both males and females in the categories of 'half the time', 'most of the time' and 'always' for condom use.

Because marital status had the potential to change from baseline to immigration, frequency of vaginal condom use was stratified by marital status at baseline. From baseline to follow-up, the percentage of both married and unmarried individuals reporting 'never use' of condoms in past 90 days increased; however, married individuals had a greater increase (127.8\%) than unmarried individuals (56.5\%) to report 'never use' of condom in the past 90 days. The increase in 'never use' in the past 90 days among unmarried individuals was considered high risk (Table 7). Findings for marital status at follow up are not presented in Table 7 because they were similar to those when stratifying by marital status at baseline.

\section{[TABLES 4 HERE]}

Number of sexual partners in the past 90 Days 
There was a $40.1 \%$ decrease in sexual partners for men from baseline to follow up, versus a non-significant $4 \%$ decrease for women (Table 4). When stratified by marital status at baseline, there was no significant change for married individuals; unmarried individuals had a significant decrease in mean number of partners from 1.55 to $1.04(\mathrm{p}<.001)$ (Table 5). The findings were similar when stratifying by marital status at follow up and thus are not presented on the table.

\section{[TABLE 5 HERE]}

\section{HIV Risk behavior Classification}

There was a statistically significant change in the distribution of HIV risk behavior between baseline and follow up for women but not men $(\mathrm{P}<0.05)$ (Table 6). Specifically there was an increase in the low-moderate risk category, and a decrease or no change in all other risk categories including the lowest risk and highest risk categories. When stratified, there was also a statistically significant change in the distribution of HIV risk behavior between baseline and follow up for married but not unmarried people $(\mathrm{p}<0.05$ (Table 7). Again there was an increase in the low moderate risk category and a decrease or no change in all other risk categories.

[TABLES 6 AND 7 HERE]

\section{Multivariate analysis: HIV risk behavior on Social Capital}

After adjusting for time, gender, and marital status at baseline, there was a marginal negative association between 'friend and other' social capital and the number of partners $(\beta=.06$, $\mathrm{p}=.06)$; 'group' social capital and the number of partners $(\beta=.03, \mathrm{p}=.1)$. There was no significant association between the frequency of condom use and any of the social capital variables.

\section{Discussion}

In this prospective study of influences on protective behavior among recent Latino immigrants, there was a decrease in social capital which is consistent with existing literature 
(Deren, Shedlin, Decena, \& Mino, 2005). All immigrants regardless of documentation status, experienced a decline in total social capital, and the greatest decline were in the 'family', 'friends and others' and 'group' social capital sub categories of the instrument. Other authors have attributed such a decline to new immigrants moving to a new environment, having feelings of isolation and estrangement because they are separated from their families/friends in their home countries (Battacharya, 2005; Deren, Shedlin, Decena, \& Mino, 2005).

A decline condom use over time signifies a likely increase in HIV risk behavior; however the decrease in 'number of partners' is contradictory and suggests lower risk. If these results are interpreted in the context of the declining social capital, it is possible that as social capital decreased, social networks also decreased, thereby curbing an individual's likelihood of meeting new sexual partners. The decline in the number of sexual partners can be partially explained by more married people at follow up. If sexual encounters were more likely to be within monogamous relationships (among spouses or familiar individuals/friends), then condom use would have decreased (East, 2007), and the decrease in condom use may not represent a real increased risk for HIV.

A final possible explanation for the difference in results between the HIV risk indicators decreased number of partners and low condom use is limited disposable income. Although the population had an increase in income levels, the median income was still well below the median income for Miami-Dade County $(\$ 43,947)$, (U.S. Census Bureau: State and County QuickFacts, June 6 2013), and participants may not have had enough disposable income for social activities that foster development of new sexual relationships and, if there were new partners purchasing condoms for sex with those new partners. As length of residence in the U.S. increases, there may be erosion of original protective cultural values and additional income can trigger higher risk sexual behavior (Deren, Shedlin, Decena, \& Mino, 2005). 
The study found no association between the likelihood of 'never use' condoms within the past 90 days and the change in social capital. This study may have been unable to demonstrate an association between social capital and HIV risk behavior because the change in condom use was not large enough. At baseline or pre-immigration the frequency of condom use was between half of the time and less than half the time among all study participants. The frequency decreased to under less than half the time at follow up. Additionally, two years may not have been enough time for an association to be established between the decline in social capital and the decline in condom use. If there is any association between social capital and condom use, it is likely to be weak.

There was a marginal direct association between the decline in 'friend and other' social capital and the decline in the number of sexual partners. The 'friend and other' category included friends, neighbors, co-workers, landlord/apartment managers, teachers, counselors, doctors, other health providers, other mental health providers, social service providers and clergy/rabbi. For this association, increased access to health care services (doctors, health providers, mental health providers and social service providers) and elements of religiosity (clergy/rabbi) may have been protective, decreasing high risk sexual behavior, namely multiple sexual partners (Jemmott, Jemmott III, \& Villarruel, 2002; McCree, Wingood, DiClemente, Davies, \& Harrington, 2003; Oliva, Rienks, \& McDermid, 1999; Santelli, Lowry, Brener, \& Robin, 2000).

Our results are consistent with other study findings. In a qualitative study (Shedlin, Decena, \& Oliver-Velez, 2005), male Latino immigrants expressed feelings of isolation and difficulty finding appropriate Latina female sexual partners. Additionally, the male participants also reported less condom use with female commercial sex workers or non-commercial sex workers. This is another example of reduction in the number of sexual partners among immigrants, but also low condom use. 
Female participants in the Shedlin, Decena \& Oliver-Velez study (2005) expressed protecting themselves against sexual diseases and 'keeping their men from having sex with other women' as one of the motivating factors for immigration. The findings in Shedlin, Decena \& Oliver-Velez (2005) qualitative study may partially explain why a greater change in sexual risk behavior was seen among men in this study and why there is greater monogamy postimmigration.

\section{Limitations}

The primary source of bias in this study is related to recall bias as all pre immigration behaviors were asked retrospectively. Another possible source of bias may be the difference between participants who were retained and those who were lost to follow up. The lost to follow up are likely not similar to those retained.

According to 2010 data from the U.S. Census Bureau, the breakdown of Latinos in Miami-Dade County by specific origin are 34.3\% Cuban, 4.6\% Colombian, 4.2\% Nicaraguan, 2.2\% Honduran and the rest from other countries (U.S. Census Bureau, 2011). In the study sample Cubans, Colombians and Hondurans together represented the majority of the sample at $42.1 \%$, $17.6 \%$, and $12.5 \%$ respectively. These sub-groups are over represented in the study sample possibly due to the method of recruitment. Additionally, although respondent driven sampling was a practical method to sample with this hard-to-reach sample, the sample is likely not as representative of the target population as a random sample.

The social capital instrument was developed a priori. If a different instrument had been used, the findings could have been different. Social capital is typically applicable at a group or community level. However for this study social capital is measured at an individual level, and then applied to the group of focus - recent Latino immigrants. One should be cautious about inferences using this method, as aggregate social capital at a community level may not be accurately expressed as a sum of individual level social capital (Office of National Statistics, 
United Kingdom, 2001). However, there are a number of quantitative and qualitative studies that have used social capital and social capital-related variables at an individual level which support the use of this variable at an individual level in this study (Battacharya, 2005; Cené et al., 2011; P. M. Pronyk et al., 2008; P. Pronyk et al., 2008; Reynoso-Vallejo, 2011; Swendeman, Basu, Das, Jana, \& Rotheram-Borus, 2009)

\section{Conclusion}

The study found a decline in social capital for new Latino immigrants in South Florida. The change in sexual risk behavior was more complex: post immigration participants reported less condom use, but also fewer sexual partners. When HIV risk was assessed, there was a decrease in lowest risk sexual behavior (one partner and 'always' condom use), but also a decrease in highest risk sexual behavior (multiple partners with 'never' condom use). Lowest risk sexual behavior may have decreased because of less condom use, including among those who reported only one partner. Highest risk sexual behavior may have decreased because the number of partners decreased or there was more monogamy because of a greater number of married/common law participants at follow up.

This study examined immigrants who were in the U.S. for three or fewer years. If results from other studies postulate that greater acculturation to the U.S. is linked to high risk sexual behavior (Battacharya, 2005; Shedline, 2005), findings from this study expands on that theory and suggests that the initial years after immigration represent a potentially important moment for education and outreach to prevent higher risk sexual behavior from increasing. To understand the full spectrum of the change of risk behavior from pre to post immigration, future research with longer follow up time and refined measurements for high risk sexual behavior should explore the evolution of HIV risk among this group as they progress from recent to more acculturated immigrants. Additionally, as the process of assimilation continues, social capital will also change and may 
have a greater influence on HIV risk among immigrants. There are important health implications for immigrants arriving into Miami where HIV incidence is high, and Latinos are at increased risk for HIV transmission (Miami-Dade County Department of Health, HIV/AIDS Surveillance, 2011), but these implications can also extend to the larger US population as these individuals continue to integrate into society and communities with large immigrant populations that may have high HIV infection rates. 


\section{References}

Abraido-Lanza, A. F., Chao, M. T., \& Florez, K. R. (2005). Do healthy behaviors decline with greater acculturation? Implications for the Latino mortality paradox. Social Science \& Medicine (1982), 61(6), 1243-1255. doi:10.1016/j.socscimed.2005.01.016

Battacharya, G. (2005). Social capital and HIV risk among acculturation Asian Indian men in New York City. AIDS Education and Prevention, 51(6), 1173.

Cené, C.,W.C.W., Akers, A. Y. A. Y., Lloyd, S. W. S. W., Albritton, T. T., Powell Hammond, W.,W., \& Corbie-Smith, G. (2011). Understanding social capital and HIV risk in rural African American communities. Journal of General Internal Medicine, 26(7), 737-744.

Cyrus, E., Trepka, M.J., De La Rosa, M., Gollub, E., Fennie, K., Albatineh. (2013). Does social capital matter? A systematic review of social capital and HIV risk. Unpublished manuscript.

Deren, S., Shedlin, M., Decena, C. U., \& Mino, M. (2005). Research challenges to the study of HIV/AIDS among migrant and immigrant Hispanic populations in the United States. Journal of Urban Health: Bulletin of the New York Academy of Medicine, 82(2 Suppl 3), iii1325. doi:10.1093/jurban/jti060

East, L. (2007). Use of the male condom by heterosexual adolescents and young people: Literature review. Journal of Advanced Nursing, 59(2), 103-110.

Gras, M. J., van Benthem, B. H., Coutinho, R. A., \& van den Hoek, A. (2001). Determinants of high-risk sexual behavior among immigrant groups in Amsterdam: Implications for interventions. Journal of Acquired Immune Deficiency Syndromes (1999), 28(2), 166-172.

Holtgrave, D. R., \& Crosby, R. A. (2003). Social capital poverty, and income inequality as predictors of gonorrhoea, syphilis, chlamydia and AIDS in the United States. Sexually Transmitted Infections, 79, 62-64.

Jemmott, L. S., Jemmott III, J. B., \& Villarruel, A. M. (2002). Predicting intentions and condom use among Latino college students. Journal of the Association of Nurses in AIDS Care, 13(2), 59-69.

Kasirye, O. C., Walsh, J. A., Romano, P. S., Beckett, L. A., Garcia, J. A., Evine-Kreis, B.,Schenker, M. B. (2005). Acculturation and its association with health-risk behaviors in a rural Latino population. Ethnicity and Disease, 15, 733-739.

Kenny, D. (2013). Measuring Model Fit. Retrieved November 22, 2013 from http://davidakenny.net/cm/fit.htm.

Kline, R. B. (2005). Principles and practice of structural equation modeling (2nd ed.). New York: Guilford Press.

Lengyel, T. E., Thompson, C., \& Niesl, P. J. (1997). Strength in adversity: The resourcefulness of American families in need. Milwaukee, WI: Family Service America, Incorporated, Families International, Incorporated, 1997. 
McCree, D. H., Wingood, G. M., DiClemente, R., Davies, S., \& Harrington, K. F. (2003). Religiosity and risky sexual behavior in African-American adolescent females. Journal of Adolescent Health, 33(1), 2-8.

Miami-Dade County Department of Health, HIV/AIDS Surveillance. (2011). Number of AIDS and HIV reported cases in 2009, 2010, and 2011. Retrieved May 21, 2013, from http://www.dadehealth.org/downloads/Reported\%20AIDS\%20\%20HIV\%20cases\%2020092011.pdf

Muthén, L. K., \& Muthén, B. O. (2007). Mplus user's guide (6th ed.). Los Angeles, CA: Muthén \& Muthén.

National Institute on Drug Abuse (NIDA) (Ed.). (1993). Risk behavior assessment (3rd ed.). Rockville, MD: National Institute on Drug Abuse.

Nunn, A. J., Wagner, H. U., Kamali, A., Kengeya-Kayondo, J. F., \& Mulder, D. W. (1995). Migration and HIV-1 seroprevalence in a rural Ugandan population. AIDS, 9(5), 503-506.

Office of National Statistics, United Kingdom. (2001). Social capital: A review of literature.

Oliva, G., Rienks, J., \& McDermid, M. (1999). What high-risk women are telling us about access to primary and reproductive health care and HIV prevention services. AIDS Education and Prevention: Official Publication of the International Society for AIDS Education, 11(6), 513-524.

Portes, A., \& Sensenbrenner, J. (1993). Embeddedness and immigration: Notes on the social determinants of economic action. The American Journal of Sociology, 98(6), 1320-1350.

Pronyk, P. M., Kim, J. C., Abramsky, T., Phetla, G., Hargreaves, J. R., Morison, L. A., Porter, J. D. (2008). A combined microfinance and training intervention can reduce HIV risk behaviour in young female participants. AIDS (London, England), 22(13), 1659-1665. doi:10.1097/QAD.0b013e328307a040

Pronyk, P., Harpham, T., Morison, L. A., Hargreaves, J. R., Kim, J. C., Phetla, G., Porter, J. D. (2008). Is social capital associated with HIV risk in rural South Africa? Social Science \& Medicine (1982), 66(9), 1999-2010.

Putnam, R. D. (1993). The prosperous community: Social capital and economic growth. American Prospect, 35-42.

Reynoso-Vallejo, H. (2011). Social capital influence in illicit drug use among racial/ethnic groups in the United States. Journal of Ethnicity in Substance Abuse, 10(2), 91-111. doi:10.1080/15332640.2011.572532

Sabogal, F., Faigeles, B., \& Catania, J. A. (1993). Data from the national AIDS behavioral surveys. II. Multiple sexual partners among Hispanics in high-risk cities. Family Planning Perspectives, 25(6), 257-262. 
Salaam, S., Sternberg, M., Zaidi, A., \& Aral, S. O. (2007). Social capital and rates of gonorrhea and syphilis in the United States: Spatial regression and analysis of state-level associations. Social Science \& Medicine, 64, 2324-2341.

Salganik, M. J., \& Heckathorn, D. D. (2003). Sampling and estimation in hidden populations using respondent-driven sampling. Sociological Methodology, 34(1), 193-239.

Santelli, J. S., Lowry, R., Brener, N. D., \& Robin, L. (2000). The association of sexual behaviors with socioeconomic status, family structure, and race/ethnicity among US adolescents. American Journal of Public Health, 90(10), 1582-1588.

Shedlin, M. G., Decena, C. U., \& Oliver-Velez, D. (2005). Initial acculturation and HIV risk among new Hispanic immigrants. Journal of the National Medical Association, 97(7 Suppl), $32 \mathrm{~S}-37 \mathrm{~S}$.

Swendeman, D., Basu, I., Das, S., Jana, S., \& Rotheram-Borus, M. J. (2009). Empowering sex workers in India to reduce vulnerability to HIV and sexually transmitted diseases. Social Science \& Medicine (1982), 69(8), 1157-1166.

Szreter, S., \& Woolcock, M. (2004). Health by association? Social capital, social theory, and the political economy of public health. International Journal of Epidemiology, 33, 650-667.

U.S. Census Bureau. (2011). Decennial census 2010. Department of planning and zoning.

U.S. Census Bureau: State and County QuickFacts. (June 6 2013). Miami-Dade County, Florida. Retrieved June 6, 2013, from http://quickfacts.census.gov/qfd/states/12/12086.html 


\section{TABLES}

TABLE 1: DEMOGRAPHIC CHARACTERISTICS PRE-IMMIGRATION TO TWO YEARS

FOLLOW UP $(\mathrm{N}=476 *)$

\begin{tabular}{|c|c|c|c|}
\hline & Baseline $(n=476)$ & $\begin{array}{c}\text { Follow Up } \\
(\mathrm{n}=476)\end{array}$ & $\mathrm{p}$ \\
\hline Gender & & & $>.05$ \\
\hline Male & $54.1 \%$ & $54.1 \%$ & \\
\hline Female & $45.9 \%$ & $45.9 \%$ & \\
\hline Employed & $46.9 \%$ & $48.7 \%$ & $<.05$ \\
\hline Documentation status & & & $>.05$ \\
\hline Undocumented & $28.5 \%$ & $27.9 \%$ & \\
\hline Documented & $71.5 \%$ & $72.1 \%$ & \\
\hline Mean age (18-34) & 26.8 & 27.9 & $<.05$ \\
\hline $\begin{array}{l}\text { Annual median household income } \\
(\$ 0-\$ 140,000)\end{array}$ & $\$ 1,233$ & $\$ 19,000$ & $<.05$ \\
\hline Marital Status & & & $<.05$ \\
\hline Single & $54.1 \%$ & $49.7 \%$ & \\
\hline Married & $21.8 \%$ & $23.8 \%$ & \\
\hline Common law & $12 \%$ & $13.4 \%$ & \\
\hline Divorced & $4.4 \%$ & $3.1 \%$ & \\
\hline Separated & $8.2 \%$ & $9.8 \%$ & \\
\hline Widowed & $.2 \%$ & $.2 \%$ & \\
\hline Education & & & $<.05$ \\
\hline Less than high school & $18.1 \%$ & $13.1 \%$ & \\
\hline High school & $28.5 \%$ & $36.3 \%$ & \\
\hline Some college & $33.1 \%$ & $34.2 \%$ & \\
\hline Bachelor's & $17.1 \%$ & $14.3 \%$ & \\
\hline Graduate & $3.2 \%$ & $2.1 \%$ & \\
\hline
\end{tabular}

*Note: Paired analysis for matching date from baseline $(n=527)$ and follow up $(n=476)$. There were 51 participants lost to follow up. 
TABLE 2: OVERALL CHANGES IN SOCIAL CAPITAL SCORES FROM PREIMMIGRATION TO TWO YEARS FOLLOW UP (N=476)

\begin{tabular}{lccccc}
\hline & $\begin{array}{c}\text { Baseline } \\
\text { (mean) }\end{array}$ & $\begin{array}{c}\text { Follow Up } \\
\text { (mean) }\end{array}$ & \% Change & p & \multicolumn{2}{c}{ n } \\
\hline Friends & 3.7 & 3.4 & $\downarrow 8.0$ & .002 & 474 \\
Family & 4.8 & 3.7 & $\downarrow 22.9$ & $<.001$ & 474 \\
Group & 3.0 & 1.3 & $\downarrow 56.6$ & $<.001$ & 468 \\
Agency & 4.0 & 1.1 & $\downarrow 72.2$ & $<.001$ & 468 \\
Businesses & 2.7 & 1.7 & $\downarrow 36.3$ & $<.001$ & 470 \\
Total & 18.4 & 11.4 & $\downarrow 38.0$ & $<.001$ & 474 \\
\hline
\end{tabular}


TABLE 3: CHANGES IN SOCIAL CAPITAL SCORES FROM PRE-IMMIGRATION TO TWO YEARS FOLLOW UP BY

\section{GENDER}

\begin{tabular}{|c|c|c|c|c|c|c|c|c|c|c|}
\hline & \multicolumn{5}{|c|}{ Female } & \multicolumn{5}{|c|}{ Male } \\
\hline & Baseline & Follow Up & $\%$ change & $\mathbf{p}$ & n & Baseline & Follow Up & $\%$ change & $\mathbf{p}$ & n \\
\hline Family & 3.9 & 3.6 & $\downarrow 7.7 \%$ & .028 & 218 & 3.6 & 3.4 & $\downarrow 7.5 \%$ & .026 & 256 \\
\hline Friends & 5.0 & 4.0 & $\downarrow 20.0 \%$ & $<.001$ & 218 & 4.6 & 3.5 & $\downarrow 23.9 \%$ & $<.001$ & 256 \\
\hline Group & 3.0 & 1.3 & $\downarrow 57.2 \%$ & $<.001$ & 216 & 3.0 & 1.4 & $\downarrow 54.8 \%$ & $<.001$ & 252 \\
\hline Agency & 4.2 & 1.3 & $\downarrow 69.0 \%$ & $<.001$ & 217 & 3.8 & .9 & $\downarrow 76.3 \%$ & $<.001$ & 251 \\
\hline $\begin{array}{l}\text { Busi- } \\
\text { ness }\end{array}$ & 2.7 & 1.9 & $\downarrow 29.6 \%$ & $<.001$ & 217 & 2.7 & 1.6 & $\downarrow 40.7 \%$ & $<.001$ & 253 \\
\hline Total & 18.9 & 12.2 & $\downarrow 35.6 \%$ & $<.001$ & 218 & 17.9 & 10.7 & $\downarrow 40.3 \%$ & $<.001$ & 256 \\
\hline
\end{tabular}


TABLE 4: CHANGE IN FREQUENCY OF PENILE-VAGINAL CONDOM USE AND NUMBER OF PARTNERS IN THE PAST 90 DAYS FROM BASELINE TO FOLLOW UP, BY GENDER

\begin{tabular}{|c|c|c|c|c|c|c|}
\hline & \multicolumn{3}{|c|}{ Male $(n=131)$} & \multicolumn{3}{|c|}{ Female $(n=195)$} \\
\hline & Baseline & Follow Up & \% change & Baseline & Follow up & $\%$ change \\
\hline \multicolumn{7}{|l|}{ Overall condom use } \\
\hline Never use & $37.4 \%$ & $69.7 \%$ & $\uparrow 86.3 * *$ & $53.0 \%$ & $69.5 \%$ & $\uparrow 31.1 * *$ \\
\hline $\begin{array}{l}\text { Less than half } \\
\text { the time }\end{array}$ & $10.8 \%$ & $3.6 \%$ & $\downarrow 66.6^{* *}$ & $10.7 \%$ & $3.8 \%$ & $\downarrow 64.5^{* *}$ \\
\hline Half the time & $8.2 \%$ & $3.6 \%$ & $\downarrow 56.1 * *$ & $8.4 \%$ & $3.1 \%$ & $\downarrow 63.1 * *$ \\
\hline Most of the time & $10.3 \%$ & $4.1 \%$ & $\downarrow 60.2 * *$ & $7.6 \%$ & $4.6 \%$ & $\downarrow 39.4 * *$ \\
\hline \multirow[t]{2}{*}{ Always } & $33.3 \%$ & $19.0 \%$ & $\downarrow 43.0 * *$ & $32.8 \%$ & $19.1 \%$ & $\downarrow 41.8 * *$ \\
\hline & \multicolumn{3}{|c|}{ Male $(n=239)$} & \multicolumn{3}{|c|}{ Female $(n=197)$} \\
\hline $\begin{array}{l}\text { Total number of } \\
\text { partners }\end{array}$ & 1.9 & 1.1 & $\downarrow 40.1 * *$ & .91 & .95 & $\downarrow 4.40$ \\
\hline
\end{tabular}

$* *$ Significant at alpha $\leq .05$ 
TABLE 5: CHANGE IN FREQUENCY OF PENILE-VAGINAL CONDOM USE AND NUMBER OF PARTNERS IN THE PAST 90 DAYS FROM BASELINE TO FOLLOW UP, BY MARITAL STATUS AT BASELINE

\begin{tabular}{|c|c|c|c|c|c|c|}
\hline & \multicolumn{3}{|c|}{ Unmarried $(n=203)$} & \multicolumn{3}{|c|}{ Married(n=123) } \\
\hline & Baseline & Follow Up & \% change & Baseline & Follow up & $\begin{array}{c}\% \\
\text { change }\end{array}$ \\
\hline \multicolumn{7}{|l|}{ Overall condom use } \\
\hline Never use & $50.4 \%$ & $78.9 \%$ & $\uparrow 56.5^{* *}$ & $28.1 \%$ & $64 \%$ & $\uparrow 127.8 * *$ \\
\hline $\begin{array}{l}\text { Less than half } \\
\text { the time }\end{array}$ & $10.9 \%$ & $4.1 \%$ & $\downarrow 62.3 * *$ & $12.3 \%$ & $3.4 \%$ & $\downarrow 72.3 * *$ \\
\hline Half the time & $3.9 \%$ & $.8 \%$ & $\downarrow 79.4 * *$ & $10.3 \%$ & $4.9 \%$ & $\downarrow 52.4 * *$ \\
\hline Most of the time & $10.1 \%$ & $1.6 \%$ & $\downarrow 84.1 * *$ & $10.8 \%$ & $5.9 \%$ & $\downarrow 45.3 * *$ \\
\hline Always & $24.8 \%$ & $14.6 \%$ & $\downarrow 41.1 * *$ & $38.0 \%$ & $21.7 \%$ & $\downarrow 42.8 * *$ \\
\hline & \multicolumn{3}{|c|}{ Unmarried(n=283) } & \multicolumn{3}{|c|}{ Married(n=153) } \\
\hline $\begin{array}{l}\text { Total number of } \\
\text { partners }\end{array}$ & 1.55 & 1.04 & $\downarrow 33 * *$ & 1.22 & 1.05 & $\downarrow 14$ \\
\hline
\end{tabular}

$* *$ Significant at alpha $\leq .05$ 
TABLE 6: HIV RISK CLASSIFICATION AT BASELINE AND FOLLOW UP BY GENDER

\begin{tabular}{lcccccc}
\hline & \multicolumn{3}{c}{ Male (n=131) } & \multicolumn{3}{c}{ Female $(\mathbf{n = 1 9 5 ) *}$} \\
\hline & Baseline & Follow Up & \% change & Baseline & Follow up & \% change \\
Low risk & $16.9 \%$ & $13.3 \%$ & $\downarrow 21.3$ & $30.5 \%$ & $18.3 \%$ & $\downarrow 40.0$ \\
Low-moderate risk & $61.5 \%$ & $82.1 \%$ & $\uparrow 33.5$ & $61.3 \%$ & $79.4 \%$ & $\uparrow 29.5$ \\
High-moderate risk & $9.7 \%$ & $3.1 \%$ & $\downarrow 68.0$ & $3.9 \%$ & $.8 \%$ & $\downarrow 79.4$ \\
High risk & $11.8 \%$ & $1.5 \%$ & $\downarrow 87.2$ & $4.3 \%$ & $1.5 \%$ & $\downarrow 65.1$ \\
\hline
\end{tabular}

Mc Nemar's test $\chi^{2} *$ Significant at alpha $\leq .05$ 
TABLE 7: HIV RISK CLASSIFICATION AT BASELINE AND FOLLOW UP BY MARI-

TAL STATUS AT BASELINE

\begin{tabular}{lcccccc}
\hline & \multicolumn{3}{c}{ Married $(\mathbf{n = 2 0 3})^{*}$} & \multicolumn{3}{c}{ Not married (n=123) } \\
\hline & Baseline & Follow Up & \% change & Baseline & Follow up & \% change \\
Low risk & $23.2 \%$ & $18.2 \%$ & $\downarrow 21.5$ & $21.1 \%$ & $10.6 \%$ & $\downarrow 49.7$ \\
Low-moderate risk & $58.2 \%$ & $78.8 \%$ & $\uparrow 35.4$ & $69.0 \%$ & $84.5 \%$ & $\uparrow 22.4$ \\
High-moderate risk & $10.3 \%$ & $2.0 \%$ & $\downarrow 80.6$ & $2.4 \%$ & $2.4 \%$ & 0 \\
High risk & $8.4 \%$ & $1.0 \%$ & $\downarrow 88.1$ & $7.3 \%$ & $2.4 \%$ & $\downarrow 67.1$ \\
\hline
\end{tabular}

$\mathrm{X}^{2 *}$ Significant at alpha $\leq .05$ 


\section{APPENDICES}

APPENDIX 1: SOCIAL CAPITAL MEASURE (SOCIAL ASSETS INVENTORY)

\begin{tabular}{|c|c|c|c|}
\hline \multicolumn{3}{|l|}{ FAMILY } & \\
\hline Parents & Yes $(\quad)$ & No ( ) NA( ) & ) \\
\hline Spouse or partner & Yes ( ) & No ( ) NA( ) & ) \\
\hline Own children & Yes $(\quad)$ & No ( ) NA( ) & ) \\
\hline Stepchildren & Yes ( ) & No ( ) NA( ) & ) \\
\hline Relatives or kin & Yes $(\quad)$ & No ( ) NA( ) & ) \\
\hline Spouse or partner's parents & Yes ( ) & No ( ) NA( ) & ) \\
\hline Spouse or partner's relatives & Yes ( ) & No ( ) NA( ) & ) \\
\hline Godparents & Yes ( ) & No ( ) NA( ) & ) \\
\hline \multicolumn{4}{|l|}{ FRIENDS \& OTHERS } \\
\hline Friends & Yes $(\quad)$ & No $(\quad)$ NA( $)$ & \\
\hline Neighbors & Yes () & No ( ) NA( ) & ) \\
\hline Co-workers & Yes ( ) & No ( ) NA( ) & ) \\
\hline Landlord/apartment manager & Yes $(\quad)$ & No ( ) NA( ) & \\
\hline Teacher & Yes $(\quad)$ & No ( ) NA( ) & ) \\
\hline Counselor & Yes $(\quad)$ & No ( ) NA( ) & ) \\
\hline Other mental health professional & Yes $(\quad)$ & No ( ) NA( ) & ) \\
\hline Doctor & Yes $(\quad)$ & No ( ) NA( ) & ) \\
\hline Other health providers & Yes ( ) & No ( ) NA( ) & ) \\
\hline Social service providers & Yes $(\quad)$ & No ( ) NA( ) & ) \\
\hline Clergy/ rabbi & Yes ( ) & No ( ) & ) \\
\hline \multicolumn{4}{|l|}{ GROUPS \& ASSOCIATIONS } \\
\hline Church/synagogue & Yes ( ) & No $($ ) & \\
\hline Church groups & Yes ( ) & No ( ) NA( ) & ) \\
\hline 2-step group (AA, NA) & Yes $(\quad)$ & No () & ) \\
\hline Mutual support group & Yes ( ) & No ( ) NA( ) & ) \\
\hline Sports club / team & Yes ( ) & No ( ) NA( ) & ) \\
\hline Informal social club & Yes () & No ( ) NA( ) & ) \\
\hline Health \& fitness group & Yes $(\quad)$ & No ( ) NA( ) & ) \\
\hline Ethnic group & Yes ( ) & No ( ) NA( ) & ) \\
\hline Alumni organization & Yes ( ) & No ( ) NA( ) & ) \\
\hline Political organizations & Yes $(\quad)$ & No ( ) NA( ) & ) \\
\hline Youth organization & Yes () & No ( ) NA( ) & ) \\
\hline \multicolumn{4}{|l|}{ AGENCIES } \\
\hline Charitable org. & Yes $(\quad)$ & No ( ) & ) \\
\hline Community center & Yes $(\quad)$ & No $($ ) & ) \\
\hline Child/senior daycare & Yes () & No () & ) \\
\hline Preschool program & Yes () & No $($ ) & ) \\
\hline Schools & Yes ( ) & No ( ) & ) \\
\hline Recreation program & Yes ( ) & No ( ) NA( ) & ) \\
\hline Library/library program & Yes () & No $($ ) & ) \\
\hline Police & Yes ( ) & No ( ) NA( ) & ) \\
\hline Hospitals & Yes $(\quad)$ & No ( ) NA( ) & ) \\
\hline BUSINESSES & & & \\
\hline
\end{tabular}




\begin{tabular}{|l|lll|}
\hline Neighborhood merchants & Yes ( ) & No ( ) & NA( ) \\
\hline Lending institutions (banks) & Yes ( ) & No ( ) & NA( ) \\
\hline Public transportation & Yes ( ) & No ( ) & NA( ) \\
\hline Employers & Yes ( ) & No ( ) & NA( ) \\
\hline Utility companies & Yes ( ) & No ( ) & NA( ) \\
\hline
\end{tabular}




\section{APPENDIX 2: HIV RISK CLASSIFICATION}

\begin{tabular}{|c|c|}
\hline TYPE OF RISK & $\begin{array}{c}\text { DEFINITION - NUMBER OF SEXUAL PARTNERS AND } \\
\text { FREQUENCY OF VAGINAL CONDOM USE }\end{array}$ \\
\hline Lowest risk & 1 partner and 'always' condom use in the past 90 days \\
\hline Low-moderate risk & $\begin{array}{l}1 \text { partner and 'less than half time' 'half time' or 'more than half time' } \\
\text { condom use in past } 90 \text { days } \\
>1 \text { partner and 'more than half time' condom use in past } 90 \text { days }\end{array}$ \\
\hline High-moderate risk & $\begin{array}{l}>1 \text { partner and 'half time' condom use in past } 90 \text { days } \\
>1 \text { partner and 'less than half time' condom use in past } 90 \text { days }\end{array}$ \\
\hline Highest risk & $>1$ partner and 'never' condom use in past 90 days \\
\hline
\end{tabular}




\title{
Manuscript 3
}

\section{Documentation status as a moderator between pre and post immigration social capital and} substance use among recent Latino immigrants in South Florida

\begin{abstract}
Changing social capital, or levels of social cohesions/group connectedness, among recent Latino immigrants (RLIs) can influence substance-use post-immigration. This is a longitudinal study of 476 RLIs from South and Central America and the Caribbean, in South Florida. The purpose of the study was to examine social capital (SC) and substance-use changes over time (pre immigration to two years post immigration). To assess changes pre and post-immigration, paired t-tests and $\mathrm{McNemar}$ tests were performed; to explore associations over time, a generalized linear model was used. Post-immigration, SC, hazardous drinking and illicit drug use decreased $(\mathrm{p}<.001)$. After adjusting for time, compared to males, females were $69 \%$ less likely to engage in hazardous drinking $(\mathrm{p}<.001)$, and 33\% less likely to use illicit drugs ( $\mathrm{p}=.01)$. After adjusting for gender and marital status, on average, a one-unit increase in 'business' SC was associated with an $85 \%$ increase in illicit drug use $(\mathrm{p}=.02)$. Documentation status was a moderator between SC and substance use. Providers can target these immigrant sub-populations at increased risk and incorporate $\mathrm{SC}$ components into interventions/programs.
\end{abstract}

KEYWORDS: SUBSTANCE USE, SOCIAL CAPITAL, IMMIGRANTS, DOCUMENTATION STATUS 


\section{Background}

Social capital continues to gain prominence in health research as a partial or full explanatory variable in health behavior models. There are a number of definitions for social capital, but the central idea of social capital is the idea of norms of reciprocity and trust within a community (Putnam, Leonardi, \& Nanetti, 1993), community participation, community engagement, social cohesion or neighborhood organization (Bourdieu, 1986; De Silva, McKenzie, Harpham, \& Huttly, 2005; Berkman \& Kawachi,2000; Portes \& Sensenbrenner, 1993; Putnam, 1995).

Recent immigrants who have lived in the United States (U.S) five or less years can experience a change in social capital which eventually influences substance use behavior (Deren, Shedlin, Decena \& Mino, 2005). The process of acculturation, or immigrants integrating within a host society, is one of the mechanisms by which social capital can change. Although national estimates show that Latinos have less alcohol and substance use than any other ethnic group with the exception of Asians, (SAMSHA, 2012; Centers for Disease Control and Prevention (CDC), 2013), studies have shown that Latino immigrants who have lived in the U.S. five or more years and more acculturated to U.S norms and values have higher rates of alcohol use and substance use (De La Rosa et al, 2012; Lara, Gamboa, Kahramanian, Morales, \& Bautista, 2005; Ortega, Rosenheck, Alegria, \& Desai, 2000) when compared to Latino immigrants who lived in the U.S five or less years, and are generally expected to be less acculturated. Higher rates of cigarette smoking, alcohol and illicit drug use have been linked with more acculturated or non-first generation immigrants (Bartkowski \& Xu, 2007a; Jonas, Young, Oser, Leukefeld, \& Havens, 2012; Kaplan, Napoles-Springer, Stewart, \& Perez-Stable, 2001; Lundborg, 2005b; Weitzman \& Kawachi, 2000; Winstanley et al., 2008).

In most studies, there is an inverse relationship between social capital and substance use (either alcohol or illicit drug use) where more social capital is protective (Green, Doherty, Reisinger, Chilcoat, \& Ensminger, 2010; Hodge, Marsiglia, \& Nieri, 2011; Reynoso-Vallejo, 
2011). However there have been examples where certain types of social capital increase substance use (Jonas, Young, Oser, Leukefeld, \& Havens, 2012; Lindstrom, 2004). For this reason, researchers postulate that social capital is a contextual variable, and its application and usefulness in the prediction of health behavior is correlated to the cultural context of the population to which it is being applied (Galea, Nandi, \& Vlahov, 2004). For example, Eitle, Wahl, \& Aranda (2009) found differences by country of origin in the relationship between social capital and substance behavior among immigrants.

Existing research on social capital and substance use is mostly on adolescent or young (undergraduate college students) people (Åslund \& Nilsson, 2013; Bartkowski \& Xu, 2007b; Boyce, Davies, Gallupe, \& Shelley, 2008; Curran, 2007; Erickson, Harrison, Cook, Cousineau, \& Adlaf, 2012; Kaplan, Napoles-Springer, Stewart, \& Perez-Stable, 2001; Lundborg, 2005a; Weitzman \& Kawachi, 2000; Winstanley et al., 2008), with limited evidence on changing social capital among adults, or immigrants transitioning from pre immigration to post immigration. While there are studies looking at acculturation and substance use, there are limited prospective studies on social capital and substance use specifically on RLIs from the Caribbean, South and Central America. This study addresses these research gaps by providing evidence based on a longitudinal study on the relationship between social capital, hazardous drinking and illicit drug use among RLIs from the Caribbean and South and Central America.

\section{Methods}

This was a prospective longitudinal study observing two time points (baseline/pre immigration and two year follow up/post immigration) of the original study sample. The aim of the original study was to investigate the influence of pre immigration factors on the health behavior trajectories of RLIs in Miami-Dade County. 
A respondent-driven sampling approach was primarily used to recruit participants. Although this method of recruitment can introduce some level of sampling bias, this technique has been shown to be an effective strategy in recruiting participants from hidden or difficult-to-reach populations (Salganik \& Heckathorn, 2003). Research indicates that undocumented Latino immigrants are often a hidden population due to the sensitivity of their legal status in the U.S. In the study, $28.5 \%$ of the participants were undocumented immigrants.

Participants were enrolled if they were in the U.S. for the first time; were in the U.S. 12 months or less; resided in Miami-Dade County, FL; and were between the ages of 18 and 34. Informed consent was obtained from all study participants prior to enrollment. Both the parent study and this study were reviewed and approved by Florida International University Institutional Review Board.

\section{Social Capital}

The social capital instrument or assets inventory measured access to 44 individual social capital items. The instrument categorized the individual items into five subscales. The 'family' subscale has eight items on spouses, children and relatives. The 'friends and other people' subscale has eleven items on friends, neighbors, co-workers, landlords, teachers, counselors, other mental health professionals (other than a counselor), doctors, other health providers, social service providers, and clergy. The 'groups and associations' subscale has eleven items on churches, church groups, 12-step groups, support groups, sports clubs, social clubs, health and fitness clubs, ethnic and youth groups, alumni and political organizations. The 'agency' subscale has nine items on charitable organizations, community centers, child/daycare, preschools, schools, recreation programs, library programs, police and hospitals. The 'business' subscale has five items on neighborhood merchants, banks, public transportation, employers and utility companies.

Individual items from the questionnaire determined the amount of social capital resources available to an individual for each item in each of the five subscales. The individual items were 
binary 'no (0) or yes (1)' variables. Aggregate scores included a subtotal for each subcategory and ranged from 0-11. A total social capital score was calculated as a sum of the five subcategory scores and ranged from $0-42$.

\section{Substance Use}

The Alcohol Use Identification tests (AUDIT) was administered to participants to screen for problems related to alcohol consumption, abuse (Babor, Higgins-Biddle, Saunders, \& Monteiro, 2001), and dependence at baseline (prior to immigration) and at the year 2 follow up visit (2 years post immigration). AUDIT total scores were calculated by summing all 10 items. Eight of the 10 items use a 5 point Likert scale response format $(0=$ never, $1=$ monthly or less, $2=2$ to 4 times a month, $3=2$ to 3 times a week, $4=4$ or more times a week). Sample items include "How often during the year before you came to the U.S. did you find that you were not able to stop drinking once you had started?" and "How often during the year before you came to the U.S. did you have 5 or more drinks on one occasion?" Two additional items asked whether the participant or another person has been injured as a result of the participant's drinking and whether a relative, friend, or clinician has suggested that the participant reduce her or his drinking. Possible responses to the questions were 'no', 'yes, but not during the year before coming to the U.S.' and 'yes, during the year before coming to the United States'.

The AUDIT has good reliability and validity, and its sensitivity and specificity are comparable to those of other screening measures (Allen, Litten, Fertig, \& Babor, 1997). A Cronbach's alpha coefficient of 0.81 indicated acceptable evidence of reliability with the current sample. The AUDIT score is designed to estimate the risk of hazardous drinking. A score greater than or equal to 8 is considered hazardous drinking (Babor, Higgins-Biddle, Saunders, \& Monteiro, 2001). Based on this cut off, a dichotomous AUDIT variable was created for non-hazardous versus hazardous drinking. 
Illicit drug use was based on a timeline follow back calendar which asked the participant about any illicit drug use within the past ninety days. Illicit drug was defined as an illegal narcotic (such as cocaine, marijuana or heroine) as well as any medication that was used outside of its prescribed use. A dichotomous 'drug use' variable was created and was coded as "1" if a participant ever used any illicit drug use in the past 90 days prior to the assessment or " 0 " if there was no illicit drug use.

\section{Demographic information and covariates}

A demographics form was used to collect information on participants' education, income, along with other demographic information. Covariates included in the analysis were time, marital status, and gender. Because of the interaction between documentation status and the outcome variables, the data were stratified by documentation status, and results reported separately by stratum.

Analysis

SPSS 18.0 was used to calculate frequencies and means for data, as well as post-hoc moderation analysis. To adjust for non-normality, a square root transformation was performed on continuous variables that were skewed and kurtotic (summed social capital variables). The data were assessed for outliers by using leverage values and standardized DFbeta values. Any leverage values more than four times the mean leverage score, or any standardized DFbeta more than one absolute value from the mean score were considered outliers. Based on these assessments, no outliers were detected. There was less than $1 \%$ missing for alcohol use and illicit drug use at baseline. At follow up there were $12 \%$ missing values for alcohol use and $11 \%$ missing values for illicit drug use. All other variables had less than 5\% missing values.

To assess the appropriateness of the social capital scale in this population, and to determine if the subcategories sufficiently represented the latent construct of social capital, a confirmatory factor analysis on the social capital scale for both baseline and follow up was undertak- 
en. In addition to other fit indices for the CFA, a chi-square value was ascertained. A chi square value close to zero with a p-value greater than 0.05 indicate that there is little difference between the expected and observed covariance matrices, and this is at least one indicator of good fit (Kenny, 2013). With the exception of a significant chi square, which is typical for sample sizes close to or over 500, overall the measurement model pointed toward good general fit at baseline and follow up. At baseline the $\chi^{2}(\mathrm{DF}=5)$ was $17.5, \mathrm{p}=.0036$. The root mean square of approximation (RMSEA) was .069. The comparative fit index (CFI) was .98, and the Tucker-Lewis index (TLI) was .95. The factor loadings for the subcategories of social capital were family (.5), friend and other (.76), group (.6), agency (.75) and businesses (.56). At follow up the $\chi^{2}(\mathrm{DF}=5)$ was 17.93 , $\mathrm{p}=.003$. The root mean square of approximation (RMSEA) was .074. The CFI was .95 , and the TLI was .91. The factor loadings for the subcategories of social capital were family (.46), friend and other (.73), group (.73), agency (.71) and businesses (.56). Based on these fit statistics at baseline and follow up, the individual social capital score loaded appropriately for the latent social capital score.

Differences between baseline and follow up for social capital and substance use were compared using a paired t-test for continuous variables and a Pearson Chi Square and McNemar test for binary and categorical variables in SPSS. Multivariate analysis tested for the effects of the individual social capital items, and the summed subcategories for social capital, on the substance use variables. Associations between social capital and the substance use outcome variables were measured using generalized linear model (PROCGENMOD SAS 9.3). There were three models for the aggregate social capital multivariate analysis. The first model included the social capital variable adjusting for time only; the second model included the covariates marital status and gender; the third model included the covariates and the interaction terms for time and the social capital variables. Marital status was a time varying covariate, and the second and third models were run twice with marital status at baseline and marital status at follow up. For brevity, only the re- 
sults with marital status at baseline are presented. Results were similar with the marital status at baseline and marital status at follow up. Finally associations between the individual social capital items and substance use were assessed.

\section{Results}

Sample

At baseline there were 527 participants. Fifty one participants were lost to follow up, which left a final sample size of 476 for analysis. Reasons for lost to follow up included deportation or returning voluntarily to the country of origin, withdrawing consent, and other reasons (incarceration, military enlistment and unknown reasons for loss to follow up).

In the final study sample Cubans, Colombians and Hondurans together represented the majority of the sample at $42.1 \%, 17.6 \%$, and $12.5 \%$ respectively. The rest of the participants were from other Central and South American countries. According to the 2010 census data, the breakdowns of Latinos in Miami-Dade County by specific origin are 34.3\% Cuban, $4.6 \%$ Colombian, 4.2\% Nicaraguan, 2.2\% Honduran and the rest from other countries (U.S. Census Bureau, 2011). These sub-groups are over represented in the study sample possibly due to the method of recruitment.

The sample had a significant increase in the percentage of people employed from $46.9 \%$ to $48.7 \%$, and annual median income from $\$ 1,233$ to $\$ 19,000$ (Table 1). The large increase in annual income can also be attributed to the purchase power and value of local currency in the countries of origin compared to the U.S. dollar. There was a greater loss to follow up among the less educated and older participants. There was no significant change in documentation status. There were more married participants at follow up (23.8\%) than at baseline $(21.9 \%)$.

[TABLE 1 HERE] 


\section{Social Capital}

The total social capital score had a $38 \%$ decrease from baseline to follow up. The greatest decreases for the subcategories of social capital were among 'agency', 'group' and 'business' social capital. When stratified by gender, males experienced a greater decline in total social capital $(40.3 \%$ versus $35.6 \%)$. The amount of decrease for males and females were similar for 'family' and 'friends and other' social capital. For 'agency' and 'business' social capital, men had a greater decline. Women had a greater decrease for 'group' social capital.

\section{Hazardous Drinking and Illicit Drug Use}

Results for the change in substance use from pre to post immigration are presented in Table 2. Overall, hazardous drinking decreased $32.9 \%$, and illicit drug use decreased $23 \%$ postimmigration $(\mathrm{p}<.001)$. There was a greater decline among men $(40.3 \%)$ than women $(37.5 \%)$ for hazardous drinking, and a greater decline among women $(31.0 \%)$ than men $(20.9 \%)$ for illicit drug use.

\section{[TABLE 2 HERE]}

\section{Multivariate analysis: Hazardous Drinking and Illicit Drug Use on Social Capital}

In the analysis of the individual social capital items, utilizing police services decreased

the risk of hazardous alcohol use, and having access to neighborhood merchants increased risk of illicit drug use. The individual social capital items were not stratified due to limited data.

Results for the generalized linear model on aggregate measures of social capital are presented in Tables $3 \mathrm{a}$ (unstratified) and $3 \mathrm{~b}-3 \mathrm{c}$ (undocumented and documented study participants). Before stratifying by documentation status, after adjusting for marital status and gender, on average, individuals with a one unit increase in group social capital were $24 \%$ more likely to engage in hazardous drinking. After adjusting for marital status and gender, there was a significant association between 'friend and other' and 'business' social capital and illicit drug use. On average, individuals with a one unit increase in 'friend and other' social capital were 59\% more likely to engage in illicit drug use, and with a unit increase in 'business' social capital were $85 \%$ more 
likely to engage in illicit drug use. It should be noted, however, the interaction terms for time and 'family' social capital and time and 'agency' social capital were significant indicating the effect of the 'family' and 'agency' social capital on illicit drug use changed over time (from pre to post immigration) or that the effect of 'family' and 'agency' social capital on illicit drug use were different for the two time points. Women had less risk for both hazardous drinking and illicit drug use. Before inclusion of the interaction terms but adjusting for time, on average women were $69 \%$ less likely to engage in hazardous drinking $(\mathrm{p}<.0001)$, and 33\% less likely to engage in illicit drug use $(\mathrm{p}<.05)$.

\section{[TABLE 3a HERE]}

An interaction of documentation status (at baseline and follow up) and illicit drug use was found to be significant $(\mathrm{p}<.0001)$. Therefore the sample was also stratified by documentation status. There was no significant difference in documentation status between baseline and follow up. Therefore, the sample was stratified by documentation status at baseline only. After the sample was stratified for the aggregate analysis (Tables 3b and 3c), 'group' and 'business' social capital lost significance for its relationship with substance use (hazardous drinking and illicit drug use). 'Friend and other' social capital was protective against hazardous drinking and illicit drug use for undocumented individuals $(\mathrm{OR}=.55, \mathrm{p}<.01 ; \mathrm{OR}=.56, \mathrm{p}<.05)$. For documented individuals, 'family' social capital was protective against hazardous drinking, agency social capital was protective against illicit drug use, and the relationship between 'business' social capital and illicit drug use became stronger with 'business' social capital increasing the likelihood of engaging in illicit drug use.

[TABLE 3b AND 3c HERE] 


\section{Discussion}

To our knowledge, there are no other studies that have focused on patterns of substance use and social capital among RLIs pre to post immigration. Most related studies are not on recent immigrants and look at alcohol use post immigration only. The general consensus for these studies is that post immigration, alcohol use increases with longer time in the United States (Caetano, 2003; Lara et al, 2005). Our finding of a decline in substance use is not consistent with other immigrant and substance use studies because our study uses pre-immigration as a baseline measure, and our study is one of few studies to look at recent Latino immigrants. However, the decline in hazardous alcohol consumption from pre to post immigration is in line with a previously published paper of the same population from pre immigration to one year post immigration (De La Rosa, Dillon, Sastre, \& Babino, 2013).

The unstratified aggregate analysis of subcategories of social capital and substance use showed a significant association between group social capital and hazardous drinking, and business social capital with illicit drug use. By stratifying we were able to glean more information about the relationship between different measures of social capital and substance use. One of the primary findings was that documented study participants had stronger associations with 'agency' and 'business' social capital than undocumented study participants. Since undocumented individuals have fewer opportunities to access 'agency', or 'business' social capital, it follows that these subcategories of social capital had weaker associations with substance use behavior. Conversely, only among undocumented participants was there an association between 'friends and others' social capital and hazardous drinking.

'Business' social capital increasing risk of illicit drug use was consistent throughout all of the analysis. In the unstratified analysis, an individual with one unit increase in business social capital was $85 \%$ more likely to be engaged in illicit drug use. This is explained further in the individual social capital item analysis where participants who had greater access to neighborhood 
merchants were more likely to use illicit drugs and may have been driving the aggregate business social capital result. Having greater access to neighborhood merchants implies the person may be more acculturated, with greater embeddedness and status in their local community, a greater social network, and more disposable income to use on illicit drugs. This phenomenon is seen among Cuban immigrants where newly arrived immigrants have access to "character loans" from other local Cubans who are more established in the U.S. and have the ability to offer small sum loans (Portes \& Sensenbrenner, 1993).

The relationship between social capital, documentation status and substance use may be related to segmented-assimilation theory which suggests that there are both negative and positive trajectories for documented immigrants with increased assimilation into host culture (Eitle, Wahl, \& Aranda, 2009; Rumbaut, 1997). Increasing income and employment affords documented immigrants more opportunities, but can also lead to more risky behavior.

Aggregate and individual analysis demonstrated that 'agency' social capital which included police services was a protective factor against hazardous drinking. Using the police was protective against hazardous drinking perhaps because an individual's willingness to use the police as a social resource indicates that individual's compliance with laws and social norms, including those related to alcohol use.

\section{Limitations}

The primary source of bias in this study is related to recall bias as all pre immigration behaviors were asked retrospectively. Another possible source of bias may be the difference between participants who were retained and those who were lost to follow up. Those participants lost to follow up are likely not similar to those retained. Additionally, although respondent driven sampling was a practical method to sample with this hard-to-reach sample, the sample is likely not as representative of the target population as a random sample. 
The social capital instrument was developed a priori. If a different instrument had been used, the findings may have been different. Additionally, social capital is typically applicable at a group or community level. However for this study social capital is measured at an individual level, and then applied to the group of focus - RLIs. There may be some issue with this method as aggregate social capital at a community level may not be accurately expressed as a sum of individual level social capital (Office of National Statistics, United Kingdom, 2001). However, there

are a number of quantitative and qualitative studies that have used social capital and social capital related variables at an individual level to support the use of this variable at an individual level in this study (Battacharya, 2005; Cené et al., 2011; Pronyk et al., 2008a; Pronyk et al., 2008b; Reynoso-Vallejo, 2011; Swendeman, Basu, Das, Jana, \& Rotheram-Borus, 2009).

The frequency of illicit drug use was relatively low and did not allow for further analysis on individual illicit drugs (marijuana, cocaine, heroin etc.) and their relationship with social capital. This information would have been useful in determining the type of illicit drug use and associations with social capital. Additionally, the missing values for the outcome variables at follow up (12\% for AUDIT and $11 \%$ for illicit drug use) could have skewed results. The sample size was not large enough, and there was inadequate power to complete a multivariate analysis by documentation status for the individual social capital items and substance use.

\section{Conclusion}

The study was successful in providing evidence for changing social capital and substance use among immigrants from pre- to post-immigration. However the relationship between those changes was not a simple unidirectional association. The decrease in social capital post immigration can be attributed to the change in environment and lack of familiarity with community resources, but the relationship between declining social capital and declining alcohol and illicit drug use is complex and context-dependent. If the segmented assimilation theory is applied, unless mediated by other social capital factors, substance use in this cohort may increase with further 
time in the United States owing to the likelihood of more financial success and greater acculturation.

Additional recommendations for further studies on social capital and substance use include a greater sample size that would allow separate analysis of types of illicit drugs, and longer follow up to investigate whether the trend in substance use is maintained or changes with further assimilation. While undocumented individuals remain a vulnerable population that needs to be considered when developing health policy for immigrants, based on these findings, substance use prevention policy for RLIs should focus on primary public health interventions that target those with greater access to 'business' social capital, and men as they may be at increased risk for substance use. 


\section{References}

Allen, J. P., Litten, R. Z., Fertig, J. B., \& Babor, T. (1997). A review of research on the alcohol use disorders identification test (AUDIT). Alcoholism, Clinical and Experimental Research, 21(4), 613-619.

Åslund, C., \& Nilsson, K. W. (2013). Social capital in relation to alcohol consumption, smoking, and illicit drug use among adolescents: A cross-sectional study in Sweden. International Journal for Equity in Health, 12(1), 33.

Babor, T. F., Higgins-Biddle, J. C., Saunders, J. B., \& Monteiro, M. (2001). AUDIT: The alcohol use disorders identification test: Guidelines for use in Primary Care, 2nd edition. Geneva, Switzerland: World Health Organization, Department of Mental Health and Substance Dependence.

Bartkowski, J. P., \& Xu, X. (2007a). Religiosity and teen drug use reconsidered: A social capital perspective. American Journal of Preventive Medicine, 32(6 Suppl), S182-94. doi:10.1016/j.amepre.2007.03.001

Bartkowski, J. P., \& Xu, X. (2007b). Religiosity and teen drug use reconsidered: A social capital perspective. American Journal of Preventive Medicine, 32(6, Supplement), S182-S194. doi:10.1016/j.amepre.2007.03.001

Battacharya, G. (2005). Social capital and HIV risk among acculturation Asian Indian men in New York City. AIDS Education and Prevention, 51(6), 1173.

Berkman, L., Kawachi, I (eds.) (2000). Social cohesion, social capital and health. In Social Epidemiology. Oxford: Oxford University Press, 174-190.

Bourdieu, P. (1986). The forms of capital. Handbook of Theory and Research for the Sociology of Education, 241-258.

Boyce, W. F., Davies, D., Gallupe, O., \& Shelley, D. (2008). Adolescent risk taking, neighborhood social capital, and health. Journal of Adolescent Health, 43(3), 246-252. doi:10.1016/j.jadohealth.2008.01.014

Caetano, R. (2003). Alcohol-related health disparities and treatment-related epidemilogical findings among Whites, Blacks, and Hispanics in the United States. Alcoholism: Clinical and Experimental Research, 27, 1337-1339.

Cené, C.,W.C.W., Akers, A. Y. A. Y., Lloyd, S. W. S. W., Albritton, T. T., Powell Hammond, W.,W., \& Corbie-Smith, G. (2011). Understanding social capital and HIV risk in rural African American communities. Journal of General Internal Medicine, 26(7), 737-744.

Centers for Disease Control and Prevention (CDC). (2013). HIV among Hispanics/Latinos. Retrieved June 24, 2013, from http://www.cdc.gov/hiv/latinos/index.htm

Coleman, J.S. (1988). Social capital in the creation of human capital. American Journal of Sociology, 94, S95-S120. 
Curran, E. M. (2007). The relationship between social capital and substance use by high school students. Journal of Alcohol \& Drug Education, 51(2), 51-59.

De La Rosa, M., Sanchez, M., Dillon, F.R., Ruffin, B.A., Blackson, T., Schwartz, S. (2012). Alcohol use among Latinos: A comparison of pre-immigration, post-immigration, and U.S. born Latinos. Journal of Immigrant and Minority Health, 14(3), 371-378

De La Rosa, M., Dillon, F., Sastre, F., \& Babino, R. (2013). Alcohol use among recent Latino immigrants before and after immigration to the United States. The American Journal on Addictions, 22(2), 162-168.

Deren, S., Shedlin, M., Decena, C.U., Mino, M. (2005). Research challenges to the study of HIV/AIDS among migrant and immigrant Hispanic populations in the United States. Journal of Urban Health: Bulletin of the New York Academy of Medicine, 82(2)suppl3, iii13-iii25.

De Silva, M., McKenzie, K., Harpham, T., \& Huttly, S. R. A. (2005). Social capital and mental illness: A systematic review. Journal of Epidemiology and Community Health (1979), 59(8), 619-627.

Eitle, T. M., Wahl, A. M., \& Aranda, E. (2009). Immigrant generation, selective acculturation, and alcohol use among Latina/o adolescents. Social Science Research, 38(3), 732-742.

Erickson, P. G., Harrison, L., Cook, S., Cousineau, M., \& Adlaf, E. M. (2012). A comparative study of the influence of collective efficacy on substance use among adolescent students in Philadelphia, Toronto, and Montreal. Addiction Research Theory, 20(1), 11-20. doi: $10.3109 / 16066359.2010 .530710$

Galea, S., Nandi, A., \& Vlahov, D. (2004). The social epidemiology of substance use. Epidemiologic Reviews, 26, 36-52. doi:10.1093/epirev/mxh007

Green, K. M., Doherty, E. E., Reisinger, H. S., Chilcoat, H. D., \& Ensminger, M. (2010). Social integration in young adulthood and the subsequent onset of substance use and disorders among a community population of urban African Americans. Addiction (Abingdon, England), 105(3), 484-493. doi:10.1111/j.1360-0443.2009.02787.x

Hodge, D. R., Marsiglia, F. F., \& Nieri, T. (2011). Religion and substance use among youths of Mexican heritage: A social capital perspective. Social Work Research, 35(3), 137-146.

Jonas, A. B., Young, A. M., Oser, C. B., Leukefeld, C. G., \& Havens, J. R. (2012). OxyContin(R) as currency: OxyContin(R) use and increased social capital among rural Appalachian drug users. Social Science \& Medicine (1982), 74(10), 1602-1609. doi:10.1016/j.socscimed.2011.12.053; 10.1016/j.socscimed.2011.12.053

Kaplan, C. P., Napoles-Springer, A., Stewart, S. L., \& Perez-Stable, E. J. (2001). Smoking acquisition among adolescents and young Latinas: The role of socioenvironmental and personal factors. Addictive Behaviors, 26(4), 531-550. 
Kenny, D. (2013). Measuring Model Fit. Retrieved November 22, 2013 from

http://davidakenny.net/cm/fit.htm.

Lara, M., Gamboa, C., Kahramanian, M. I., Morales, L. S., \& Bautista, D. E. (2005). Acculturation and Latino health in the United States: A review of the literature and its sociopolitical context. Annual Review of Public Health, 26, 367-397. doi:10.1146/annurev.publhealth.26.021304.144615

Lindstrom, M. (2004). Social capital, the miniaturisation of community and self-reported global and psychological health. Social Science \&Medicine, 59(3), 595-605.

Lundborg, P. (2005a). Social capital and substance use among Swedish adolescents. Social Science \& Medicine (1982), 61(6), 1151.

Lundborg, P. (2005b). Social capital and substance use among Swedish adolescents--an explorative study. Social Science \& Medicine (1982), 61(6), 1151-1158.

doi:10.1016/j.socscimed.2004.12.031

Mohler-Kuo, M., Lee, J.E., Wechsler, H. (2003). Trends of marijuana and other illicit drug use among college students: results from 4 Harvard School of Public Health College Alcohol Study surveys: 1993 - 2001. Journal of American College Health, 52(1), 17-24.

Muthén, L. K., \& Muthén, B. O. (2007). Mplus user's guide (6th ed.). Los Angeles, CA: Muthén \& Muthén.

Office of National Statistics, United Kingdom. (2001). Social capital: A review of literature.

Ortega, A. N., Rosenheck, R., Alegria, M., \& Desai, R. A. (2000). Acculturation and the lifetime risk of psychiatric and substance use disorders among Hispanics. The Journal of Nervous and Mental Disease, 188(11), 728-735.

Portes, A., \& Sensenbrenner, J. (1993). Embeddedness and immigration: Notes on the social determinants of economic action. The American Journal of Sociology, 98(6), 1320-1350.

Pronyk, P. M., Kim, J. C., Abramsky, T., Phetla, G., Hargreaves, J. R., Morison, L. A., Porter, J. D. (2008a). A combined microfinance and training intervention can reduce HIV risk behaviour in young female participants. AIDS (London, England), 22(13), 1659-1665. doi:10.1097/QAD.0b013e328307a040

Pronyk, P., Harpham, T., Morison, L. A., Hargreaves, J. R., Kim, J. C., Phetla, G., Porter, J. D. (2008b). Is social capital associated with HIV risk in rural South Africa? Social Science \& Medicine (1982), 66(9), 1999-2010.

Putnam, R. D. (1995). Bowling alone: America's declining social capital. Journal of Democracy, $6(1), 65-78$.

Putnam, R. D., Leonardi, R., \& Nanetti, R. (1993). Making Democracy Work: Civic Tradition in Modern Italy. Princeton, New Jersey: Princeton University Press. 
Reynoso-Vallejo, H. (2011). Social capital influence in illicit drug use among racial/ethnic groups in the United States. Journal of Ethnicity in Substance Abuse, 10(2), 91-111. doi:10.1080/15332640.2011.572532

Rumbaut, R. G. (1997). Assimilation and its discontents: Between rhetoric and reality. The International Migration Review, 31(4), 923-960.

Salganik, M. J., \& Heckathorn, D. D. (2003). Sampling and estimation in hidden populations using respondent-driven sampling. Sociological Methodology, 34(1), 193.

Substance Abuse and Mental Health Services Administration (SAMHSA). (2012). Results from the 2011 National Survey on Drug Use and Health: Summary of National Findings. NSDUH Series H-44, HHS Publication No. (SMA) 12-4713. Rockville, MD: Substance Abuse and Mental Health Services Administration, 2012.

Swendeman, D., Basu, I., Das, S., Jana, S., \& Rotheram-Borus, M. J. (2009). Empowering sex workers in India to reduce vulnerability to HIV and sexually transmitted diseases. Social Science \& Medicine (1982), 69(8), 1157-1166.

U.S. Census Bureau. (2011). Decennial census 2010. Department of planning and zoning.

Weitzman, E. R., \& Kawachi, I. (2000). Giving means receiving: The protective effect of social capital on binge drinking on college campuses. American Journal of Public Health, 90(12), 1936-1939.

Winstanley, E. L., Steinwachs, D. M., Ensminger, M. E., Latkin, C. A., Stitzer, M. L., \& Olsen, Y. (2008). The association of self-reported neighborhood disorganization and social capital with adolescent alcohol and drug use, dependence, and access to treatment. Drug and Alcohol Dependence, 92(1-3), 173-182. doi:10.1016/j.drugalcdep.2007.07.012 


\section{TABLES AND FIGURES}

TABLE 1: DEMOGRAPHICS OF SAMPLE POPULATION, BASELINE TO FOLLOW $\mathrm{UP}(\mathrm{N}=\mathbf{4 7 6})$

\begin{tabular}{|c|c|c|c|}
\hline & Baseline & Follow Up & $\mathrm{p}$ \\
\hline Gender & & & $>.05$ \\
\hline Male & $54.1 \%$ & $54.1 \%$ & \\
\hline Female & $45.9 \%$ & $45.9 \%$ & \\
\hline Employed & $46.9 \%$ & $48.7 \%$ & $<.05$ \\
\hline Documentation status & & & $>.05$ \\
\hline Undocumented & $28.5 \%$ & $27.9 \%$ & \\
\hline Documented & $71.5 \%$ & $72.1 \%$ & \\
\hline Mean age (18-34) & 26.8 & 27.9 & $<.05$ \\
\hline $\begin{array}{l}\text { Annual median household income (0- } \\
140,000)\end{array}$ & $\$ 1,233$ & $\$ 19,000$ & $<.05$ \\
\hline Marital Status & & & $<.05$ \\
\hline Single & $54.1 \%$ & $49.7 \%$ & \\
\hline Married & $21.8 \%$ & $23.8 \%$ & \\
\hline Common law & $12 \%$ & $13.4 \%$ & \\
\hline Divorced & $4.4 \%$ & $3.1 \%$ & \\
\hline Separated & $8.2 \%$ & $9.8 \%$ & \\
\hline Widowed & $.2 \%$ & $.2 \%$ & \\
\hline Education & & & $<.05$ \\
\hline Less than high school & $18.1 \%$ & $13.1 \%$ & \\
\hline High school & $28.5 \%$ & $36.3 \%$ & \\
\hline Some college & $33.1 \%$ & $34.2 \%$ & \\
\hline Bachelor's & $17.1 \%$ & $14.3 \%$ & \\
\hline Graduate & $3.2 \%$ & $2.1 \%$ & \\
\hline
\end{tabular}


TABLE 2: CHANGE IN SUBSTANCE USE PRE TO POST IMMIGRATION OVERALL AND BY GENDER (n=476)

\begin{tabular}{|c|c|c|c|c|c|c|c|c|}
\hline & \multicolumn{4}{|c|}{ Baseline } & \multicolumn{2}{|c|}{ Follow Up } & $\begin{array}{c}\% \\
\text { change }\end{array}$ & $\mathbf{P}$ \\
\hline \multirow{4}{*}{$\begin{array}{l}\text { Illicit drug use } \\
\text { Hazardous } \\
\text { Drinking }\end{array}$} & \multicolumn{4}{|c|}{$13.0 \%$} & \multicolumn{2}{|c|}{$9.9 \%$} & $-23.0 \%$ & $<.001$ \\
\hline & \multicolumn{4}{|c|}{$25.9 \%$} & \multicolumn{2}{|c|}{$15.6 \%$} & $-32.9 \%$ & $<.001$ \\
\hline & \multicolumn{4}{|c|}{ Female } & \multicolumn{4}{|c|}{ Male } \\
\hline & Baseline & $\begin{array}{c}\text { Follow- } \\
\text { up }\end{array}$ & $\%$ change & $\mathbf{p}$ & Baseline & $\begin{array}{c}\text { Follow- } \\
\text { up }\end{array}$ & $\%$ change & $\mathbf{p}$ \\
\hline $\begin{array}{l}\text { Illicit Drug } \\
\text { Use }\end{array}$ & $8.7 \%$ & $6.0 \%$ & $-.31 .0 \%$ & $<.001$ & $16.7 \%$ & $13.2 \%$ & $-20.9 \%$ & $<.001$ \\
\hline $\begin{array}{l}\text { Hazardous } \\
\text { Drinking }\end{array}$ & $13.3 \%$ & $8.3 \%$ & $-37.5 \%$ & .05 & $36.7 \%$ & $21.9 \%$ & $-40.3 \%$ & $<.001$ \\
\hline
\end{tabular}


TABLE 3A: UNSTRATIFIED EFFECT OF HAZARDOUS DRINKING AND ILLICIT DRUG USE ON SOCIAL CAPITAL FROM PRE IMMIGRATION TO POST IMMIGRATION USING GENERALIZED LINEAR MODEL (n=476)

\begin{tabular}{|c|c|c|c|c|c|c|}
\hline & \multicolumn{3}{|c|}{ HAZARDOUS DRINKING } & \multicolumn{3}{|c|}{ ILLICIT DRUG USE } \\
\hline & $\begin{array}{l}\text { MODEL } 1 \\
\text { OR }\end{array}$ & $\begin{array}{c}\text { MODEL } 2 \\
\dagger \text { AOR }\end{array}$ & $\begin{array}{c}\text { MODEL } 3 \\
\text { †AOR }\end{array}$ & $\begin{array}{l}\text { MODEL } 1 \\
\text { OR }\end{array}$ & $\begin{array}{c}\text { MODEL } 2 \\
\text { †AOR }\end{array}$ & $\begin{array}{c}\text { MODEL } 3 \\
\quad \dagger \text { AOR }\end{array}$ \\
\hline Change in family social capital & $.85^{*}$ & .90 & .96 & .93 & .99 & 1.04 \\
\hline Change in friend and other social capital & .76 & .81 & .73 & $.58 * *$ & $1.59 * *$ & .53 \\
\hline Change in agency social capital & .83 & .93 & .89 & .74 & .74 & .92 \\
\hline Change in group social capital & $1.32 * *$ & $1.24^{*}$ & 1.11 & 1.04 & 1.06 & .84 \\
\hline Change in business social capital & 1.15 & 1.06 & .94 & $1.94 * *$ & $1.85^{* *}$ & $1.56^{*}$ \\
\hline Time & 1.35 & 1.34 & 1.63 & 1.52 & 1.60 & 3.60 \\
\hline Marital status at baseline & & 1.13 & 1.08 & & 1.35 & 1.22 \\
\hline Gender & & $.31 * * *$ & $.32 * * *$ & & $.67 *$ & .67 \\
\hline Time*family social capital & & & .61 & & & $.38^{*}$ \\
\hline Time*friend and other social capital & & & .89 & & & 1.25 \\
\hline Time*agency social capital & & & 1.04 & & & $.52 *$ \\
\hline Time* group social capital & & & 1.34 & & & 1.58 \\
\hline Time*business social capital & & & 1.61 & & & 1.75 \\
\hline $\begin{array}{l}\text { Note: Time } 0=\text { baseline, } 1=2 \text { year follow ul } \\
\text { lower ordered variables. } \\
\dagger \text { Model } 2 \text { adjusted for time, marital status } \\
\text { interaction terms with social capital variab } \\
* \mathrm{P}<.05 \\
* * \mathrm{P}<.01 \\
* * * \mathrm{P}<.0001\end{array}$ & $\begin{array}{l}\text { p; Marital stat } \\
\text { at baseline an } \\
\text { les. }\end{array}$ & $\begin{array}{l}\text { us } 0=\text { unmarri } \\
\text { d gender; Mo }\end{array}$ & $\begin{array}{l}\text { ed, } 1=\text { marriec } \\
\text { del } 3 \text { adjustec }\end{array}$ & $\begin{array}{l}\text { sender } 0=\text { fem } \\
\text { r time, marita }\end{array}$ & $\begin{array}{l}\text { ale, } 1=\text { male. } C \\
1 \text { status at bas }\end{array}$ & $\begin{array}{l}\text { dds ratios pr } \\
\text { eline, gender, }\end{array}$ \\
\hline
\end{tabular}


TABLE 3B: EFFECT OF HAZARDOUS DRINKING AND ILLICIT DRUG USE ON SOCIAL CAPITAL FROM PRE IMMIGRATION TO POST IMMIGRATION AMONG UNDOCUMENTED PEOPLE USING GENERALIZED LINEAR MODEL $(n=476)$

\begin{tabular}{|c|c|c|c|c|c|c|}
\hline & \multicolumn{3}{|c|}{ HAZARDOUS DRINKING } & \multicolumn{3}{|c|}{ ILLICIT DRUG USE } \\
\hline & $\begin{array}{c}\text { MODEL } 1 \\
\text { OR }\end{array}$ & $\begin{array}{c}\text { MODEL } 2 \\
\quad \nmid \text { AOR }\end{array}$ & $\begin{array}{c}\text { MODEL } 3 \\
\quad \nmid \text { AOR }\end{array}$ & $\begin{array}{c}\text { MODEL } 1 \\
\text { OR }\end{array}$ & $\begin{array}{c}\text { MODEL } 2 \\
\quad \nmid \text { AOR }\end{array}$ & $\begin{array}{c}\text { MODEL } 3 \\
\quad \text { †AOR }\end{array}$ \\
\hline Change in family social capital & .99 & 1.03 & 1.08 & .96 & .98 & 1.00 \\
\hline Change in friend and other social capital & $.53 * * *$ & $.55 * *$ & .91 & $.52 * *$ & $.56^{*}$ & .84 \\
\hline Change in agency social capital & 1.07 & 1.19 & 1.41 & 1.03 & 1.00 & .86 \\
\hline Change in group social capital & 1.27 & 1.28 & .92 & 1.04 & 1.19 & .84 \\
\hline Change in business social capital & .95 & .88 & 1.23 & 1.37 & 1.36 & 1.89 \\
\hline Time & $.80 * *$ & $2.45 * *$ & 1.49 & 1.49 & 1.49 & 5.04 \\
\hline Marital status at baseline & & 1.16 & 1.16 & & 1.34 & 1.18 \\
\hline Gender & & $.19 * * *$ & $.18 * * *$ & & $.37 *$ & .28 \\
\hline Time*family social capital & & & .91 & & & .46 \\
\hline Time*friend and other social capital & & & 1.40 & & & .09 \\
\hline Time*agency social capital & & & 1.80 & & & 1.75 \\
\hline Time* group social capital & & & 1.17 & & & 1.76 \\
\hline Time*business social capital & & & .56 & & & .40 \\
\hline
\end{tabular}

Note: Time $0=$ baseline, $1=2$ year follow up; Marital status $0=$ unmarried, $1=$ married; Gender $0=$ female, $1=$ male. Odds ratios presented for lower ordered variables.

$\dagger$ Model 2 adjusted for time, marital status at baseline and gender; Model 3 adjusted for time, marital status at baseline, gender, and time interaction terms with social capital variables.

$* \mathrm{P}<.05$

$* * \mathrm{P}<.01$

$* * * \mathrm{P}<.0001$ 
TABLE 3C: EFFECT OF HAZARDOUS DRINKING AND ILLICIT DRUG USE ON SOCIAL CAPITAL FROM PRE IMMIGRATION TO POST IMMIGRATION AMONG DOCUMENTED IMMIGRANTS USING GENERALIZED LINEAR MODEL

\begin{tabular}{|c|c|c|c|c|c|c|}
\hline & \multicolumn{3}{|c|}{ HAZARDOUS DRINKING } & \multicolumn{3}{|c|}{ ILLICIT DRUG USE } \\
\hline & $\begin{array}{l}\text { MODEL } 1 \\
\text { OR }\end{array}$ & $\begin{array}{c}\text { MODEL } 2 \\
\quad \uparrow \text { AOR }\end{array}$ & $\begin{array}{c}\text { MODEL } 3 \\
\quad \dagger \text { AOR }\end{array}$ & $\begin{array}{l}\text { MODEL } 1 \\
\text { OR }\end{array}$ & $\begin{array}{c}\text { MODEL } 2 \\
\text { †AOR }\end{array}$ & $\begin{array}{c}\text { MODEL } 3 \\
\dagger \text { AOR }\end{array}$ \\
\hline Change in family social capital & $.79 * * *$ & $.83^{*}$ & .91 & .93 & 1.00 & 1.07 \\
\hline Change in friend and other social capital & 1.02 & 1.05 & .73 & .68 & .69 & 19 \\
\hline Change in agency social capital & $.75^{*}$ & .84 & .84 & .63 & $.62 * *$ & 1.00 \\
\hline Change in group social capital & 1.18 & 1.13 & 1.02 & .93 & .97 & .78 \\
\hline Change in business social capital & 1.27 & 1.15 & .91 & $2.33 * * *$ & $2.20 * *$ & 1.41 \\
\hline Time & 1.06 & 1.02 & .99 & 1.53 & 1.75 & .51 \\
\hline Marital status at baseline & & 1.15 & 1.08 & & 1.44 & 1.29 \\
\hline Gender & & $.36^{* * *}$ & $.37 * * *$ & & .88 & .85 \\
\hline Time*family social capital & & & .51 & & & $.34 *$ \\
\hline Time*friend and other social capital & & & 1.07 & & & 4.26 \\
\hline Time*agency social capital & & & 0.00 & & & $.31 * * *$ \\
\hline Time* group social capital & & & 1.32 & & & 1.44 \\
\hline Time*business social capital & & & $2.36^{* *}$ & & & $4.22 * *$ \\
\hline
\end{tabular}

$(\mathrm{n}=\mathbf{4 7 6 )}$

Note: Time $0=$ baseline, $1=2$ year follow up; Marital status $0=$ unmarried, $1=$ married; Gender $0=$ female, $1=$ male. Odds ratios presented for lower ordered variables.

$\dagger$ Model 2 adjusted for time, marital status at baseline and gender; Model 3 adjusted for time, marital status at baseline, gender, and time interaction terms with social capital variables.

* $\mathrm{P}<.05$

$* * \mathrm{P}<.01$

$* * * \mathrm{P}<.0001$ 


\section{Conclusion}

The dissertation provided additional evidence for an existing association between social capital and HIV risk behavior, and substance use. Further, the dissertation gave information on these associations among RLIs. Immigrants do not follow one homogenous acculturation path post-immigration. The process of adaptation to the host country is multifaceted and is dependent on other factors such as documentation status, and different types of social capital that may differ for pre to post immigration.

The theoretical framework for the study was based on a model focusing on culture and cultural change affecting behavior and group norms (Handwerker, 2002). Other theoretical frameworks such as the life course approach or the social stress model of substance abuse prevention could have been used (Rhodes and Jason, 1988, Lindenberg et al, 1999). But these models attribute a person's cumulative life experience beginning from childhood, and its impact on adult decisions and behavior which may have an effect on health status and disease outcome (Kuh et al, 1997), without taking into consideration any life change in adult hood such as immigration.

To consider early life experience and the process of immigration together, influencing sexual behavior and substance use post immigration, the theoretical model asserted by Handwerker was more appropriate. Handwerker discusses the development of culture (both individual and group) as an evolving process which occurs over the course of life, through different experiences and interaction with others. As culture evolves, individuals "organize activities and [create] new ways to think about domains of understanding" (Handwerker, 2002). Therefore, in application to the proposed study, the individual's life experience, including the process of immigration ultimately influences decisions related to sexual risk behavior post immigration.

Furthermore, as the individual adapts to the host country, components contributing to social capital may change. For example, pre immigration family cohesion may have a prominent 
place in the sphere of the individual's social capital, but if an individual is immigrating alone without family, family support will be limited and that individual will find support in other areas such as civic engagement or support from friends.

The original proposed central hypothesis for the dissertation was that substance use would act as a moderator between the change in HIV risk behavior and social capital. However preliminary analysis showed there was no evidence in this sample for substance use as moderator, and the analysis plan was revised to look at the relationship between social capital and substance use and, social capital and HIV risk behavior, independently. This is how the two original studies for manuscripts two and three were engendered. Because the original aim was primarily to look at the changes between social capital and HIV risk behavior, the systematic review (manuscript 1) concentrated on social capital and HIV risk behavior. Although the relationship between social capital and substance use was not one of the original objectives, it produced some key findings of the dissertation. Revising the dissertation to include substance use as another primary outcome was cogent, since there is a relationship between HIV risk behavior and substance use (Leigh and Stall, 1993, Shurtleff and Lawrence, 2012).

The intent of the dissertation was to expand the existing knowledge base about HIV risk behavior among RLIs post immigration, by exploring the roles of social capital and substance use. There were some limitations to the studies which are identified in the manuscripts but included the method of recruitment, inadequate sample size for more in depth multivariate analysis, and measures that were developed a priori. Despite these limitations, there were several important findings:

- Social capital declined among RLIs post immigration.

- There was a decline in condom use among RLIs post immigration.

- There was a decline in the number of sexual partners among RLIs post immigration. 
- Substance use (hazardous drinking and illicit drug use) declined among RLIs post immigration.

- There was an association between social capital and HIV risk behavior, although social capital appeared to be protective or increase HIV risk based on the type of behavior.

- There was an association between changing social capital and substance use, but like HIV risk behavior, the effect of social capital varied by type of social capital.

- Business social capital was associated with an increase illicit drug use among RLIs

- Documentation status was a moderator between social capital and substance use:

○ Undocumented RLIs were less likely to engage in hazardous drinking if they had more access to 'friend and other' social capital.

○ Documented RLIs were less likely to use illicit drugs if they had more access to agency social capital.

- Documented RLIs were more likely to use illicit drugs if they had some business social capital.

- There were gender differences for the change in HIV risk behavior as well as the change in substance use.

\section{Public Health Implications}

Florida continues to receive large numbers of Latino immigrants and simultaneously is an epicenter for HIV-positive populations. Due to acculturative stress, Latino immigrants may modify sexual behavior and increase risk for STD/HIV transmission in a population that has a high HIV prevalence (Miami) (CDC, 2007). Determining how the composition of social capital changes among RLIs after immigration will guide policy makers on areas that may negatively or positively influence the health and well-being of all immigrants, and by extension the US population. 
Existing research has not fully explored HIV risk behavior among recent Latino immigrants. Findings from the existent literature are not consistent on whether increased acculturation decreases or increases risk for HIV transmission. However, if acculturation does increase risk, the acculturation process can be considered a possible point of intervention for addressing HIV risk behavior, and specifically targeting Latino immigrants immediately following immigration into the United States.

The disproportionate burden of HIV among Latino populations continues to be a public health concern and issue. Growing global interconnectivity and regional proximity in the United States attest to the relevance and importance of researching these populations, specifically as it pertains to the HIV epidemic. Findings from this study contribute to the body of literature on immigrant populations and HIV/AIDS in the United States, and specifically to the Latino immigrant population unique to South Florida.

It is important to target immigrants because rates of immigration continue to increase in the U.S., and five of the seven top sending regions to the U.S. are the Caribbean, South or Central America (Camarota, 2012). US policy on immigration continues to be controversial, but welladapted immigrants are considered a partial solution to the aging population and shrinking work force in the United States (Espenshade, 2001). Therefore, as current rates of immigration continue, it is important for new immigrants to assimilate to their new environment in such a way that they are successful members in their new communities. This dissertation showed that 'successful adaptation' is not necessarily reflected through financial success and progress. In fact, one major finding was that immigrants with more access to 'business' social capital had a greater likelihood of illicit drug use.

As immigrants navigate through the acculturation process, certain social capital oriented public health policy can contribute to prevention of high risk HIV behavior, hazardous drinking and illicit drug use. Social capital is a broad term and can include a wide array of approaches, but 
based on the findings of the dissertation, one suggested primary prevention policy is communitybased efforts within Latino enclaves in South Florida. For example, community-based efforts can increase different types of social capital that aid in prevention of high HIV risk behavior and substance use. Encouraging local neighborhood merchants in enclaves to provide information to their clientele, especially male clientele, on the risks associated with unprotected sex and substance use is one approach. Another idea is for neighborhood merchants to provide minor incentives to their clientele for HIV testing. The first manuscript has examples where this type of promotion of social capital in microfinance projects among women have been effective in reducing HIV risk (Pronyk et al, 2008, Swendeman, D., Basu, I., Das, S., Jana, S., \& RotheramBorus, M. J., 2009), and the same concept may be applicable to neighborhood merchants and male RLIs. Different variations of this model can be tailored to specific community attributes and needs.

The dissertation makes a contribution to this research area by providing evidence for relationships among social capital, HIV risk behavior and substance use among recent immigrants. These findings can be a useful tool for researchers to help decide whether social capital should be integrated into prevention models. The dissertation could not address all the study gaps, and further investigation is needed. Nevertheless, the findings do support previous findings in the research area and provide new evidence and information that help decipher this complex topic of investigation. 


\section{References}

Camarota, S.A. (2012). Immigrants in the United States: A profile of America's foreign born population. Center for Immigration Studies, Backgrounder and Reports.

Espenshade, T.J. (2001). High-end immigrants and the shortage of skilled labor. Population Research and Policy Review, 20(1-2), 135-141.

Handwerker, W.P. (2002). The construct validity of cultures: Cultural diversity, culture theory, and a method of ethnography. American Anthropologist, 104(1), 106-122.

Kuh, D., Power, C., Blane, D. Bartley, M. (1997). A life course approach to chronic disease epidemiology. In: Kuh, D., Ben-Shlomo, Y. eds. Oxford, United Kingdom: Oxford University Press

Leigh, B.C., Stall, R. (1993). Substance use and risk sexual behavior for exposure to HIV. American Psychologist, 48(10), 1035-1045.

Lindenberg, C.S., Strickland, O., Solorzano, R., Galvis, C., Dreher, M., Darrow, V.C. (1999). Correlates of alcohol and drugs use among low-income Hispanic immigrant childbearing women living in the U.S.A., International Journal of Nursing Studies, 36, 3-11

Pronyk, P. M., Kim, J. C., Abramsky, T., Phetla, G., Hargreaves, J. R., Morison, L. A., \& Porter, J. D. (2008). A combined microfinance and training intervention can reduce HIV risk behaviour in young female participants. AIDS (London, England), 22(13), 1659-1665. doi: 10.1097/QAD.0b013e328307a040

Rhodes, J.E., Jason, L.A., (1988). The social stress model of alcohol and other drug abuse: A basis for comprehensive, community-based prevention. In: Prevention Research Findings. Division of Health and Human Services, office of Substance Abuse Prevention, Washing, D.C.

Shurtleff, D. \& Lawrence,D. (2012). HIV and Substance Abuse: A Commentary. Current HIV Research, (10), 366-368, PMID: 22591360

Swendeman, D., Basu, I., Das, S., Jana, S., \& Rotheram-Borus, M. J. (2009). Empowering sex workers in India to reduce vulnerability to HIV and sexually transmitted diseases. Social Science \& Medicine (1982), 69(8), 1157-1166. 


\section{Appendices: Supplemental Tables and Figures}

Figures

Figure 1: Theoretical frame work for the relationship between social capital, substance use and HIV risk behavior from pre to post immigration

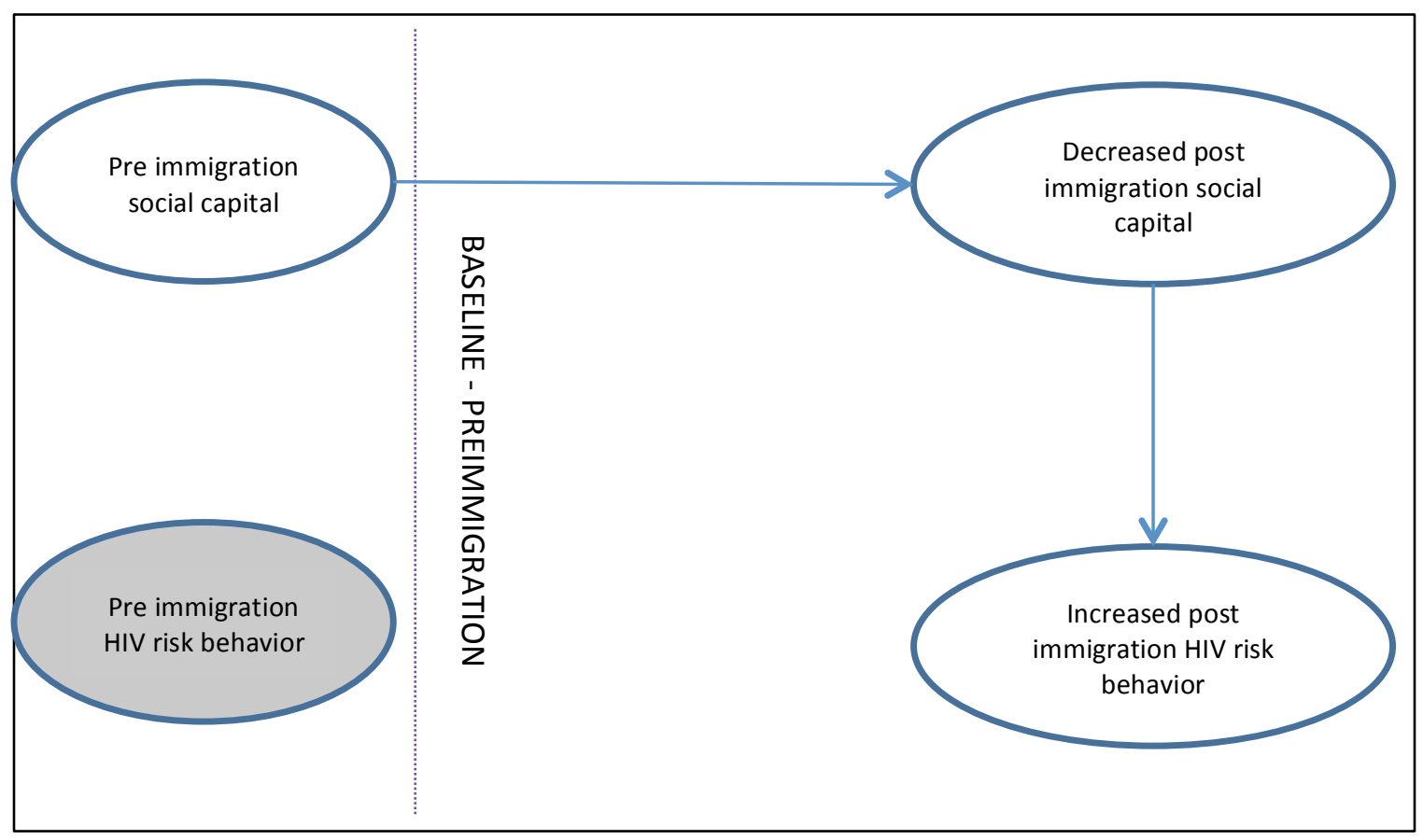

Note: Pre immigration HIV risk behavior will be controlled for during analysis 
Figure 2: Seminal works for the evolution of social capital

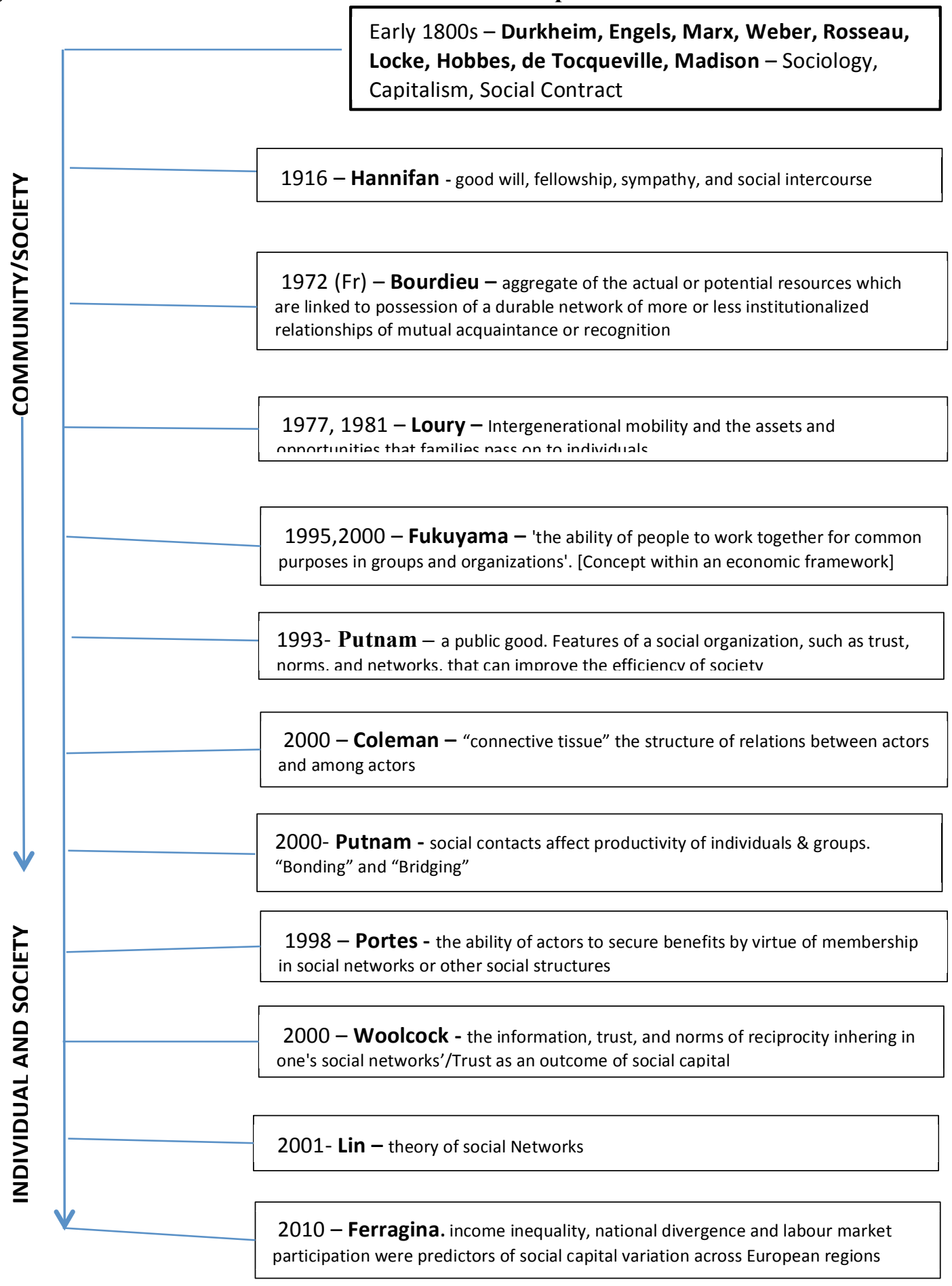


Figure 3: AUDIT Questionnaire

\begin{tabular}{|c|c|}
\hline \multicolumn{2}{|c|}{$\begin{array}{l}\text { THE ALCHOL USE DISORDERS IDENTIFICATION TEST } \\
\text { The next questions will ask about your use of alcohol in the last } 12 \text { months. These questions refer } \\
\text { to your use of alcohol. Remember to please answer honestly and to the best of your ability. In } \\
\text { the last } 12 \text { months... }\end{array}$} \\
\hline $\begin{array}{l}\text { 1. How often do you have a drink containing al- } \\
\text { cohol? } \\
\text { (0) Never } \\
\text { (1) Monthly or less } \\
\text { (2) } 2 \text { to } 4 \text { times a month } \\
\text { (3) } 2 \text { to } 3 \text { times a week } \\
\text { (4) } 4 \text { or more times a week }\end{array}$ & $\begin{array}{l}\text { 2. How many drinks containing alcohol do you } \\
\text { have on a typical day when you are drinking? } \\
\text { (0) } 1 \text { or } 2 \\
\text { (1) } 3 \text { or } 4 \\
\text { (2) } 5 \text { or } 6 \\
\text { (3) } 7,8 \text { or } 9 \\
\text { (4) } 10 \text { or more }\end{array}$ \\
\hline $\begin{array}{l}\text { 3. How often do you have } 5 \text { or more a drinks } \\
\text { on one occasion? } \\
\text { (0) Never } \\
\text { (1) Less than monthly } \\
\text { (2) Monthly } \\
\text { (3) Weekly } \\
\text { (4) Daily or almost daily }\end{array}$ & $\begin{array}{l}\text { 4. How often during the last year have you foun } \\
\text { that you were not able to stop drinking once you } \\
\text { had started? } \\
\text { (0) Never } \\
\text { (1) Less than monthly } \\
\text { (2) Monthly } \\
\text { (3) Weekly } \\
\text { (4) Daily or almost daily }\end{array}$ \\
\hline $\begin{array}{l}\text { 5. How often during the last year have you failed } \\
\text { to do what was normally expected from you be- } \\
\text { cause of your drinking? } \\
\text { (0) Never } \\
\text { (1) Less than monthly } \\
\text { (2) Monthly } \\
\text { (3) Weekly } \\
\text { (4) Daily or almost daily }\end{array}$ & $\begin{array}{l}\text { 6. How often during the last year have you } \\
\text { needed a first drink in the morning to get your- } \\
\text { self going after a heavy drinking session? } \\
\text { (0) Never } \\
\text { (1) Less than monthly } \\
\text { (2) Monthly } \\
\text { (3) Weekly } \\
\text { (4) Daily or almost daily }\end{array}$ \\
\hline $\begin{array}{l}\text { 7. How often during the last year have you had } \\
\text { feelings of guilt or remorse after drinking? } \\
\text { (0) Never } \\
\text { (1) Less than monthly } \\
\text { (2) Monthly } \\
\text { (3) Weekly } \\
\text { (4) Daily or almost daily }\end{array}$ & $\begin{array}{l}\text { 8. How often during the last year have you } \\
\text { been unable to remember what happened the } \\
\text { night before because you had been drinking? } \\
\text { (0) Never } \\
\text { (1) Less than monthly } \\
\text { (2) Monthly } \\
\text { (3) Weekly } \\
\text { (4) Daily or almost daily }\end{array}$ \\
\hline
\end{tabular}


9. Have you or someone else been injured as a result of your drinking?

(0) No

(2) Yes, but not in the last year

(4) Yes, during the last year
10. Has a relative or friend or a doctor or other health worked been concerned about your drinking or suggested you cut down?

(0) No

(2) Yes, but not in the last year

(4) Yes, during the last year

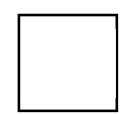




\section{Tables}

Table 1: Change in mean level of helpfulness of social capital

\begin{tabular}{lcccccc}
\hline & $\begin{array}{l}\text { Time 1 } \\
\text { (mean) }\end{array}$ & $\begin{array}{r}\text { Time 2 } \\
\text { (mean) }\end{array}$ & \% Change & $\mathrm{p}$ & $\mathrm{n}$ \\
\hline Friends & 3.75 & 3.45 & 8 & .002 & 474 \\
Family & 4.8 & 3.7 & 22.9 & $<.001$ & 474 \\
Group & 3.0 & 1.3 & 60 & $<.001$ & 468 \\
Agency & 4.0 & 1.11 & 72 & $<.001$ & 468 \\
Businesses & 2.73 & 1.74 & 36.3 & $<.001$ & 470 \\
Total & 18.4 & 11.4 & 38 & $<.001$ & 474 \\
\hline
\end{tabular}


Table 2: Change in social capital by gender

\begin{tabular}{|c|c|c|c|c|c|c|c|c|c|c|}
\hline & & & Female & & & & & Male & & \\
\hline & $\mathbf{T 1}$ & $\mathbf{T 2}$ & $\begin{array}{c}\% \\
\text { change }\end{array}$ & $\mathbf{p}$ & n & T1 & $\mathbf{T 2}$ & $\begin{array}{c}\% \\
\text { change }\end{array}$ & p & n \\
\hline Family & 3.9 & 3.6 & 7 & .028 & 218 & 3.6 & 3.33 & 8 & .026 & 256 \\
\hline Friends & 5 & 4 & 20 & $<.001$ & 218 & 4.6 & 3.5 & 23 & $<.001$ & 256 \\
\hline Group & 3.04 & 1.3 & 65 & $<.001$ & 216 & 3.01 & 1.36 & 54 & $<.001$ & 252 \\
\hline Agency & 4.2 & 1.3 & 69 & $<.001$ & 217 & 3.8 & .90 & 76 & $<.001$ & 251 \\
\hline Bus & 2.7 & 1.92 & 28 & $<.001$ & 217 & 2.7 & 1.6 & 40 & $<.001$ & 253 \\
\hline total & 18.9 & 12.2 & 35.6 & $<.001$ & 218 & 17.87 & 10.67 & 40.3 & $<.001$ & 256 \\
\hline
\end{tabular}


Table 3: Change in HIV risk behavior by marital status

\begin{tabular}{|c|c|c|c|c|c|c|}
\hline & \multicolumn{3}{|c|}{ Unmarried $(n=203)$} & \multicolumn{3}{|c|}{ Married(n=123) } \\
\hline & Baseline & $\begin{array}{c}\text { Follow } \\
\text { Up }\end{array}$ & $\begin{array}{c}\% \\
\text { change }\end{array}$ & Baseline & Follow up & $\begin{array}{c}\% \\
\text { change }\end{array}$ \\
\hline Never use & $50.4 \%$ & $78.9 \%$ & $\uparrow 24.8 \%$ ** & $28.1 \%$ & $64 \%$ & $\uparrow 35.9 \%$ ** \\
\hline $\begin{array}{l}\text { Less than half the } \\
\text { time }\end{array}$ & $10.9 \%$ & $4.1 \%$ & $\downarrow 4.0 \% * *$ & $12.3 \%$ & $3.4 \%$ & $\downarrow 8.9 \% * *$ \\
\hline Half the time & $3.9 \%$ & $.8 \%$ & $\downarrow 4.1 \% * *$ & $10.3 \%$ & $4.9 \%$ & $\downarrow 5.4 \% * *$ \\
\hline Most of the time & $10.1 \%$ & $1.6 \%$ & $\downarrow 4.9 \% * *$ & $10.8 \%$ & $5.9 \%$ & $\downarrow 4.9 \% * *$ \\
\hline Always & $24.8 \%$ & $14.6 \%$ & $\downarrow 9.8 \% * *$ & $38 \%$ & $21.7 \%$ & $\downarrow 16.2 \% * *$ \\
\hline No of partners & 1.55 & 1.04 & $\downarrow 33 \% * *$ & 1.22 & 1.05 & $\downarrow 14.0 \%$ \\
\hline
\end{tabular}


VITA

Elena Cyrus

Born, New York, NY, USA

1994-1999

B.A., International Relations

Florida International University

Miami, FL

$1998-2001$

Clinical Research Coordinator

Department of Rheumatology

University of Miami School of Medicine

Miami, FL

1999- 2002

MPH, Public Health

University of Miami School of Medicine

Miami, FL

2002- 2004

University of Michigan/USAID/Engender Health International Development Associate

Ann Arbor, MI

Washington, DC

Accra, Ghana, West Africa

2004- 2006

Prevention Research Specialist

Family Health International/FHI 360

Arlington, VA

$2006-2008$

Clinical Research Manager

Family Health International/FHI 360

Arlington, VA

$2009-2011$

Graduate Assistant

Florida International University

Miami, FL

$2011-2013$

Student Trainee

Center for Research on U.S. Latino HIV/AIDS and Drug Abuse (CRUSADA)

Florida International University

Miami, FL

2011 - present

Doctoral candidate

Florida International University

Miami, FL 


\section{PUBLICATIONS AND PRESENTATIONS}

\section{PAPERS}

Sastre, F., Rojas, P., Cyrus, E., De La Rosa, M., Khoury, A.H. (2013). Tackling health disparity in the Caribbean: Recommendations from the Triangulating on Health Equity Summit. Global

Health Promotion (accepted).

Gollub, E.L., Cyrus-Cameron, E., Armstrong, K., Boney, T., Mercer, D., Fiore, D., Chattre, S. (2013). Active drug-using women use female-controlled methods to reduce HIV/STI: Results from a randomized trial. ISRN Addiction (accepted).

Rojas, P., Dillon, F., Cyrus, E., De La Rosa, M., Ravelo, G. (2012).Determinants of HIV/STD Risk Behaviors among Recent Latino Immigrants in South Florida. Journal of the Association of Nurses in AIDS Care (JANAC). Epub ahead of print.

Gollub, E.L., Cyrus-Cameron, E., Armstrong, K., Boney, T., Chattre, S. (2012). Basic body knowledge in street-recruited, active drug-using women enrolled in a 'Body Empowerment' Intervention Trial. AIDS Care, Epub ahead of print. doi: 10.1080/09540121.2012.748167

Kapina, M., Reid, C., Roman, K., Cyrus-Cameron, E., Kwiecien, A., Weiss, S., and, Vermund, SH. (2009). HIV incidence rates and risk factors for urban women in Zambia: Preparing for a microbicide clinical trial. Sexually Transmitted Diseases, 36(3), 129. doi:

10.1097/OLQ.0b013e318190191d

POSTERS and PRESENTATIONS

Cyrus, E., Rojas, P., Dillon, F., Ravelo, G., De La Rosa, M. (October 2012). Pre-immigration determinants of HIV/STD risk behaviors among recent Latino immigrants to South Florida. Presentation, American Public Health Association (APHA) Annual meeting, San Francisco, CA.

Gollub, E., Cyrus-Cameron, E., Dévieux, J.G., Jean-Gilles, M., Neptune, S., Michel, H., Pelletier, V. (2011). Men don't need to know everything ("Gason pa bezwen konen tout bagay"). Implementing a pilot study on the acceptability of a contraceptive cervical cap among HaitianAmerican women". Presentation, Multipurpose Prevention Technology Symposium, Washington, DC.

Gollub, E., Cyrus-Cameron, E. (2011). Implementing a pilot study on the acceptability of a women-controlled contraceptive barrier among Haitian-American women. Panel Presentation, Triangulating on Health Equity conference, San Juan, Puerto Rico. 